\title{
Optimizing Investments in Georgia's HIV Response
}

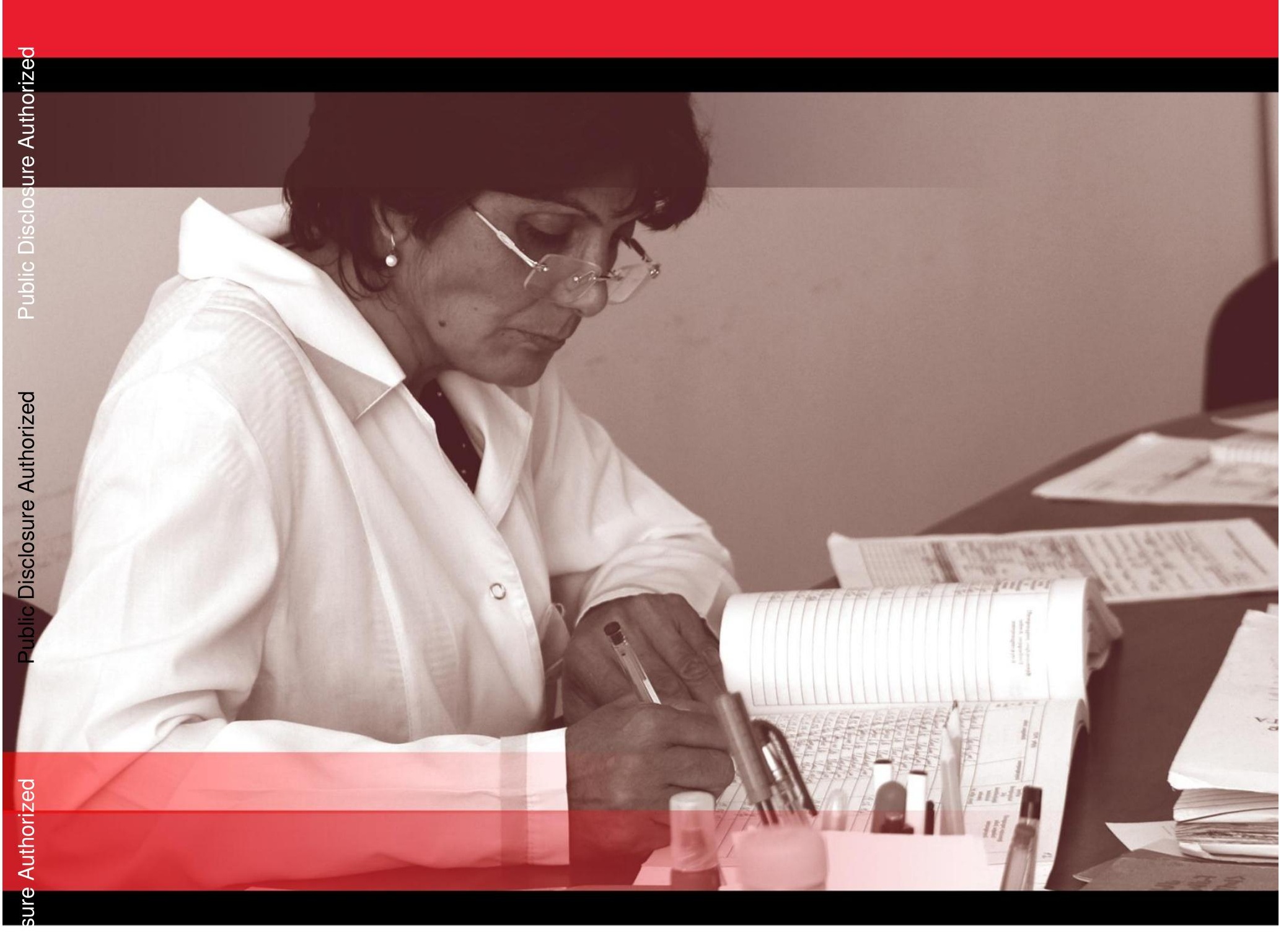

() TheGlobalFund UNAIDS

NCDC

sIal.

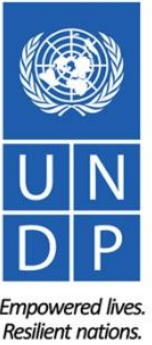

UNSW

\&WORLD BANKGRoup 
Cover Image: Creative Commons Doctor's Office by Lily A. is licensed under CC BY-NC-ND 2.0. 
OPTIMIZING INVESTMENTS

IN GEORGIA'S HIV RESPONSE

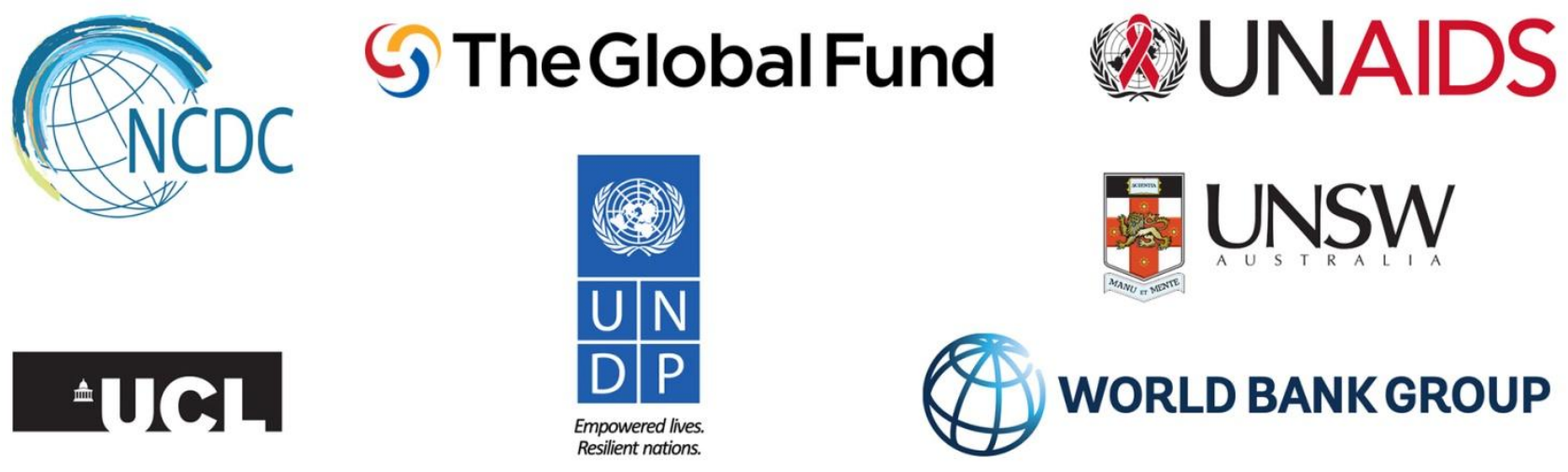


(C) International Bank for Reconstruction and Development / The World Bank 1818 H Street NW, Washington DC 20433

Internet: www.worldbank.org; Telephone: 2024731000

This work is a product of the staff of The World Bank with external contributions. Note that The World Bank does not necessarily own each component of the content included in this work. The World Bank therefore does not warrant that the use of the content contained in the work will not infringe on the rights of third parties. The risk of claims resulting from such infringement rests solely with you.

The contents of this report do not necessarily represent the views and positions of the World Bank, UNAIDS, UNDP, the Global Fund, participating government agencies or other partner institutions. In particular, the findings and modeling analyses presented in this report focus primarily on the cost considerations and epidemiological effects of HIV programs. Individual findings represented in tables or specific sections of this report should not be viewed or cited in isolation. They should be seen in the context of the overall recommendations of this report and other considerations such as equity in service access and health benefits beyond the HIV response.

Nothing herein shall constitute or be considered to be a limitation upon or waiver of the privileges and immunities of The World Bank, all of which are specifically reserved.

Rights and Permissions

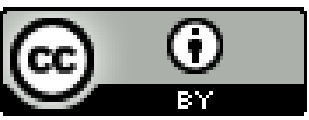

This work is available under the Creative Commons Attribution 3.0 Unported licence (CC BY 3.0) http://creativecommons.org/licences/by/3.0. Under the Creative Commons Attribution license, you are free to copy, distribute and adapt this work, including for commercial purposes, under the following conditions:

Attribution - Please cite the work as follows: The World Bank. 2015. Optimizing Investments in Georgia's HIV Response Washington DC: World Bank. License: Creative Commons Attribution CC BY 3.0

Translations - If you create a translation of this work, please add the following disclaimer along with the attribution: This translation was not created by The World Bank and should not be considered an official World Bank translation. The World Bank shall not be liable for any content or error in its translation.

All queries on rights and licenses should be addressed to the Office of the Publisher, The World Bank, 1818 H Street NW, Washington DC, 20433, USA; fax: 202-522-2625; email: pubrights@worldbank.org. 


\section{CONTENTS}

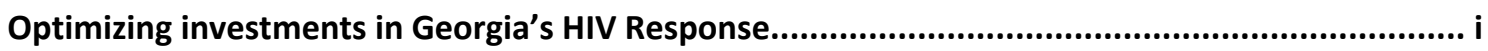

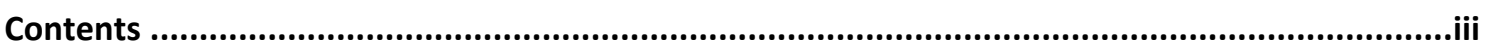

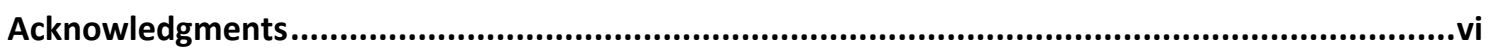

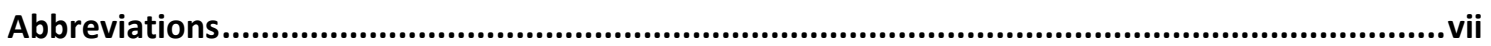

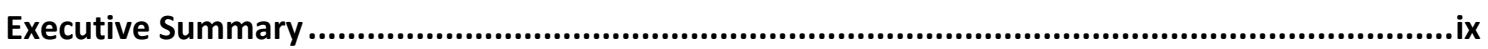

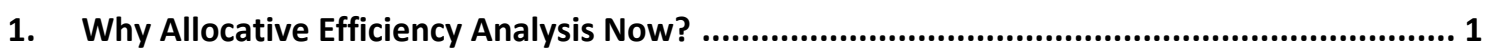

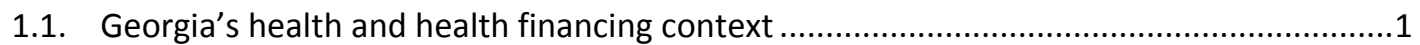

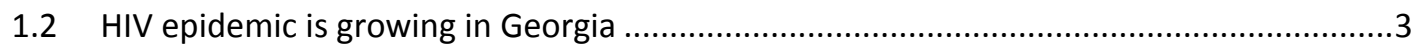

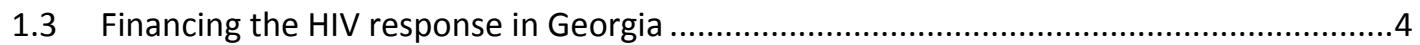

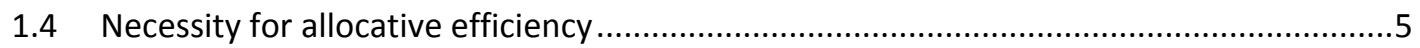

2. How Will This Report Answer Key Questions? ............................................................................ 7

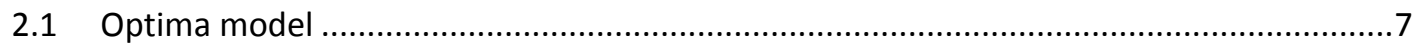

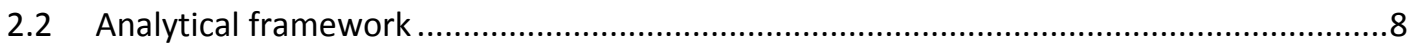

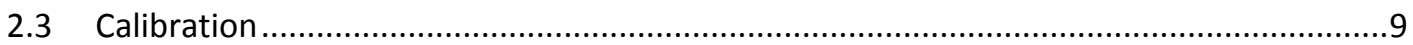

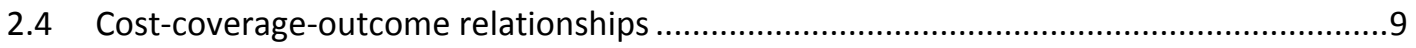

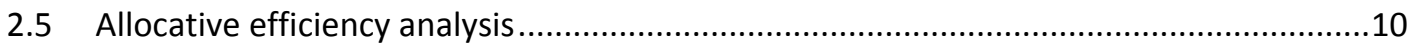

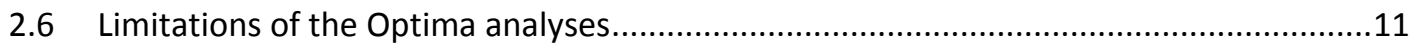

3. What Are the Expected Trends in the Epidemic If Current Spending

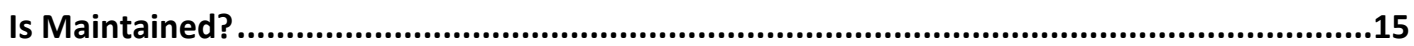

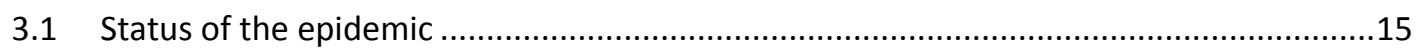

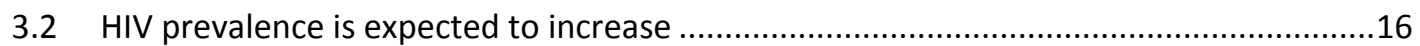

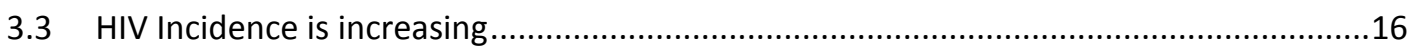

3.4 AIDS-related deaths are low but increasing in number .................................................17

3.5 Number of people requiring HIV treatment will increase ................................................18

4. What Are the Impacts of Past and Current Spending? .........................................................19

4.1 Prevention receives the majority of current funding...................................................19

4.2 Prevention could be better targeted within and among key populations........................20

4.3 Investing in an HIV response averts infections and deaths .........................................21

5. Predicting the Trajectory of the HIV Epidemic: Comparing HIV

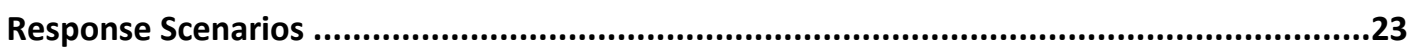

6. What Can Be Improved by Optimizing Efficiencies under Current Funding? .........................29

7. What Might Be Gained or Lost from Changes in HIV Spending and Allocation? .....................33

8. How Much Will It Cost to Achieve the Targets of the National HIV Strategic Plan?................37

9. What Is the Long-Term Financial Commitment to HIV Services for PLHIV? ...........................39

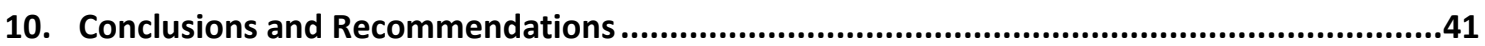




\section{Appendixes}

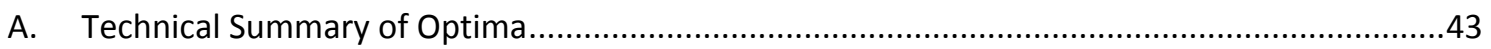

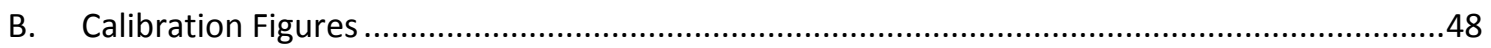

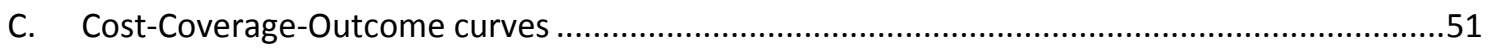

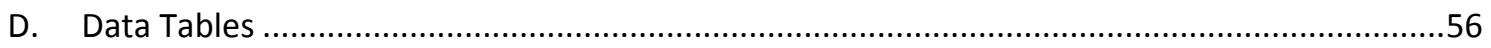

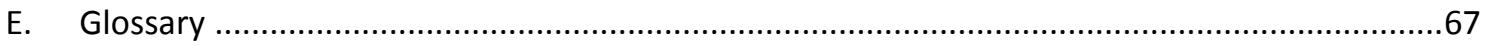

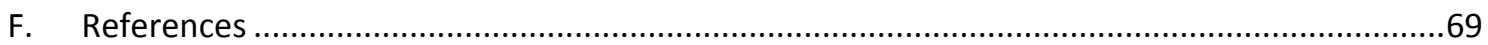

\section{Figures}

1.1 Disability adjusted life years (DALYs) due to different causes by age, 2010

1.2 Government health expenditure as a percentage of total health expenditure in the ECA Region, 2013

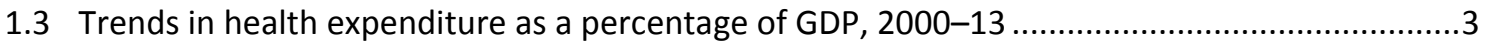

1.4 Overall spending on HIV/AIDS in Georgia, 2006-14 ...........................................................

1.5 Funding for HIV in Georgia, by funding source, 2006-14 (\%) ..................................................

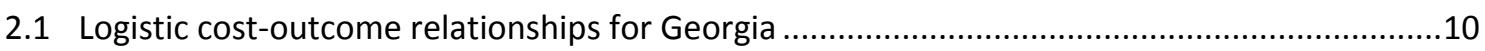

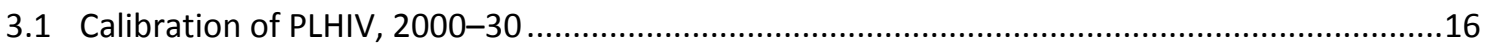

3.2 Calibrated number of new HIV infections per year, 2000-30 ..............................................17

3.3 Calibration-predicted number of deaths due to HIV in Georgia, assuming

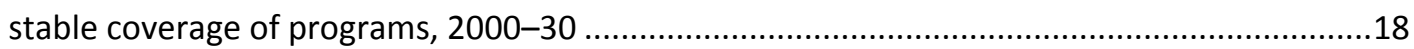

4.1 HIV expenditure in Georgia by type of spending, 2006-14 ..................................................19

4.2 Trends in spending across key priority prevention and treatment programs, 2010-14

4.3 Model-estimated impact of current spending compared to no spending on the HIV response, $2015-30^{\mathrm{a}}$.

5.1 Model-predicted evolution of annual HIV prevalence under different scenarios, 2000-30

5.2 Model-predicted evolution of annual HIV incidence under different scenarios, 2000-30

5.3 Model-predicted evolution of annual HIV-related deaths under different scenarios, 2000-30

5.4 Model-predicted prevalence for MSMW under different scenarios, 2000-30.....

6.1 Comparison of current and optimized budget allocation to minimize both new infections and deaths for 2015-30 (\%)

7.1 Optimized allocations to minimize HIV incidence and deaths by 2030 at different budget levels (2014 budget)*

7.2 Comparing the allocation of 2014 spending against an optimized allocation of 150 percent of current spending 
7.3 Comparing the impact on prevalence, deaths, and new infections of 2014 spending against an optimized allocation of 150 percent of the 2014 budget

8.1 Minimum annual spending required to meet National HIV Strategic Plan targets (2014 level)

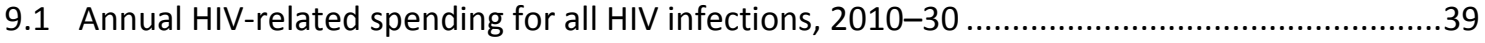

9.2 Annual HIV-related spending for all new HIV infections. 2010-30 .40

Tables

1.1 Trends in health expenditure in Georgia, 2006-13 .....................................................2

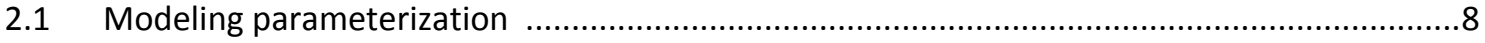

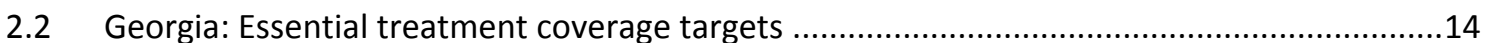

3.1 Population size estimates and prevalence among key affected populations, most recent year available.

3.2 ART coverage in Georgia, 2011-14

4.1 Comparing costs of programs in the ECA Region (US\$)

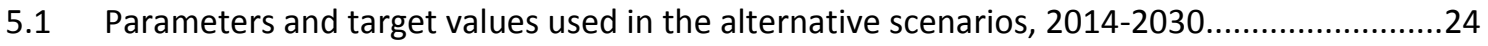

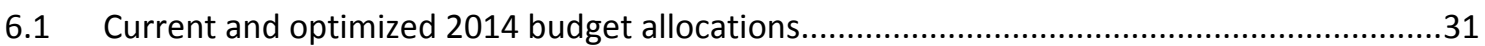




\section{ACKNOWLEDGMENTS}

The HIV allocative efficiency programme, of which this study is part, is managed by the World Bank and supported by the Global Fund to Fight AIDS, Tuberculosis and Malaria (Global Fund); the United Nations Program on HIV/AIDS (UNAIDS); and the United Nations Development Programme (UNDP). The Steering Committee of the programme-comprising Christoph Hamelmann (UNDP), Manoela Manova (UNAIDS), Emiko Masaki (World Bank), Shufang Zhang (Global Fund), and Feng Zhao (Chair and World Bank Task Team Leader)-provided overall guidance to the country studies. The four agencies also cosponsored the various study activities.

The core analysis and report writing team included Alexander Asatiani, David Baliashvili, Irma Khonelidze, Ekaterine Ruadze, Ketevan Stvilia, and Maia Tsereteli (National Center for Disease Control and Public Health); Otar Chokoshvili (Infectious Diseases, AIDS and Clinical Immunology Research Center); Hassan Haghparast-Bidgoli, Laura Grobicki, Jasmina PanovskaGriffiths, and Jolene Skordis-Worrall (University College London); Clemens Benedikt (World Bank); and Cliff C. Kerr (University of New South Wales). Substantial additional technical inputs were provided by Robyn M. Stuart and David P. Wilson (UNSW); Marelize Görgens and Emiko Masaki (World Bank); Roman Hailevic and Manoela Manova (UNAIDS); David Kokiashvili, Dejan Loncar, Tsovinar Sakanyan, and Shufang Zhang (Global Fund); and Predrag Đurić and Christoph Hamelmann (UNDP).

The Optima model, which was applied in this study, was developed by the University of New South Wales (UNSW) and the World Bank. Data collection for Georgia was carried out by national consultants and facilitated by UNAIDS and the World Bank. Michael Borowitz and Nicolas Cantau (Global Fund), Jean-Elie Malkin and Vinay P. Saldanha (UNAIDS), Christoph Hamelmann (UNDP), and David Wilson (World Bank) conceptualized this Regional initiative on HIV allocative efficiency.

The authors also would like to thank all other stakeholders and colleagues who provided insights and support. Alicia Hetzner edited the report. 


\section{ABBREVIATIONS}

$\mathrm{AE}$

AIDS

ART

Clients

DALY

ECA

Females 15-49

Females 50+

FSW

GARPR

GDP

GEL

Global Fund

HIV

HTC

IBBS

IDU

Males 15-49

Males 50+

MSM

MSMW

NHA

OST

PLHIV

PMTCT

PWID

PY

STI

THE

UCL

UNAIDS

UNSW

YLL allocative efficiency

acquired immune deficiency syndrome

antiretroviral therapy

clients of sex workers

disability-adjusted life year

Europe and Central Asia

females 15-49 years old, excluding other population groups in this age group

females 50 years and older, excluding other population groups in this age group

female sex workers

Global AIDS Response Progress Report of Georgia 2013

gross domestic product

Georgian currency

The Global Fund to Fight AIDs, Tuberculosis and Malaria

human immunodeficiency virus

HIV testing and counselling

integrated bio-behavioral surveillance

injecting drug use

males 15-49 years old excluding the other population groups in this age group

males 50 years and older excluding other population groups in this age group

men who have sex with men

men who have sex with men and women

national health accounts

opiate substitution therapy

people living with HIV

prevention of mother-to-child transmission

people who inject drugs

person years

sexually transmitted infection

total health expenditure

University College London

Joint United Nations Programme on HIV/AIDS

University of South Wales

years of life lost 


\section{EXECUTIVE SUMMARY}

Georgia has a concentrated but growing HIV epidemic. Over the past decade, HIV prevalence has increased among all population groups, particularly among men who have sex with men (MSM).

If current conditions (behaviors and service coverage) are sustained up to 2030, the epidemic is expected to stabilize among female sex workers (FSWs). At the same time, HIV prevalence among people who inject drugs (PWID) and the clients of female sex workers (FSW) may increase, but at a slower rate than in the past. Optima analyses suggest the necessity to invest in PWID programs, including needle-syringe programs (NSP) and opiate substitution therapy (OST), at a level similar to 2014 spending. Given the relatively high cost of OST provision, increases in coverage may require additional technical efficiency analyses to identify ways to reduce the average OST costs.

MSM account for the largest proportion of new infections and experience the highest prevalence levels of HIV (13 percent in 2012). ${ }^{1}$ However, prevention programs that specifically target MSM currently account for approximately only 3 percent of HIV spending. Given the high HIV prevalence, increasing the resources to, and coverage of, MSM programs could be particularly beneficial. A large proportion of MSM in Georgia also have female partners 67 percent and 51 percent in $2010^{2}$ and 2012, ${ }^{3}$ respectively).

The HIV epidemic in the general population is expected to increase due largely to the increasing HIV prevalence among MSM and existing prevalence among PWID. Prevention and treatment for MSM are expected to be the most cost-effective approaches to minimize the downstream effects.

The HIV epidemic among PWID in Georgia has stabilized due to significant and prolonged efforts to target this population. Although targeting of MSM was projected to be a critical component of the future HIV response, this action alone will not be sufficient to contain the epidemic overall, even at increased levels. Both PWID and MSM populations should be targeted as much as possible through strong preventive efforts complemented by a comprehensive test-and-offer-treatment approach.

Testing key populations and their sexual partners is the most cost-effective strategy to identify those who require antiretroviral therapy (ART). From 2004 to 2014, Georgia has expanded ART coverage and expects additional improvements in coverage. According to Optima analyses, ART will remain an essential component of the HIV response, but it alone will not be sufficient to halt the epidemic. Due to the high cost of testing and counselling to identify even one person living with HIV in a population currently experiencing low HIV prevalence,

\footnotetext{
Curatio International Foundation 2013a.

Curatio International Foundation 2011.

Curatio International Foundation 2013a.
} 
widespread HIV testing and counselling for the general population were not part of the optimized mix of interventions.

Opportunities exist to further optimize investments. The allocative efficiency of Georgia's current programs could be further improved by increasing investments in ART. If the 2014 annual budget of approximately US $\$ 14.8$ million were allocated more optimally among key populations and interventions, an additional 2,969 (15.5 percent of the current level) new infections could be prevented by 2030 .

Improvements in technical efficiency may provide additional gains. Although this study did not include detailed analysis of technical efficiency and unit costs, the total cost per person reached within Georgia's programs suggests there could be an opportunity for efficiency gains by using optimized resource allocation. The National HIV Strategic Plan 2016-2018 ${ }^{4}$ already aims for higher coverage at a lower unit cost in some programs. However, additional technical efficiency analysis is recommended, particularly for programs that currently absorb large proportions of HIV funding such as opiate substitution therapy (OST) and ART.

The health and economic burden of HIV in Georgia is growing. If the current budget and combination of HIV programing continue without improvements in allocative or technical efficiency, HIV incidence is expected to increase. The care and treatment of people living with HIV in Georgia, therefore, will lead to a substantial and increasing burden of disease (BOD) as well as associated direct and indirect costs. Optimized resource allocation would reduce the number of new HIV infections.

Figure 1 Comparing the allocation of 2014 spending against an optimized allocation of 150 percent of 2014 spending (similar to the draft National HIV Strategic Plan budget)

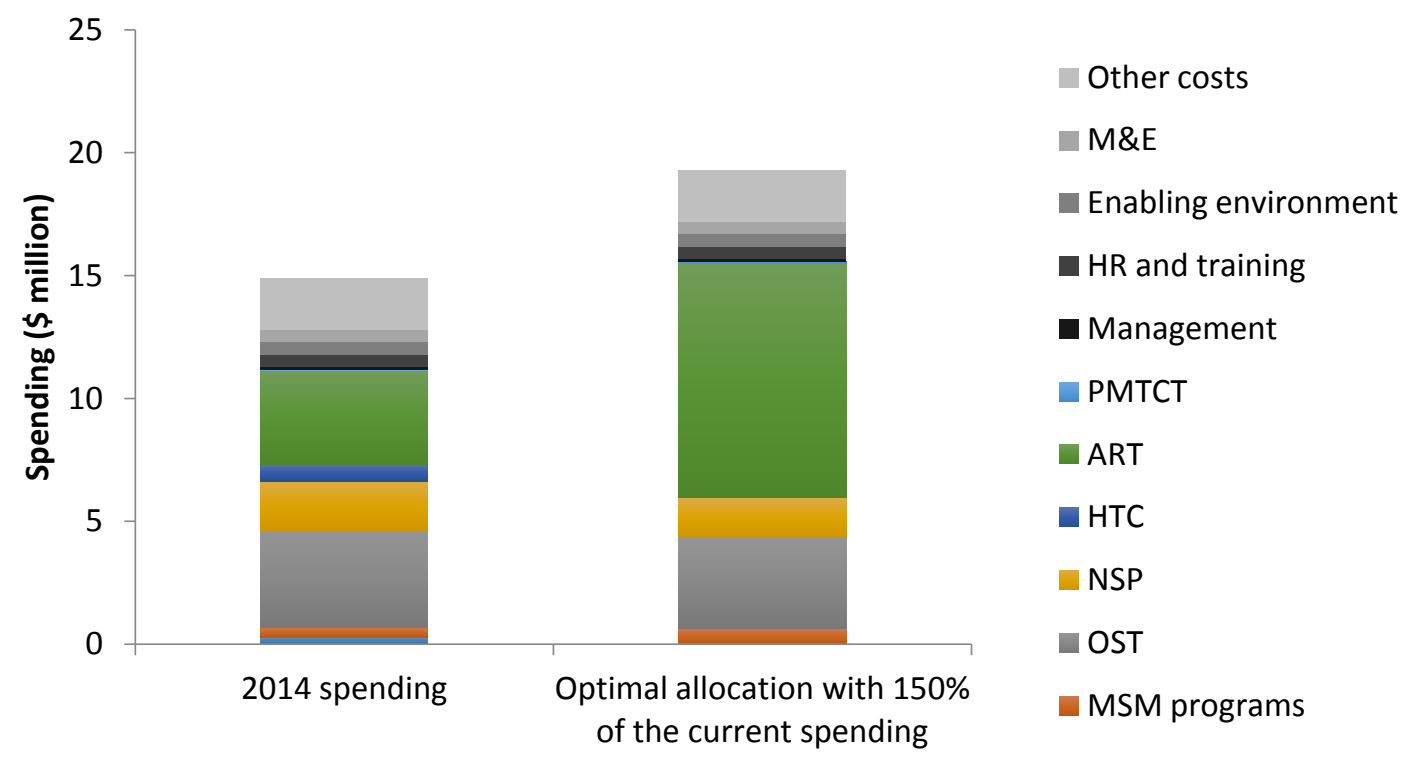

In the long term, the model predicts that HIV resource needs will increase with rising incidence and prevalence. However, the analysis estimates that optimizing current allocations by increasing spending on ART provision while sustaining investment in key populations could save approximately $\$ 224,635$ annually. The results also show that

4 The national strategic plan was at a stage of final draft at the time of completion of this report. 
optimizing the allocation of current spending would lower annual spending commitments for newly infected PLHIV by approximately 15 percent.

Current annual spending will not be enough to achieve National HIV Strategic Plan and international targets. To fill resource gaps, additional domestic resources must be allocated to HIV spending. Although domestic funding for HIV in Georgia has increased since 2006, much of the increase has been financed through out-of-pocket expenditure by households. Reliance on out-of-pocket spending could delay care-seeking, increase the risk of additional infections, reduce the cost-effectiveness of treatment, and ultimately reduce the technical efficiency of HIV spending. For these reasons, transitional funding mechanisms should aim to increase state participation in healthcare financing. 



\section{WHY ALLOCATIVE EFFICIENCY ANALYSIS NOW?}

\subsection{Georgia's health and health financing context}

\subsubsection{Burden of disease}

Georgia's overall burden of disease is characterized by a mix of significant causes of morbidity and mortality (Figure 1.1). There is a continued contribution of neonatal and child mortality to the overall number of disability adjusted life years (DALYs). In the population of reproductive age (15-49 years), the largest contributors are noncommunicable diseases, followed by injuries. In the population aged 50 years and above, noncommunicable diseases, particularly cardio and circulatory diseases and cancer, are the dominant causes of DALYs lost. Considering that the 478 DALYs directly attributable to HIV in $2010^{5}$ mostly affect key populations and their sexual partners, HIV prevention and treatment remain important components of health service delivery to these populations.

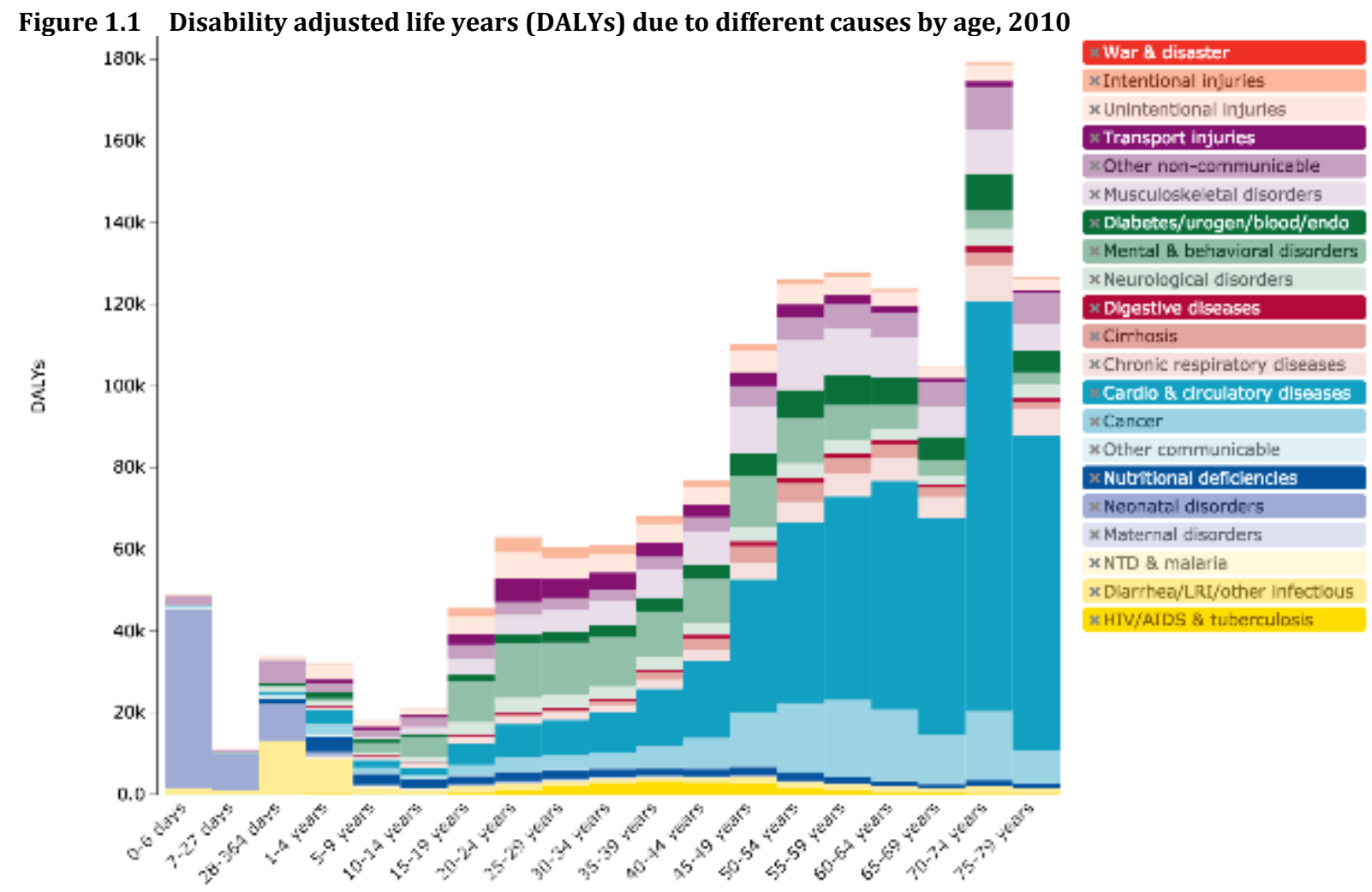

Source: University of Washington 2014.

5 University of Washington 2014. 


\subsubsection{Health care financing}

According to Georgia National Health Accounts (NHA) data, total health expenditure has been increasing since 2000, reaching US\$1522 million in 2013. Private health expenditure, mainly in the form of out-of-pocket formal and informal payments for service at the point of delivery, dominates health expenditure. In 2013 an estimated 78 percent of total health expenditure came from private sources compared to only 22 percent from government sources (Table 1.1). According to World Health Organization (WHO) estimates (Figure 1.2), government health spending in Georgia constitutes one of the lowest proportions of total health expenditure in the Europe and Central Asia (ECA) Region. Although not fully explored in this report, such heavy reliance on private and out-of-pocket spending is likely to deter preventive care-seeking and may delay early detection of disease. In Georgia's context, out-of-pocket payments comprise both formal fees and substantive informal fees (Chanturidze and others 2009). As discussed later, this reliance may result in higher treatment costs and poorer outcomes.

Table 1.1 Trends in health expenditure in Georgia, 2006-13

\begin{tabular}{|c|c|c|c|c|c|c|}
\hline Indicator & 2008 & 2009 & 2010 & 2011 & 2012 & 2013 \\
\hline GDP (current prices, US\$ million) & 12799.3 & 10766.8 & 11638.5 & 14434.6 & 15846.5 & 16140.0 \\
\hline Total health expenditure (US\$ million) & 1151.9 & 1098.2 & 1175.5 & 1356.9 & 1457.9 & 1522.4 \\
\hline Total health expenditure (US\$ per capita) & 260.6 & 249.3 & 266.2 & 310.3 & 332.9 & 349.9 \\
\hline Total health expenditure as a \% of GDP & 9.0 & 10.2 & 10.1 & 9.4 & 9.2 & 9.4 \\
\hline $\begin{array}{l}\text { Government health expenditure as a \% of total } \\
\text { health expenditure }\end{array}$ & 19.8 & 22.3 & 22.8 & 18.1 & 18.0 & 21.5 \\
\hline $\begin{array}{l}\text { Private health expenditure as a } \% \text { of total health } \\
\text { expenditure }\end{array}$ & 80.2 & 77.7 & 77.2 & 81.9 & 82.0 & 78.5 \\
\hline $\begin{array}{l}\text { Government health expenditure as a } \% \text { of total } \\
\text { government expenditure }\end{array}$ & 4.8 & 6.1 & 6.6 & 5.3 & 5.2 & 6.7 \\
\hline $\begin{array}{l}\text { External resources for health as a percentage of } \\
\text { total health expenditure }\end{array}$ & 10.1 & 5.5 & 2.9 & 2.8 & 3.0 & 2.6 \\
\hline $\begin{array}{l}\text { Out-of-pocket health expenditure as a \% of } \\
\text { private health expenditure }\end{array}$ & 80.1 & 85.6 & 89.5 & 79.3 & 78.9 & 78.9 \\
\hline $\begin{array}{l}\text { Out-of-pocket health expenditure as a } \% \text { of total } \\
\text { health expenditure }\end{array}$ & 64.2 & 66.6 & 69.1 & 64.9 & 64.7 & 61.9 \\
\hline
\end{tabular}

Source: WHO National Health Accounts Database, http://apps.who.int/nha/database/Select/Indicators/en.

Figure 1.2 Government health expenditure as a percentage of total health expenditure in the ECA Region, 2013

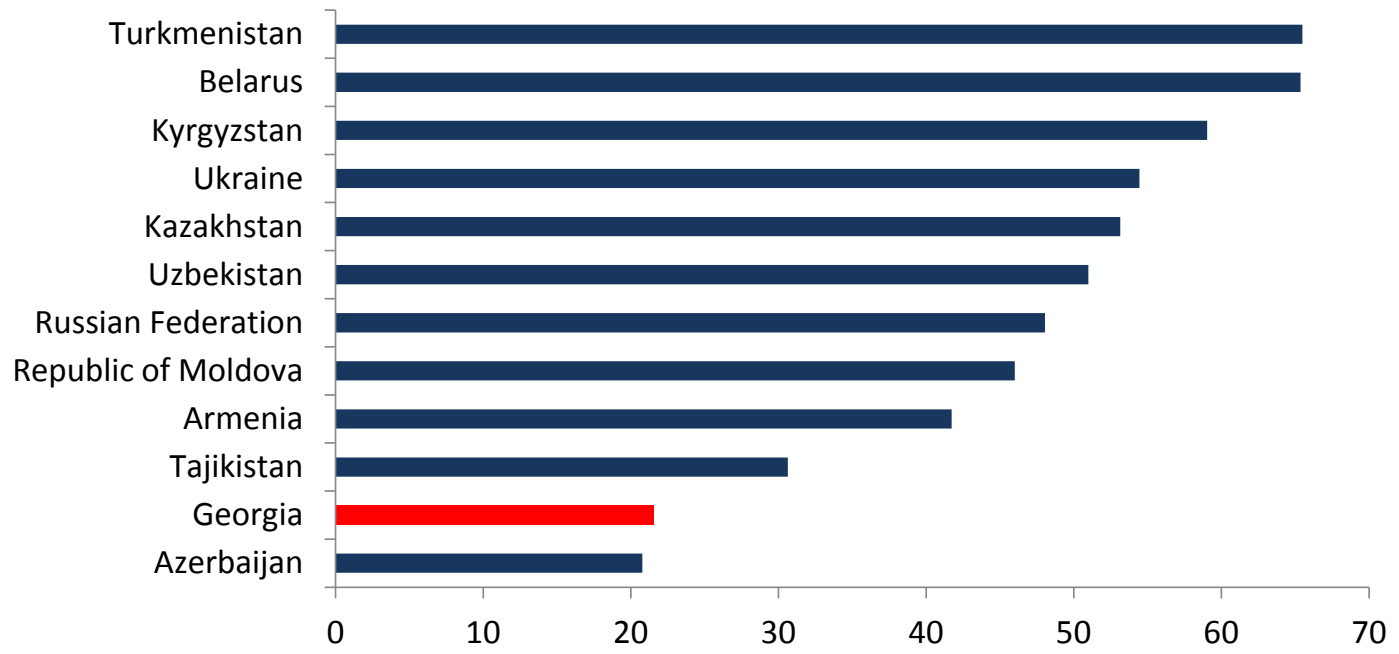

Source: WHO estimates from WHO National Health Accounts Database, http://apps.who.int/nha/database/Select/Indicators/en. 
In Georgia, for the most part, total health expenditure as a percentage of GDP been decreasing since 2009. The exception was in 2013, when spending increased slightly to 9.4 percent of GDP. Despite the preceding decline, the 2013 percentage remains higher than in other countries in the Region, in which, on average, total health expenditure is 6 percent of GDP (Figure 1.3). Georgia's total health expenditure as a percentage of GDP is approximately equal to the Organisation for Economic Co-operation and Development (OECD) country average. However, health expenditure in the majority of OECD countries relies less on out-of-pocket health spending than in Georgia.

Figure 1.3 Trends in health expenditure as a percentage of GDP, 2000-13

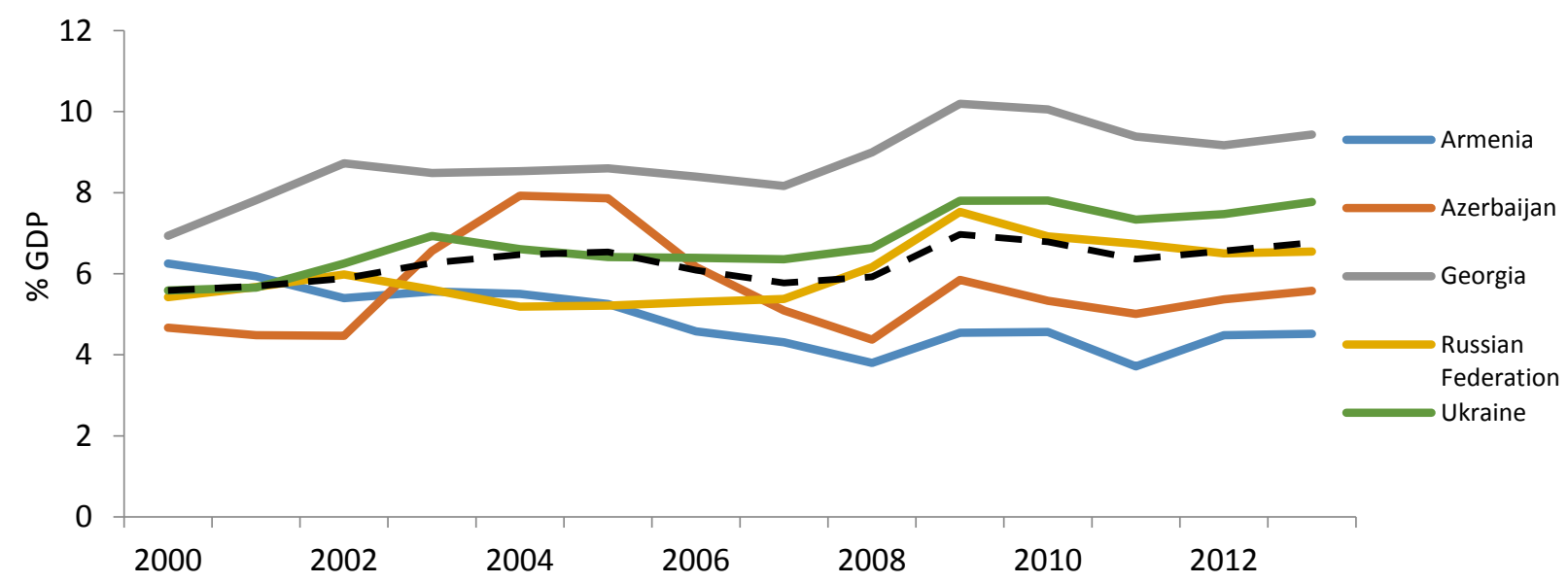

Source: WHO National Health Account Database, http://apps.who.int/nha/database/Select/Indicators/en.

\subsection{HIV epidemic is growing in Georgia}

Despite relatively low overall prevalence, the HIV epidemic remains a significant public health concern in Georgia. Since the detection of the first case in 1989, new HIV diagnoses in the country have increased steadily, reaching 10.9 per 100,000 in 2013 (UNAIDS 2013). Cumulatively since the onset of the epidemic, 5,127 new infections were registered in August 2015,6 an increase from 3,641 (41 percent) at the end of 2012. Cumulatively, since the onset of the HIV epidemic1,037 registered AIDS deaths were recorded by August 2015.7 The HIV epidemic is concentrated among key affected populations: people who inject drugs (PWID); female sex workers (FSW); and men who have sex with men (MSM). In Georgia, the MSM category includes men who have sex with men and women (MSMW).

According to Optima estimates, at least 33 percent of these key populations are not aware of their status as indicated by recent integrated bio-behavioral surveillance survey (IBBSS) findings. ${ }^{8}$ Low detection rates lead to late presentation for treatment. Late treatment adversely affects treatment outcomes and significantly increases short-term mortality risk. Approximately 50 percent of newly HIV-diagnosed persons in Georgia already have AIDS, and up to 70 percent of newly HIV-diagnosed patients have with CD4 cell counts of less than 350 (WHO 2014a). Despite this relatively high rate of persons who present late for treatment,

National AIDS Centre, http://aidscenter.ge/epidsituation_eng.html.

National AIDS Centre, http://aidscenter.ge/epidsituation_eng.html.

8 From the 2015 Georgia Final Draft National HIV Strategic Plan: 26.2\% of MSM (73 of 278) in 2010 and 33.9\% of MSM (74 of 218) in 2012 reported being tested for HIV in the last year according to the IBBSS study. 
mortality among HIV patients in Georgia has decreased substantially since the country made treatment available to all PLHIV who are eligible and diagnosed.9

\subsection{Financing the HIV response in Georgia}

From 2006-14, total HIV spending in Georgia increased nearly 140 percent (Figure 1.4). Current reliance on international donors for a substantive portion of HIV financing, coupled with an expected reduction in international assistance in the medium-to-long terms are key challenges to the sustainability of Georgia's HIV programming. These challenges will be compounded if HIV incidence continues to rise.

Figure 1.4 Overall spending on HIV/AIDS in Georgia, 2006-14

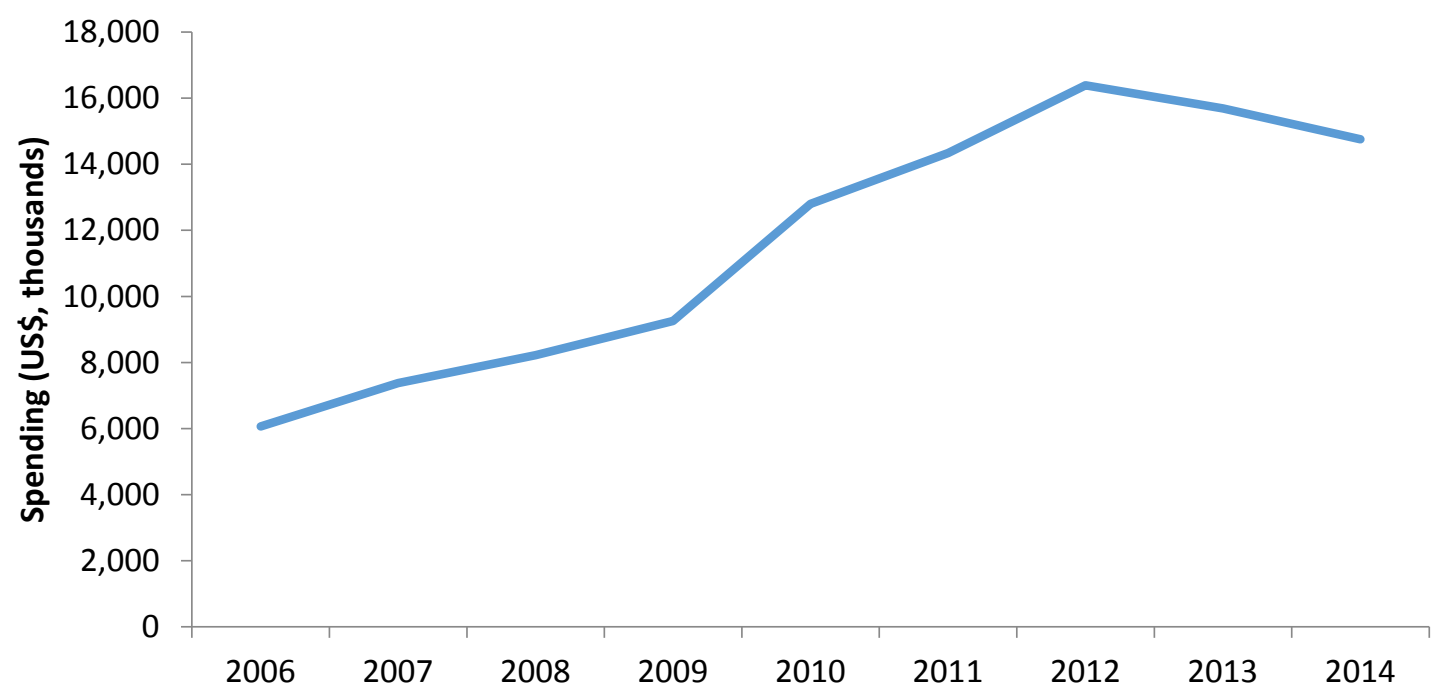

Source: Prepared by the authors based on National Center for Disease Control and Public Health 2014 and the final draft National Strategic Plan 2016-20.

\subsubsection{Donors contribute significant but declining share of HIV funding}

As mentioned above, most HIV funding in Georgia historically has come from international sources. To date, the majority of funding has come from the Global Fund to Fight AIDS, Tuberculosis and Malaria (Global Fund). However, the level of donor funding has varied substantially over time. In 2014, domestic funding, that is, combined state and out-of-pocket (private) spending, was marginally higher than international funding. Out-of-pocket spending includes only the formal contribution made by PWID who utilized opiate substitution therapy (OST) services at the state-funded centers.10 Because out-of-pocket spending does not include informal payments or payment outside of National HIV Program delivery sites, for example, for condoms or needles in pharmacies, it is likely to be underestimated.

The ongoing fallout of the 2008 economic crisis has reduced the prospect of increasing or stabilizing the international funding for national HIV responses in the ECA Region. The Global Fund is the primary funding partner for key HIV programs in Georgia. As a result of the eligibility and cofinancing requirements of the Global Fund's new funding model, external HIV

9 From the Georgia Final Draft National HIV Strategic Plan: The all-cause mortality rate peaked in 2004, with 10.74 deaths per 100 person-years (PY) (95\% CI: 7.92-14.24) and significantly decreased after the widespread availability of ART to 4.02 per 100 PY $(95 \%$ CI: 3.28-4.87) reported in $2012(\mathrm{p}<0.0001)$. There was more than a 3-fold decrease in AIDS-related mortality from 6.49 deaths per 100 PY (95\% CI: 4.34-9.32) in 2004 to 2.05 deaths per 100 PY (95\% CI: 1.53-2.68) in 2012 ( $\mathrm{p}<0.0001)$.

10 The state-funded OST program is based on a cofunding principle. Copayment for the patients enrolling in these programs was $\$ 150 \mathrm{GEL} / \mathrm{month}$ before 2013 and was reduced to $\$ 110 \mathrm{GEL} /$ month in 2013 . However, these centers serve HIV/AIDS patients for free (USAID 2014). 
funding is likely to decline. This likelihood leads to concern about the sustainability of Georgia's long-term national HIV response. Funding partners increasingly are technically supporting countries to establish transitional funding mechanisms that will facilitate the shift from international to domestic financing of HIV programs.

Since 2006, the share of domestic resources spent on HIV programs in Georgia has quadrupled, from 10.0 percent in 2006 to 52.4 percent in 2014 (Figure 1.5). As noted, much of this increase in domestic funding has been financed through out-of-pocket (private) expenditure.11

Further reducing Georgia's dependence on external donor funding may require the establishment of short-term transitional funding mechanisms to supplement and redirect domestic funding sources to increase state participation in healthcare financing.

Figure 1.5 Funding for HIV in Georgia, by funding source, 2006-14 (\%)

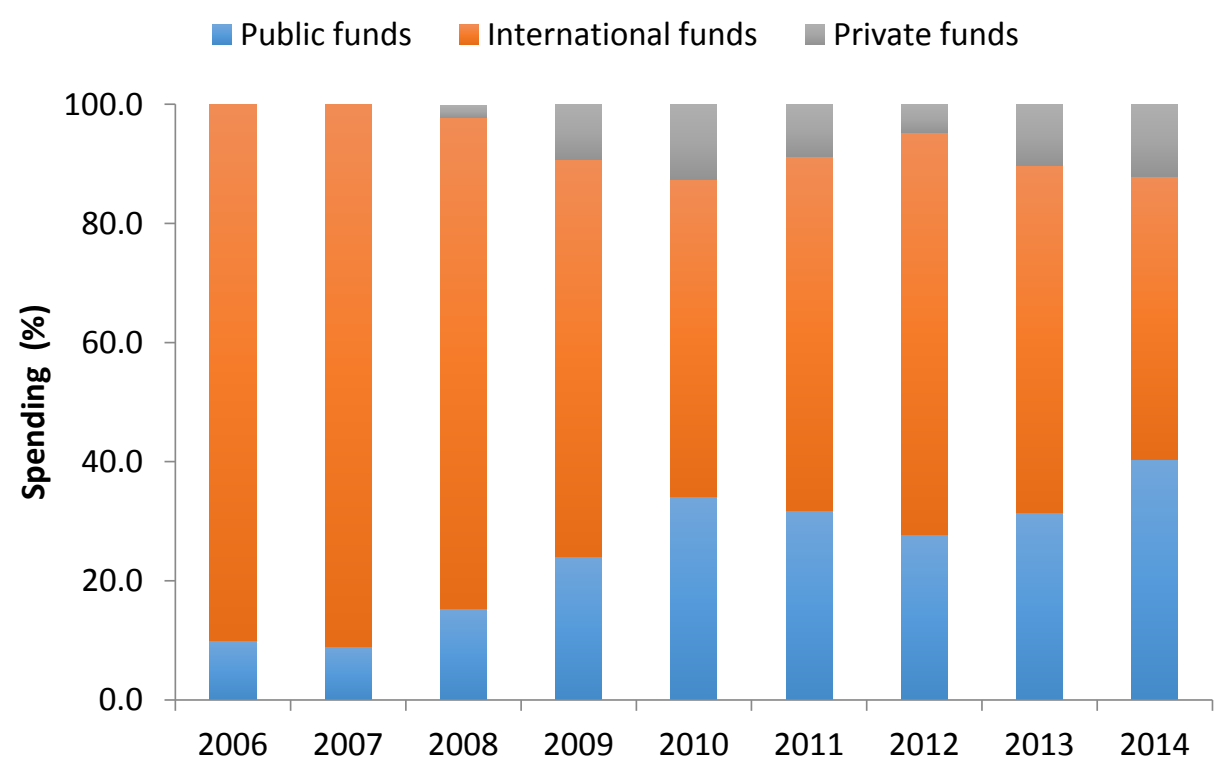

Source: Prepared by the authors based on National Center for Disease Control and Public Health 2014 and the final draft National Strategic Plan 2016-20.

\subsection{Necessity for allocative efficiency}

Current HIV programs are faced with the necessity to scale up prevention while providing ongoing treatment to a larger number of people living with HIV than ever before. In the current environment of increasingly limited resources for HIV epidemic responses, focused design and efficiency in program delivery are essential to ensure that programs can do more with less.

To maximize the impact of program investment and best realize the long-term health and economic benefits of HIV programs, a shift toward investment thinking in the design of HIV responses is being promoted globally by UNAIDS and cosponsors. Investment cases are being developed by a number of countries to understand HIV epidemics as well as to design, deliver, and sustain effective HIV responses. In support of HIV investment cases, a group of ECA countries are conducting allocative efficiency (AE) analyses. In 2014 and 2015 AE analyses

11 National Center for Disease Control and Public Health 2014 
were carried out in Armenia, Belarus, Georgia, Kazakhstan, Kyrgyzstan, Moldova, and Ukraine. ${ }^{12}$ This report summarizes the results of the analyses for Georgia.

In addition, this report provides insights on the progress made and gaps that remain to reach key international commitments. In the 2011 United Nations Political Declaration on HIV and AIDS, countries agreed to reduce sexual and injection-related transmission by 50 percent, virtually eliminate mother-to-child-transmission, initiate 80 percent of eligible PLHIV on treatment, and end HIV-related discrimination by 2015 (UNGASS 2011). The 2014 Gap Report illustrated that substantial additional efforts will be required in most countries to achieve these targets (UNAIDS 2014c). Against this background, UNAIDS globally defined a Fast-Track strategy to achieve the goal of Ending AIDS by 2030 (UNAIDS 2014b). Fast Track includes new initiatives such as the 90-90-90 targets. They set out to achieve that 90 percent of all PLHIV are diagnosed; 90 percent of diagnosed PLHIV are on ART; and 90 percent of PLHIV on ART are virally suppressed. The Fast-Track approach also emphasizes the need to focus on the geographic areas and communities most affected by HIV and recommends that resources be concentrated on the programs that have demonstrated the greatest impact.

In Georgia's context, the investment case is complemented by a human rights-based approach to health care. Georgia is one of the countries in ECA to have signed the 2004 Dublin Declaration of Partnership to Fight HIV/AIDS in Europe and Central Asia. As set out in the final draft National HIV Strategic Plan $(2015,18)$, this approach will be operationalized through a range of methods: improved accessibility and quality of essential services (including opioid substitution treatment), optimized treatment regimens, strengthened surveillance and monitoring, removal of legislative and regulatory obstacles to effective service delivery, protection of human rights, and reducing stigma. All of these are significant deterrent factors in Georgia (USAID 2014). As is explained more fully later in the report programs that critical from a rights perspective are protected from funding cuts in the optimization analysis. Thereby a provision is made in the model to ensures, for example, that PMTCT programs are maintained; that people on treatment do not lose access to that treatment; and that people who need treatment but are not yet on it are not denied access.

\subsubsection{Allocative efficiency in HIV}

The concept of allocative efficiency refers to the maximization of health outcomes, with the least costly mix of health interventions within a defined budget envelope. HIV allocative efficiency studies generally try to answer the question "How can a given HIV funding amount be optimally allocated to the combination of HIV response interventions that will yield the highest impact?"13

There is wide consensus that better outcomes could be achieved in many settings with a given amount of HIV funding; or that given outcomes could be achieved with less HIV funding if resources were distributed optimally or if resources were used in the most efficient ways. Mathematical modeling is one way to determine optimized HIV resource allocation within defined budget envelopes. The HIV allocative efficiency (AE) analysis in this study was carried out using the Optimization and Analysis Tool (Optima). The results can be utilized to better serve the needs of decision makers and health planners.

\footnotetext{
12 Aspects of the analytical process and the presentation of findings have been based on the Optima analyses and accompanying reports for six other countries in the Region.

13 For published study reports see, for example, Republic of Tajikistan 2014 and Fraser and others 2014.
} 


\section{HOW WILL THIS REPORT ANSWER KEY QUESTIONS?}

This report summarizes how Georgia may be able to better allocate current HIV spending to maximize health outcomes. The findings can assist the government to strengthen its HIV investment case, by which it is attempting to increase the effectiveness of its HIV investments and define the corresponding priorities, strategies, and impacts of its HIV response.

\subsection{Optima model}

To assess HIV epidemic trends, the analysts used Optima's epidemic module, which consists of a mathematical model of HIV transmission and disease progression. Optima uses best-practice HIV epidemic modeling techniques and incorporates evidence on biological transmission probabilities, detailed infection progression, sexual mixing patterns, and drug injection behaviors. Data relating to programs and costs associated with programs were used in an integrated analysis to determine an optimized distribution of investment under defined scenarios.

To populate the Optima model, data from the final draft of the National HIV Strategic Plan 2016-2018 ${ }^{14}$ were supplemented with published data and information from national registers. The model then was used to describe the likely trajectory of the epidemic in Georgia and how that epidemic could best be contained and treated with available financial resources.

Optima was calibrated to HIV prevalence data points available from the different subpopulations (such as FSW, PWID, and MSMW) at specific time points as well as to data points on the number of people on ART. The calibration was performed in consultation with experts on the Georgian epidemic. Section 2 and appendix B provide additional details regarding the calibration process.

To assess how incremental changes in spending affect HIV epidemics and thus determine the optimized funding allocation, the model parameterizes the relationships among the cost of HIV intervention programs, the coverage level attained by these programs, and the resulting outcomes. These relationships are specific to the country, population, and program being considered.

Using the relationships among cost, coverage and outcome-in combination with Optima's epidemic module-it is possible to calculate how incremental changes in funding allocated to each program will impact overall epidemic outcomes. Furthermore, by using a mathematical optimization algorithm, Optima is able to determine the "optimal" allocation of funding across different HIV programs.

14 Data and text were taken from the final draft of the National HIV Strategic Plan (March 2015), which was not the final National HIV Strategic Plan. Results should be interpreted accordingly. 


\subsection{Analytical framework}

To tailor the model to a given context, analysts selected a number of parameters that describe the country population, levels of expenditure, programs to be included or excluded, time frames, and baseline scenario. The parameters appropriate to the Georgian context are listed in Table 2.1.

Table 2.1 Modeling parameterization

\begin{tabular}{|c|c|c|}
\hline Category & Parameterization in Optima Model & Description/Assumptions \\
\hline $\begin{array}{l}\text { Populations defined in the } \\
\text { model }\end{array}$ & $\begin{array}{l}\text { Female sex workers } \\
\text { Clients of sex workers } \\
\text { Men who have sex with men and women } \\
\text { People who inject drugs } \\
\text { Males aged } 15-49 \\
\text { Females aged } 15-49 \\
\text { Other males, aged } 50+ \\
\text { Other females, aged } 50+\end{array}$ & $\begin{array}{l}\text { Females aged 15-49 } \\
\text { Males aged 15-49 } \\
\text { Males, aged 15-49 } \\
\text { Males aged 15-49 } \\
\text { Males aged 15-49 years excluding } \\
\text { MSMW, clients, and males who } \\
\text { inject drugs in this age group } \\
\text { Females, aged 15-49 years } \\
\text { excluding FSW in this age group } \\
\text { Males, aged 50+ } \\
\text { Females, aged } 50+\end{array}$ \\
\hline $\begin{array}{l}\text { Expenditure areas defined } \\
\text { in the model and included } \\
\text { in optimization analysisa }\end{array}$ & $\begin{array}{l}\text { Programs for female sex workers and clients } \\
\text { (package) } \\
\text { Programs for men who have sex with men and } \\
\text { women (package) } \\
\text { Opiate substitution therapyb } \\
\text { Needle-syringe program and other prevention } \\
\text { for people who inject drugs (package) } \\
\text { HIV testing and counselling } \\
\text { Antiretroviral therapy } \\
\text { Prevention of mother-to-child transmission }\end{array}$ & $\begin{array}{l}\text { Condom distribution, HIV testing } \\
\text { and counselling, community } \\
\text { outreach } \\
\text { Condom distribution, HIV testing } \\
\text { and counselling, community } \\
\text { outreach } \\
\text { Provision of medication and } \\
\text { related counselling } \\
\text { Needle and syringe exchange, } \\
\text { condom distribution, HIV testing } \\
\text { and counselling, community } \\
\text { outreach } \\
\text { HIV test kits and pre- and post- } \\
\text { testing counselling } \\
\text { Antiretroviral drugs, related } \\
\text { laboratory monitoring, and } \\
\text { clinical visits } \\
\text { HIV testing of pregnant women, } \\
\text { counselling and provision of } \\
\text { antiretroviral prophylaxis for } \\
\text { women living with HIVc }\end{array}$ \\
\hline $\begin{array}{l}\text { Expenditure areas not } \\
\text { included in mathematical } \\
\text { optimization: Indirect } \\
\text { programs (because the } \\
\text { effect on HIV incidence, } \\
\text { morbidity/mortality not } \\
\text { clear or because the } \\
\text { expenditure is central } \\
\text { systems expenditure } \\
\text { essential for multiple } \\
\text { program areas) }\end{array}$ & $\begin{array}{l}\text { Costs for indirect programs, also called enablers } \\
\text { and synergies, have not been optimized (because } \\
\text { they do not have measurable epidemic impact) } \\
\text { but instead were fixed at agreed amounts. The } \\
\text { components of HIV spending that will not be } \\
\text { included in the optimization analysis are: } \\
\text { Management HR and training } \\
\text { Enabling environment, including legal and } \\
\text { regulatory frameworks } \\
\text { Monitoring, evaluation, surveillance, and } \\
\text { research }\end{array}$ & \\
\hline
\end{tabular}




\begin{tabular}{|c|c|c|}
\hline Category & Parameterization in Optima Model & Description/Assumptions \\
\hline $\begin{array}{l}\text { Time frames for which } \\
\text { optimization was } \\
\text { considered }\end{array}$ & $\begin{array}{l}\text { 2000: Starting year for data entry } \\
\text { 2016-18: Government's timeline to achieve } \\
\text { national strategic plan targets } \\
\text { 2020: Interim timeline for international targets } \\
\text { 2030: New UNAIDS deadline to end AIDS }\end{array}$ & \\
\hline Baseline scenario funding & $\begin{array}{l}2014 \text { Global AIDS Response Progress Report } \\
\text { values }\end{array}$ & \\
\hline
\end{tabular}

Note: a = "HIV testing and counselling" and "ART" programs include services for all populations (including key populations). HIV testing services and related outreach, which are targeted specifically at key populations, are included within programs for key populations; $b=$ Because OST has substantial benefits outside of HIV (as will be elaborated in the "limitations of the analysis"), a constraint was established by putting limit of $60 \%$ reduction in OST budget allocation (that is, not reduce the funding more than 60\%) in all optimization analysis (analyses 1-4) to prevent the optimized budget allocation from removing or reducing allocations to OST; c = A comprehensive four-pronged approach to PMTCT also includes provision of contraception. For the vast majority of women, the primary purpose of contraception in this concentrated epidemic is not PMTCT but pregnancy prevention, Therefore, it was decided not to include contraception-related costs in this analysis (apart from the cost for condom promotion for key populations covered in FSW, MSM, and PWID programs).

\subsection{Calibration}

A key stage in the Optima modeling process is a stage known as "calibration." Calibration aims to align the Optima-projected trends with the historically observed trends in HIV prevalence in different population groups in a given context. Given the challenges inherent in aligning epidemiological and behavioral data, the calibration for Georgia was performed manually (by varying relevant model parameters to attain the best fit between model-projected and historic HIV prevalence across different population cohorts) and in close collaboration with in-country stakeholders.

Once the Optima model is calibrated, it can describe future expected trends in the HIV epidemic (chapter 3 ).

\subsection{Cost-coverage-outcome relationships}

The relationship between program spending and coverage is shown in the left panel of Figure 2.1. This relationship describes the level of output achieved with a specific level of financial input. In the context of these analyses, output is defined as the availability of a service to a specific proportion of the target population. Coverage refers to the number reached in the population. For example, this relationship would describe how many FSW could be provided with a standard package of services with an investment of US\$0-US\$1,000,000. The relationship between coverage levels and outcome is shown in the right panel. This relationship describes the proportion of people who will adopt a specific behavior (such as condom use or consistent use of ARVs leading to viral suppression). These analyses were produced in collaboration with Georgia experts. The full set of figures can be seen in appendix C.

The cost-coverage-outcome relationships are utilized, together with the calibration projections, to run the optimization and scenario analyses described in sections 5, 6, 7, and 8 . 
Figure 2.1 Logistic cost-outcome relationships for Georgia
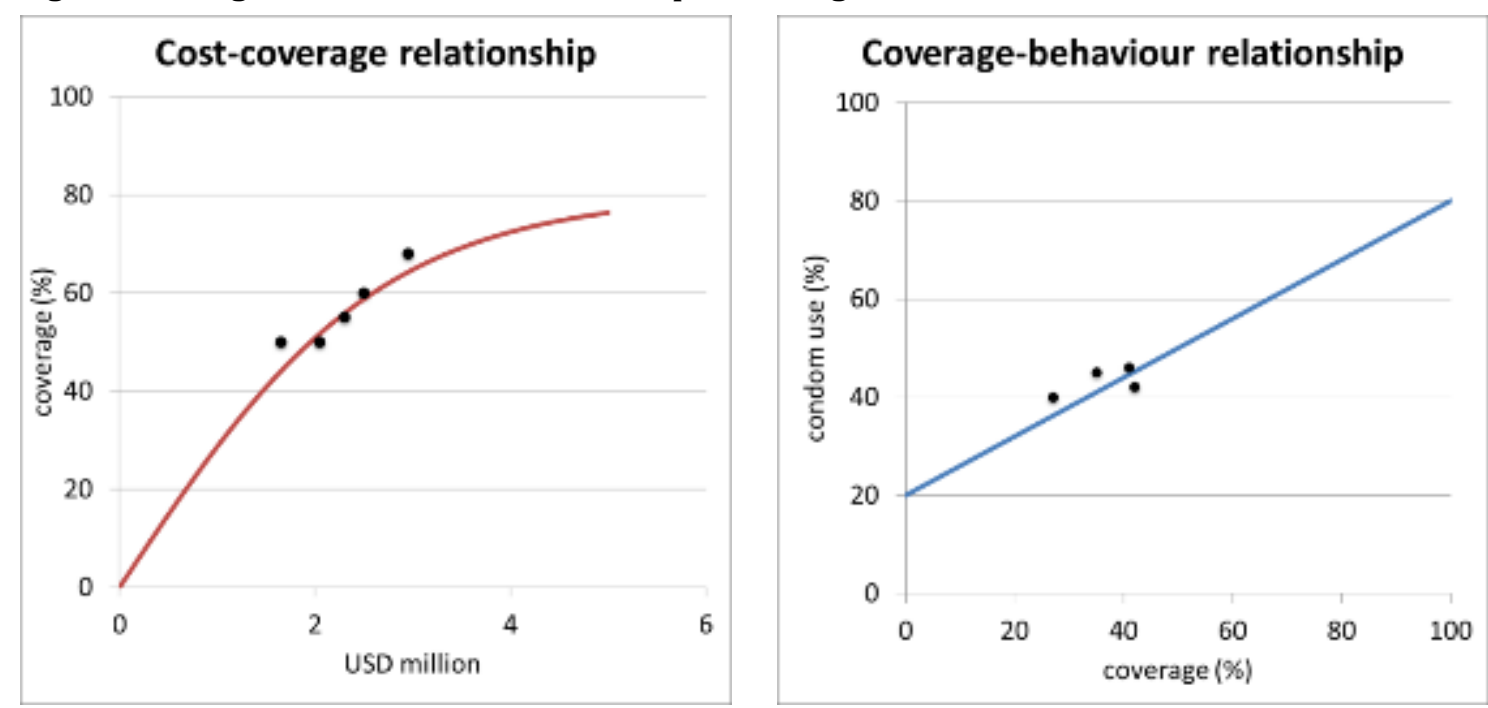

Note: Black dots represent available spending and coverage data, and associated behaviors. Solid curves are the best fitting or assumed relationships.

\subsection{Allocative efficiency analysis}

Efficiency analyses must be informed by local priorities. Georgia set the priorities for its HIV response in the final draft of its National HIV Strategic Plan. The plan also describes the key impacts, outcomes, and targets intended by end-2018. These priorities and targets are:

a. Increase domestic funding of the HIV response from 32 percent (2013) to 70 percent

b. Contain HIV prevalence among PWID, FSW, and prisoners at below 5 percent

c. Hold HIV prevalence among MSM below 15 percent

d. Reduce the rate of late HIV detection from 70 percent to 35 percent

e. Reduce AIDS-related mortality to fewer than 2 deaths per 100,000 population

f. Essential treatment coverage targets are shown in Table 2.2.

Table 2.2 Georgia: Essential treatment coverage targets

Percentage of adults and children with HIV known to be on treatment 12 months after initiating treatment among patients initiating antiretroviral therapy

\begin{tabular}{ll}
\hline Percentage of newly diagnosed persons who are enrolled in care & $>90$
\end{tabular}

Percentage of people on ART tested for viral load (VL) with VL level $\leq 1000$ copies $/ \mathrm{ml}$ after 12 months of therapy

Number and percent of adults and children receiving antiretroviral therapy according

Source: Government of Georgia 2015, 28.

Note: $*$ Denominator is based on the Spectrum estimates and will be changed in line with the regular Spectrum updates.

To support the National HIV Strategic Plan priorities and assist Georgia in meeting its targets, this report answers four questions:

1. How can Georgia optimize the allocation of its current HIV funding?

2. What might be gained from increased investment in HIV programming?

3. What is the minimum spend that would be required to meet the National HIV Strategic Plan targets? 
4. What are the long-term resource needs of Georgia's HIV response? This question refers to the liabilities arising from the commitment to provide HIV and related health services in the future.

Each of these questions is the subject of an analytical module detail below.

\section{Analysis 1: How can Georgia optimize the allocation of HIV funding?}

Analysis 1 compares the trajectory of the epidemic and key outcomes under the current allocation of resources against an optimized allocation of resources. For this analysis, the funding levels are not varied-only the way that funding is spent. The aim is to determine how Georgia can allocate available resources to achieve maximum impact, and how close this maximum impact will be to the National HIV Strategic Plan targets described.

Analysis 1 asks the following specific questions:

What will be the expected annual levels of HIV incidence, HIV prevalence, and AIDS-related deaths if current funding allocations are maintained? The results of this analysis are described in section 3 and explored in section 5.

If funding is kept at the same level, but resources are allocated differently according to the optimization model, what will be the expected annual levels of HIV incidence, HIV prevalence, and AIDS-related deaths?

The results of this analysis are described in section 6 .

\section{Analysis 2: What might be gained from increased investment in HIV programs?}

Analysis 1 is was based on maintaining current funding allocations. In contrast, Analysis 2 explores what could be achieved by increasing the available budget. Analysis 2 aims for the maximum possible reduction of new deaths and infections. The results appear in section 7 .

\section{Analysis 3: What is the minimum spend required to meet the National HIV Strategic Plan targets?}

Analysis 3 identifies the minimum resource requirements to achieve the National HIV Strategic Plan targets. This analysis assesses the gaps in funding required to achieve the national targets. The results appear in section 8 .

\section{Analysis 4: What are the long-term financial commitments to the HIV response?}

Analysis 4 reviews the impact of current investment choices on long-term financial commitments. This analysis compares the commitments expected to result from the current allocation of the 2014 budget against the optimized allocation of the 2014 budget described in section 6 . The findings from this analysis are presented in section 9.

\subsection{Limitations of the Optima analyses}

All mathematical models have their strengths and limitations. Results should therefore be interpreted with the necessary caution. In particular, it is important to note that:

All model forecasts are subject to uncertainty. Therefore, point-estimates are indicative of trends rather than exact figures.

The model calibration depends as much on the quality of input data as on the quality of the model itself. The country and study teams have done everything possible to ensure the best possible data quality but it is never possible to have a complete, or completely certain dataset. 
The best model calibration rarely will achieve an exact match with historical data, but will mirror as closely as possible their key trends.

There were some data gaps in Georgia. Missing data are most common for the general population and for the clients of sex workers. As in other models, estimates of HIV prevalence in the general population were derived from data in pregnant women as a proxy for prevalence in the female general population. The average overall population prevalence value was used for the male general population. There were no data available for clients. Therefore, an assumed population size of 10 percent of the general adult male population (15-49 age group) was used.

The modeling approach used to calculate relative cost-effectiveness among programs includes assumptions about the impact of increases or decreases in availability of funding for programs. These assumptions are based on unit costs and observed ecological relationships between outcomes of program coverage or risk behavior and the amount of money spent on programs in the past, assuming that increases in spending would cause some saturation in the possible effects of programs.

Where possible, the cost-coverage-outcome relationships were derived from actual cost and coverage values as well as from the expected cost and coverage values based on the final draft of the National HIV Strategic Plan 2016-2018.

The analysis presented in this report does not determine the technical efficiency of programs because technical efficiency was outside the scope of the analysis. However, gains in technical efficiency would lead to lower unit costs and therefore would affect the optimized resource allocation described in this report.

Modeling the optimization of allocative efficiencies depends critically on the availability of evidence-based parametric estimates of the effectiveness and cost-efficiency of individual interventions. Interventions/programs for which these parametric estimates do not exist, such as for many of the critical enablers, will be excluded from the mathematical optimization analysis. However, their exclusion does not mean that these programs should not receive funding. In addition, there are uncertainties around parameter estimates of some of the critical clinical interventions (such as ART and the parameter estimates such as the preventive effect of ART). These uncertainties could distort the results.

Effects of the programs outside the HIV endpoints are not included in this model. Such programs include the wider health and non-health benefits of OST (beyond those directly related to HIV) and the effects of needle exchange programs on hepatitis, Given that, in the case of OST, there are significant benefits beyond HIV outcomes, the optimized budget allocation was prevented from removing or reducing allocations to OST by limiting the percent reduction in OST budget allocation (that is, not reducing the funding more than 60 percent).

Along the same lines, the Optima modeling approach does not seek to quantify the human rights; stigma and discrimination; or ethical, legal or psychosocial implications of providing or withdrawing care. However, the authors acknowledge that these are important aspects to consider.

Other models may produce different projections than these produced by Optima. Differential results are an underlying property of using differing designs of theoretical mathematical frameworks. However, the estimates presented in this report are not significantly different from the epidemic trends projected in the UNAIDS estimation process using the Spectrum model. In addition, the analyses presented in this report have made use of the best available 
country data, experience gained from applying the Optima model in over 20 countries, and comparisons within the ECA Region for the validation and contextualization of inputs and findings wherever possible. 


\section{WHAT ARE THE EXPECTED TRENDS IN THE EPIDEMIC IF CURRENT SPENDING IS MAINTAINED?}

\subsection{Status of the epidemic}

In 2013 the estimated rate of new diagnosis in Georgia was 10.9 per 100,000 (Georgia 2014). At the end of 2014, 4,695 PLHIV were registered. ${ }^{15}$ According to Spectrum, the modelestimated number of PLHIV in 2014 is 6,800. ${ }^{16}$ Results from the Optima analysis for the same year suggest that the number was 6,300 (Figure 3.1). The 2013 HIV prevalence among the general population was estimated at 0.07 percent (NCDC 2014). Table 3.1 shows the population sizes and the rates among key affected populations.

Table 3.1 Population size estimates and prevalence among key affected populations, most recent year available

\begin{tabular}{lrr}
\hline $\begin{array}{l}\text { Population } \\
\text { PSW }\end{array}$ & $6,525^{\mathrm{a}}$ & $\begin{array}{r}\text { Prevalence } \\
\text { (most recent value) (\%) }\end{array}$ \\
Clients & (est.) 111,000 & $1.30^{\mathrm{b}}$ \\
MSMW & $17,215^{\mathrm{c}}$ & (est.) 0.12 \\
PWID & $45,000^{\mathrm{e}}$ & $13.00^{\mathrm{d}}$ \\
\end{tabular}

Note: a Curatio International Foundation and Centre for information and counseling on reproductive Health Tanadgoma. 2014a; $b=$ Curatio International Foundation and Centre for information and counseling on reproductive Health-Tanadgoma 2013c; c = Curatio International Foundation and Centre for information and counseling on reproductive Health - Tanadgoma 2014b; $d=$ Curatio International Foundation and Centre for information and counseling on reproductive Health - Tanadgoma 2013a; e = Curatio International Foundation and Public Union Bemoni, 2012; f = Curatio International Foundation and Public Union Bemoni 2013b.

On the current trajectory, maintaining current levels of funding and current allocations to programs-the total number of PLHIV is projected to increase to 7,900 by 2020 and to 9,900 by 2030 (Figure 3.1). This projection is based on an expected increase in incidence and a projected decrease in the death rate among PLHIV due to the positive effect of ART. The majority of new PLHIV will be MSMW because the prevalence in this group is projected to continue to increase over the next 15 years (Figure 3.1).

While the number of deaths currently is low, that, too, is expected to rise. The remainder of this chapter describes these modelled projections based on the results of the calibration (see also appendix B.

\footnotetext{
15 National Aids Centre. http://aidscenter.ge/epidsituation_eng.html.

16 Spectrum /Epidemic Projection Package 2014, vers. 5.03.
} 
Figure 3.1 Calibration of PLHIV, 2000-30

\section{PLHIV}

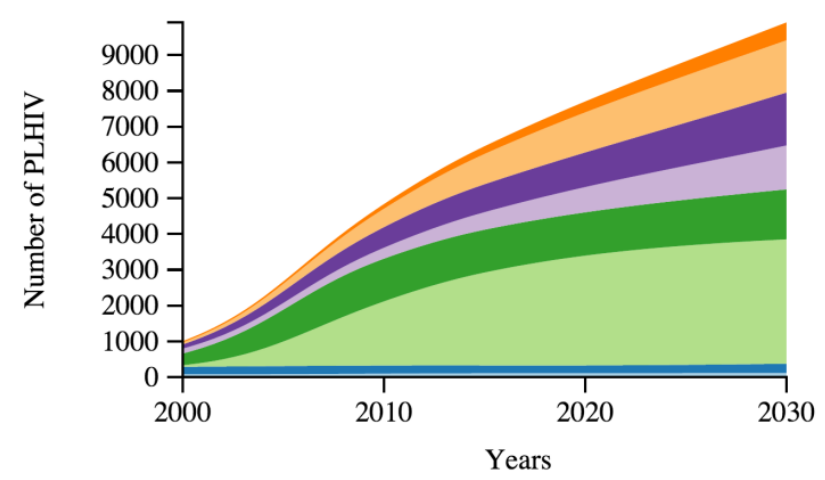

FSW
Clients
MSMW
PWID
Males 15-49
Females 15-49
Males [50+]
Females [50+]

\subsection{HIV prevalence is expected to increase}

Overall HIV prevalence is projected to increase from modelled-estimates of 0.18 percent in 2014 to 0.23 percent in 2020 and 0.28 percent by 2030 . HIV prevalence in the MSM population increased from 7 percent in 2010 to 13 percent in 2012, and the model predicts an increase to 18 percent by 2020 and 20 percent by 2030 . HIV prevalence is expected to virtually stabilise among FSWs and in keeping with stabilising prevalence among FSWs, prevalence among FSW clients is also projected to stabilise. However, there is significant uncertainty around this finding due to the lack of primary data on this key population described in chapter 2 . The model estimates that prevalence among PWID could still increase but at a slower rate than in the past, due in part to decreasing rates of needle sharing. The model estimates that, if current conditions are maintained, HIV prevalence in this population will stabilize at approximately 3 percent after 2014, and could increase again moderately by 2030. To maintain this expected trend, keeping rates of needle sharing low is essential.

\subsection{HIV Incidence is increasing}

One of the main factors underpinning the increase in HIV prevalence described above is an expected increase in HIV incidence (the number of new infections per year). Since 2000, overall incidence has increased. The model predicts that, during 2014-30, incidence will increase from 580 new infections per year in 2014 to 679 new infections per year in 2020, and to 860 per year by 2030 (Figure 3.2). These projections are consistent with the rising number of new HIV diagnoses in Georgia. Much of the expected increase in incidence is driven by the share of transmission attributed to unprotected sex between MSMW and their male and female partners. Low condom use between MSMW and commercial partners is a particular cause for concern. ${ }^{17}$ The high probability of sex between MSM and female partners also implies a

17 The proportion of MSM who reported condom use at their last anal insertion with a paid partner was $67 \%(8 / 12)$ in 2010 and $50 \%$ (4/8) in 2012. Given that the denominator for paid partners is very small, this proportion should be interpreted with caution. (Curatio International Foundation 2013a) 
potential for increasing HIV incidence among these female partners who will be difficult to reach with programs, as their background characteristics are likely similar to the wider female adult population. .

Figure 3.2 Calibrated number of new HIV infections per year, 2000-30

\section{New infections}

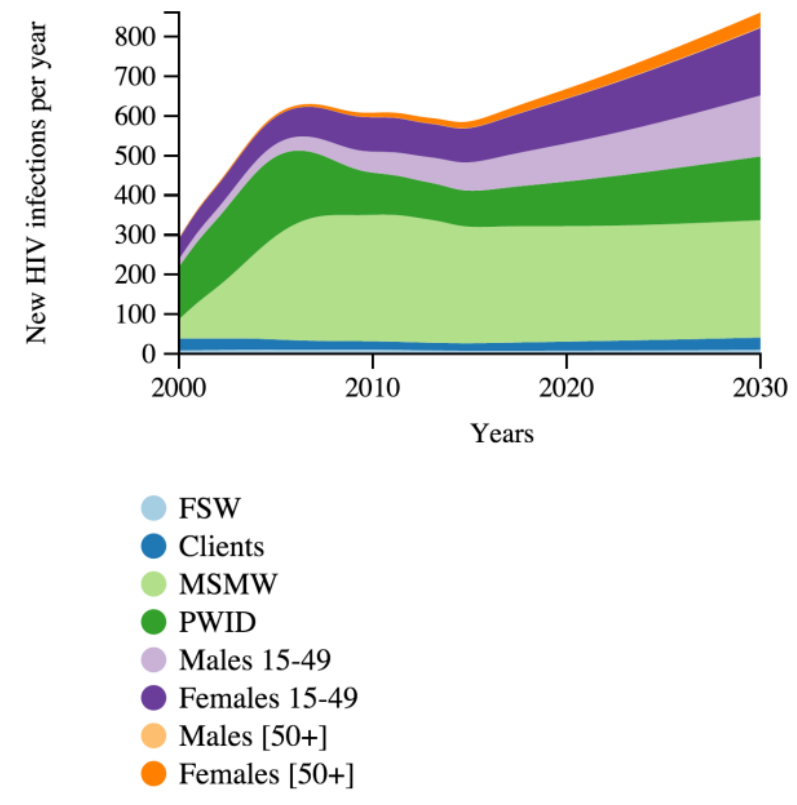

\subsection{AIDS-related deaths are low but increasing in number}

Until 2010, the number of AIDS-related deaths was estimated to be low and stable, reflecting the low-level epidemic of the 1990s. However, the number of deaths is projected to increase with the expanding key population epidemics of the past decade.

ART has slowed the increase in AIDS-related mortality. However, overall, with the current coverage of ART, the number of deaths attributable to HIV is predicted to increase from 170 per year in 2014 to 270 in 2020 and 400 by 2030 (Figure 3.3).

HIV testing and ART provision are funded by the state and the Global Fund to Fight AIDS, Malaria and Tuberculosis (Global Fund). ${ }^{18}$ Nevertheless, poorer outcomes on ART will be caused, at least in part, by the late presentation for testing and treatment described earlier in this report and again in section 4 .

18 National Center for Disease Control and Public Health 2014. 
Figure 3.3 Calibration-predicted number of deaths due to HIV in Georgia, assuming stable coverage of programs, 2000-30

\section{Deaths}

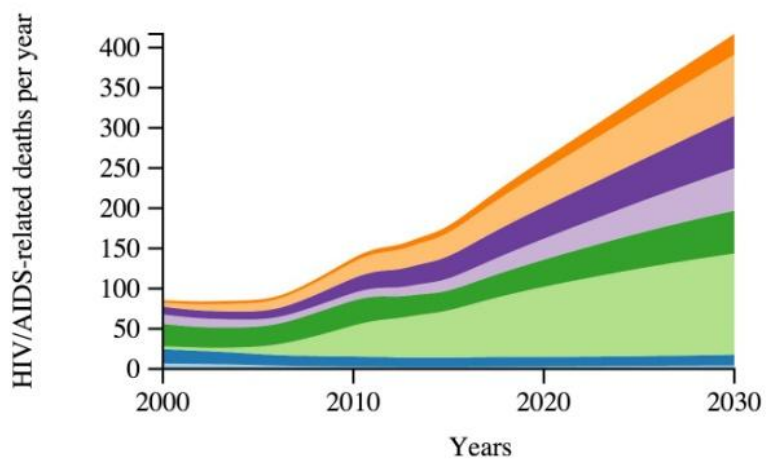

FSW

Clients

MSMW

PWID

Males 15-49

Females 15-49

Males $[50+]$

Females $[50+]$

\subsection{Number of people requiring HIV treatment will increase}

Table 3.2 shows the ART coverage in Georgia from 2011 to 2014. The World Health Organization (WHO) 2013 treatment guidelines are to commence treatment when a patient's CD4 count drops below 500 and to adopt a universal access approach. Following this approach has enabled Georgia to achieve a high treatment coverage of PLHIV who are eligible for treatment. However, the large difference in the numbers on treatment and the estimated population in need suggests a sizeable treatment gap. ${ }^{19}$

Table 3.2 ART coverage in Georgia, 2011-14

\begin{tabular}{|c|c|c|c|c|c|c|}
\hline \multirow[b]{2}{*}{ Year } & \multicolumn{2}{|c|}{ Number of PLHIV on ART } & \multicolumn{2}{|c|}{ Coverage among diagnosed } & \multicolumn{2}{|c|}{ Spectrum-derived coverage } \\
\hline & $\begin{array}{r}\text { National } \\
\text { target }\end{array}$ & $\begin{array}{r}\text { Actual } \\
\text { achievement }\end{array}$ & $\begin{array}{r}\text { Number } \\
\text { eligible } \\
(C D 4<350)\end{array}$ & $\begin{array}{r}\text { Covered from } \\
\text { eligible PLHIV } \\
(\%)\end{array}$ & $\begin{array}{r}\text { Total } \\
\text { estimated } \\
\text { number of } \\
\text { PLHIV }\end{array}$ & $\begin{array}{r}\text { From total } \\
\text { estimated } \\
\text { PLHIV } \\
(\%)\end{array}$ \\
\hline 2011 & 1,290 & 1,245 & 1,295 & 96 & 5,400 & 23 \\
\hline 2012 & 1,540 & 1,640 & 1,750 & 94 & 5,900 & 28 \\
\hline 2013 & 1,820 & 2,092 & 2,300 & 91 & 6,400 & 33 \\
\hline 2014 & 2,110 & 2,541 & 2,675 & 95 & 6,800 & 37 \\
\hline
\end{tabular}

Source: Georgian Final Draft National HIV Strategic Plan, 11.

19 In 2012, 70.4\% of newly identified HIV infected people had a CD4 count of $<350$ cells $/ \mathrm{mm} 3$ and $43.9 \%$ of these had a CD 4 count of $<200$ cells $/ \mathrm{mm} 3$ (WHO Europe 2014). 


\section{WHAT ARE THE IMPACTS OF PAST AND CURRENT SPENDING?}

\subsection{Prevention receives the majority of current funding}

To date, prevention has been the largest component of HIV spending to date (Figure 4.1). Within prevention, harm reduction programs for PWID (including OST and NSP) comprise the largest component, ranging from 54 percent to 73 percent of prevention expenditure. In 2014, 70 percent of prevention spending was allocated to harm reduction programs.

Past investment in programs specifically targeting MSM and FSWs has been relatively low. ${ }^{20}$ These investments also have varied substantially over time, suggesting a fragile financing climate for individual programs. In 2014, targeted programs for MSM and FSWs were allocated 5 percent and 3 percent of prevention funding, respectively. ${ }^{21}$ Table

Figure 4.1 HIV expenditure in Georgia by type of spending, 2006-14

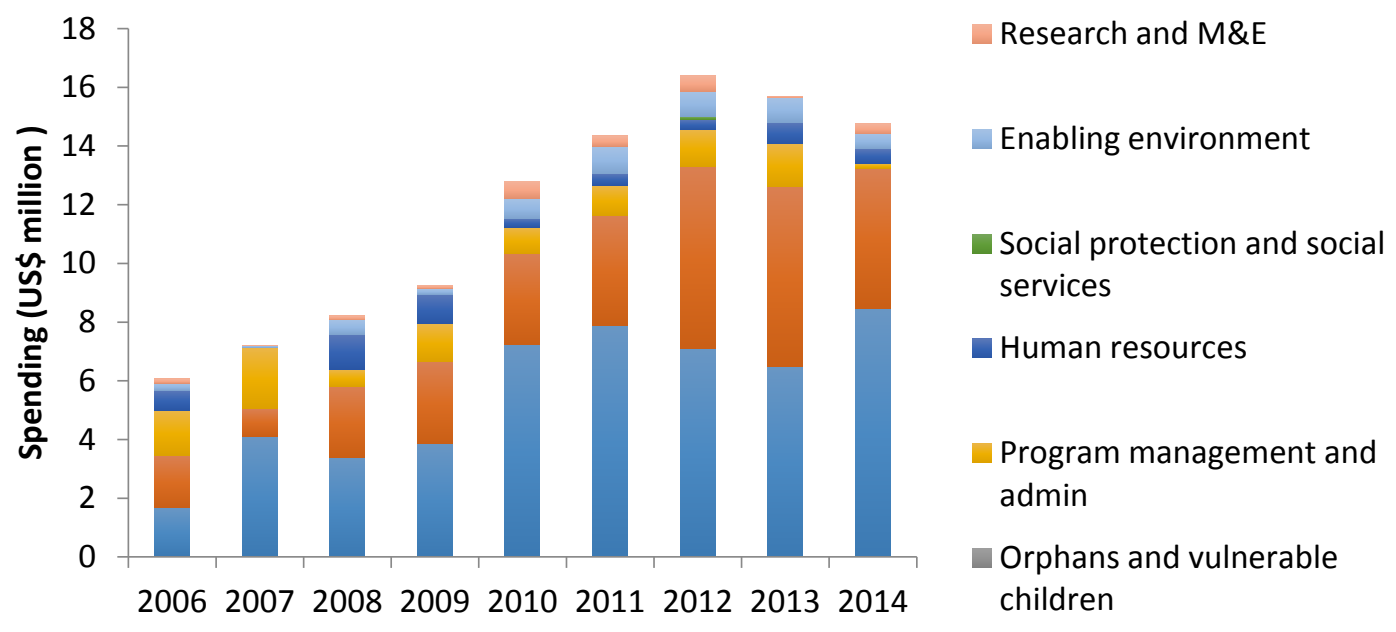

Source: National Center for Disease Control and Public Health, 2014; Government of Georgia, 2015; Data is based on annual national AIDS spending assessments and the country's Global AIDS Progress Reporting (GARPR).

20 Because many services for key affected populations are not allocated in population-specific budgets, these numbers may not include some spending targeted at the general population, which also benefits key affected populations.

21 GARPA 2010-14 and Final Draft National HIV Strategic Plan 2014. Data has been taken from the final draft of the National HIV Strategic Plan (March 2015), not the final National HIV Strategic Plan. Results should be interpreted accordingly. 
The proportion of spending allocated to indirect costs such as management and human resources has decreased since 2006. In 2014, these costs comprised approximately 9 percent of total HIV spending. ${ }^{22}$

\subsection{Prevention could be better targeted within and among key populations}

HIV prevention and treatment may not cover those in most need (Figure 4.2). Model-based estimates suggest that incidence and prevalence are increasing among males and females 1549 (who include sexual partners of PWID, MSM, and FSW and their clients) and some key populations, especially MSM. These trending increases suggest that prevention could be better targeted at MSM, including MSMW. If the role of this population in "bridging" is considered further, then the case for better, and better targeted, prevention is compelling because it would likely yield benefits for both high- and low-risk populations.

Although the increase in prevalence among PWID is expected to be small, Optima analyses suggest that a need remains to invest in programs for PWID, including needle-syringe programs (NSP) and opiate substitution therapy (OST). However, given the relatively high current cost of OST provision, increases in coverage may require additional technical efficiency analyses to identify ways to reduce the average OST costs.

Figure 4.2 Trends in spending across key priority prevention and treatment programs, 2010-14

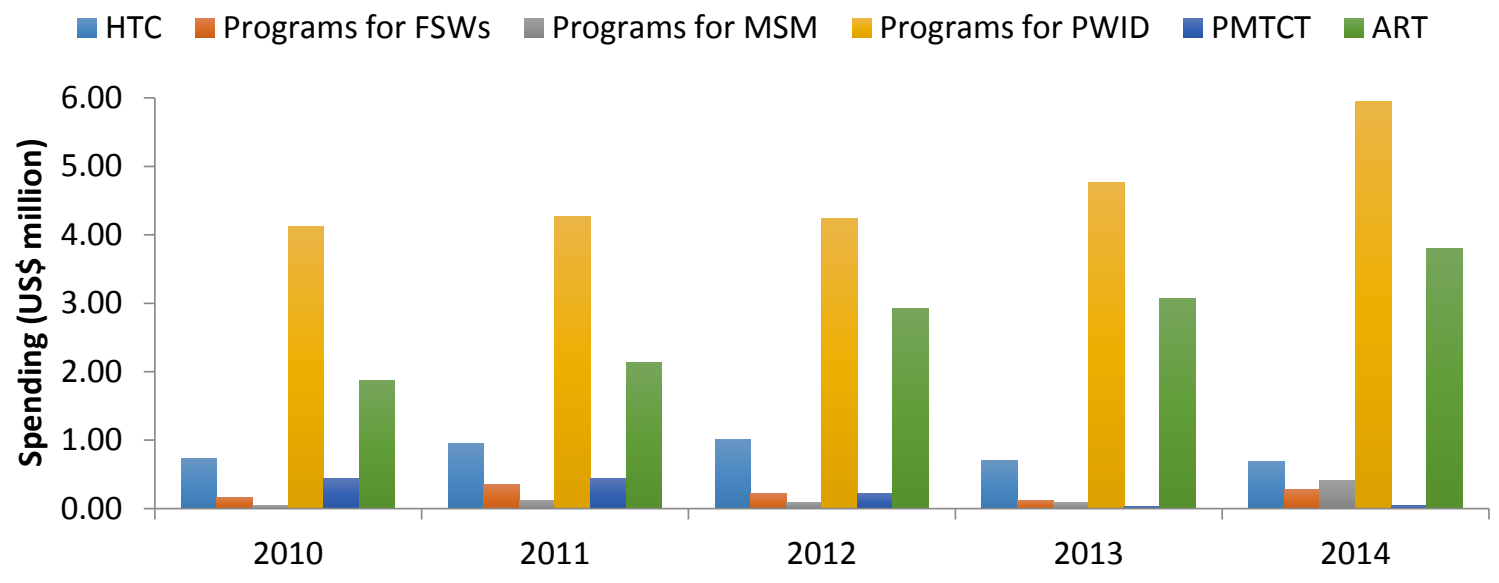

Note: HTC and ART are programs for the whole population so include people from key affected population groups.

Using the cost-coverage relationships, the unit costs at the current level of spending (2014) were derived. The unit costs for some programs, in particular OST, are high when compared with data for other countries in the Region (Table 4.1).

A more detailed review of these unit costs and a targeted technical efficiency analysis may be beneficial after this analysis has been completed. If high unit costs are reduced without compromising the quality of programs, then a clear efficiency gain is achieved, and "saved" resources can be used more effectively to combat the epidemic through reallocation to other programs.

22 Expenditure data drawn from the GARPA 2010-14 and Final Draft National HIV Strategic Plan 2014. Data has been taken from the final draft of the National HIV Strategic Plan (March 2015), not the final National HIV Strategic Plan. Results should be interpreted accordingly. 
Table 4.1 Comparing costs of programs in the ECA Region (US\$)

\begin{tabular}{|c|c|c|c|c|c|c|}
\hline \multirow[b]{2}{*}{ Cost per person reached } & \multirow{2}{*}{$\begin{array}{r}\text { Georgia, } \\
2014^{\mathrm{a}}\end{array}$} & \multicolumn{4}{|c|}{ Regional comparison ${ }^{b}$} & \multirow{2}{*}{$\begin{array}{r}\text { Georgia draft } \\
\text { national } \\
\text { strategy }\end{array}$} \\
\hline & & Lowest & Highest & Average & Median & \\
\hline FSW programs & 166.30 & 34.13 & 166.24 & 93.11 & 103.65 & 112.03 \\
\hline MSM programs & 232.35 & 13.46 & 449.13 & 142.09 & 47.79 & 133.99 \\
\hline PWID-NSP programs & 64.75 & 40.90 & 129.25 & 104.88 & 66.86 & 79.02 \\
\hline OST & $1,645.24$ & 378.17 & $1,645.24$ & 700.43 & 645.31 & $1,835.18$ \\
\hline PMTCT $^{d}$ & $8,905.27$ & 738.08 & $8,905.27$ & $4,616.80$ & $4,267.59$ & $7,147.23$ \\
\hline ART & $1,464.71$ & 576.48 & $2,278.52$ & $1,203.26$ & $1,127.29$ & $1,410.97$ \\
\hline
\end{tabular}

Note: Table 4.1 reflects how costs were categorized by countries for this analysis. The method is not based on detailed matching of classification of inputs, but on how countries classified expenses using the detailed available guidance for NASA and GARPR reports. Although this guidance is detailed and specific, differences cannot be ruled out, particularly regarding cross-cutting costs such as HR costs. In addition, even if costs are classified consistently, the comprehensiveness of service packages may differ; $a=$ Data were based on the country's data collection for the 2014 Global AIDS Response Progress Reporting; $b=$ The completed Optima data matrixes for 7 ECA countries were compiled by the study team from a range of country-specific data sources during 2014-15. These data are based primarily on coverage data from program records for 2013 and total HIV spending for a program area per 2013 GARPR and NASA reports; c = Georgia Final Draft National Strategic Plan 2014. Data were extracted from the final draft of the National HIV Strategic Plan (March 2015), not the final National HIV strategic plan. Results should be interpreted accordingly; $d=A$ comprehensive fourpronged approach to PMTCT includes providing contraception. Because the primary purpose of contraception for the vast majority of women in this concentrated epidemic is not PMTCT but pregnancy prevention, it was decided not to include contraception costs (apart from the cost for condom promotion for key populations covered in FSW, MSM, and PWID programs) in this analysis.

A number of limitations of the data presented in Table 4.1 should be noted, along with additional detail about the data used. In particular:

- Spending data for PMTCT in Georgia is an average for 2010-14 because 2013 was an outlier in the dataset

- Although all expenditure data has been extracted from NASA/GARPR reports, which follow a standard methodology, countries may not have classified all costs in the same way

- Coverage definitions and packages may differ among countries.

Consequently, Table 4.1 does not provide information about which countries deliver services more efficiently. This analysis seeks only to highlight which programs could benefit from an additional, more robust review of technical efficiency.

\subsection{Investing in an HIV response averts infections and deaths}

Model-based projections of the epidemic indicate that current spending on HIV prevention and treatment programs will continue to avert new infections and deaths. In the absence of any spending on the HIV epidemic, the model estimates that prevalence would be 0.54 percent higher; 793 more deaths would occur; and 4,224 more people would be infected (Figure 4.3). Furthermore, as noted above, the total number of PLHIV is projected to increase to 7,865 by 2020 and to 9,913 by 2030 (Figure 3.1). These projections highlight the necessity to continue investing in the HIV response. 
Figure 4.3 Model-estimated impact of current spending compared to no spending on the HIV response, 2015-30a
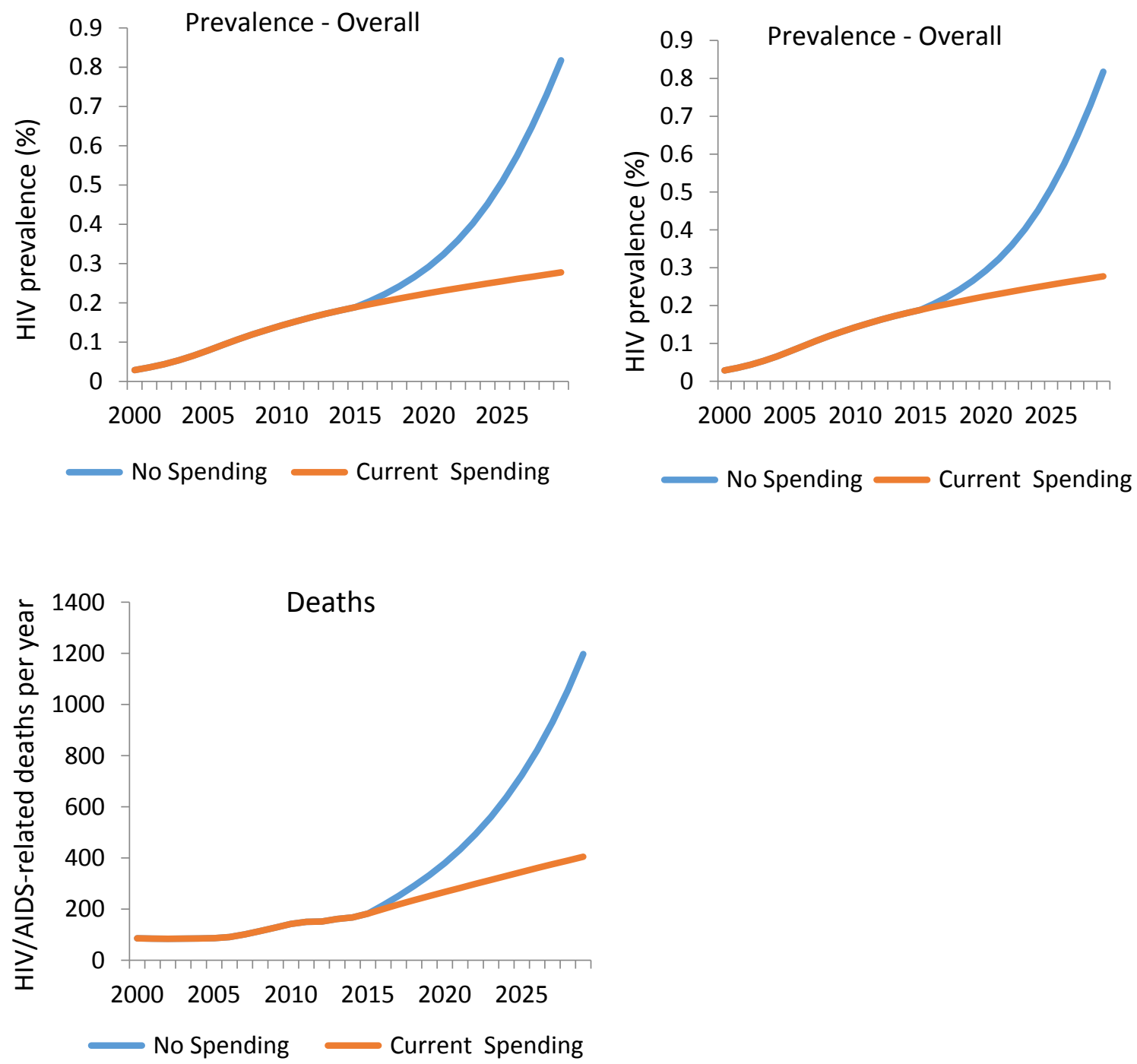

Note: a = "No spending" assumes that there is no spending on the HIV response. "Current spending" assumes that current funding levels and allocations remain stable and achieve coverage in line with the cost-coverageoutcome curves defined in the model. 


\section{PREDICTING THE TRAJECTORY OF THE HIV EPIDEMIC: COMPARING HIV RESPONSE SCENARIOS}

In the previous section, the study team compared current spending levels and allocations, against a "no spending" scenario. Figure 4.3 demonstrated that the current response to the epidemic is significantly reducing HIV prevalence, HIV incidence, and HIV-related mortality from the levels could be expected in the absence of current programs. The Optima model predicts that this positive impact is likely to persist, and even grow, in the period up to 2030. In this section, the study team ask whether reaching pre-specified targets could further reduce prevalence, incidence, and mortality. Here the study team compares the trajectory of the HIV epidemic by 2030 in Georgia under the current HIV response against 3 alternative HIV response scenarios. These are not constrained by a budget but are determined solely by targets. These scenarios were identified through extensive consultation with local stakeholders and a range of experts. In this section, the epidemic trajectory is predicted for each of these scenarios and compared with the trajectory under current programs without determining the overall budget envelope required to achieve defined targets in each scenario. The three response scenarios used for comparison were:

1. Test and offer treatment only (no prevention programs). This scenario assumed that, by 2030, 90 percent of PLHIV will be aware of their status and 90 percent of PLHIV will be on ART.23

2. Reaching National HIV Strategic Plan targets. This scenario assesses the trajectory of the HIV epidemic using the National HIV Strategic Plan (2016-18) targets for key priority prevention and treatment programs.

3. Reaching the National HIV Strategic Plan targets with a larger focus on MSMW population by increasing condom use from 73 percent to 85 percent among the MSMW population.

Table 5.1 presents detailed information on parameters and targets specified in the alternative scenarios.

23 Treatment efficacy in reducing new infections for PLHIV on ART was assumed to be $70 \%$. 
Table 5.1 Parameters and target values used in the alternative scenarios, 2014-2030

\begin{tabular}{|c|c|c|c|c|}
\hline \multirow{3}{*}{$\begin{array}{l}\text { Target } \\
\text { population }\end{array}$} & \multirow[b]{3}{*}{ Parameters } & \multicolumn{3}{|c|}{ Alternative response scenarios* } \\
\hline & & \multicolumn{2}{|c|}{$\begin{array}{cr}\text { National } \\
\text { Test and offer } & \text { Strategy } \\
\text { treatment only } & \text { (baseline-2018) }\end{array}$} & \multirow{2}{*}{$\begin{array}{r}\text { National Strategy } \\
+ \text { MSM (baseline- } \\
\text { 2018) }\end{array}$} \\
\hline & & (baseline-2030) & $(\%)$ & \\
\hline \multirow[t]{2}{*}{ FSWs $(\%)$} & $\begin{array}{l}\text { Proportion of sexual acts in which } \\
\text { condoms are used with } \\
\text { commercial partners }\end{array}$ & No change (91) & $91-95$ & $\begin{array}{l}\text { Same as national } \\
\text { strategy scenario }\end{array}$ \\
\hline & Year & $\mathrm{N} / \mathrm{A}$ & $20-50$ & $\begin{array}{l}\text { Same as national } \\
\text { strategy scenario }\end{array}$ \\
\hline $\begin{array}{l}\text { Clients of sex } \\
\text { workers }(\%)\end{array}$ & $\begin{array}{l}\text { Proportion of sexual acts in which } \\
\text { condoms are used with } \\
\text { commercial partners }\end{array}$ & No change (91) & $91-95$ & $\begin{array}{l}\text { Same as national } \\
\text { strategy scenario }\end{array}$ \\
\hline \multirow{2}{*}{ MSMW (\%) } & $\begin{array}{l}\text { Proportion of sexual acts in which } \\
\text { condoms are used with casual } \\
\text { partners }\end{array}$ & $\begin{array}{r}\text { No change } \\
(73)\end{array}$ & $73-77$ & $73-85$ \\
\hline & $\begin{array}{l}\text { Proportion of people who are } \\
\text { tested for HIV each year }\end{array}$ & $\mathrm{N} / \mathrm{A}$ & $10-50$ & $\begin{array}{l}\text { Same as national } \\
\text { strategy scenario }\end{array}$ \\
\hline \multirow{3}{*}{ PWID (\%) } & $\begin{array}{l}\text { Proportion of people who are } \\
\text { tested for HIV each year }\end{array}$ & $\mathrm{N} / \mathrm{A}$ & $43-60$ & $\begin{array}{l}\text { Same as national } \\
\text { strategy scenario }\end{array}$ \\
\hline & $\begin{array}{l}\text { Proportion of injections using } \\
\text { receptively shared needle } \\
\text { syringes }\end{array}$ & 5 & $5-3$ & $\begin{array}{l}\text { Same as national } \\
\text { strategy scenario }\end{array}$ \\
\hline & Number of people on OST & 2,890 & $2,890-4,000$ & $\begin{array}{l}\text { Same as national } \\
\text { strategy scenario }\end{array}$ \\
\hline $\begin{array}{l}\text { Female 15-49 } \\
\text { years }\end{array}$ & Proportion on PMTCT (\%) & 86 & $86-90$ & $\begin{array}{l}\text { Same as national } \\
\text { strategy scenario }\end{array}$ \\
\hline \multicolumn{2}{|c|}{ Proportion of PLHIV on ART (\%) } & $40-81$ & $40-68$ & $\begin{array}{l}\text { Same as national } \\
\text { strategy scenario }\end{array}$ \\
\hline \multicolumn{2}{|c|}{ Proportion of people aware of their status (\%) } & $60-90$ & $\mathrm{~N} / \mathrm{A}$ & $\mathrm{N} / \mathrm{A}$ \\
\hline
\end{tabular}

Note: ${ }^{*}=$ Baseline data in each scenario are from different years when the latest data were available.

The model-predicted evolution of annual HIV prevalence, incidence, and deaths (2000-30) under these conditions are shown in Figures 5.1, 5.2, and 5.3. Figure 5.4 shows the expected prevalence among MSMW for the same period, for each scenario. ${ }^{24}$

24 Whether the curve covering the historical period until 2014 in all scenarios is a calibration output should be considered. 
Figure 5.1 Model-predicted evolution of annual HIV prevalence under different scenarios, 2000-30

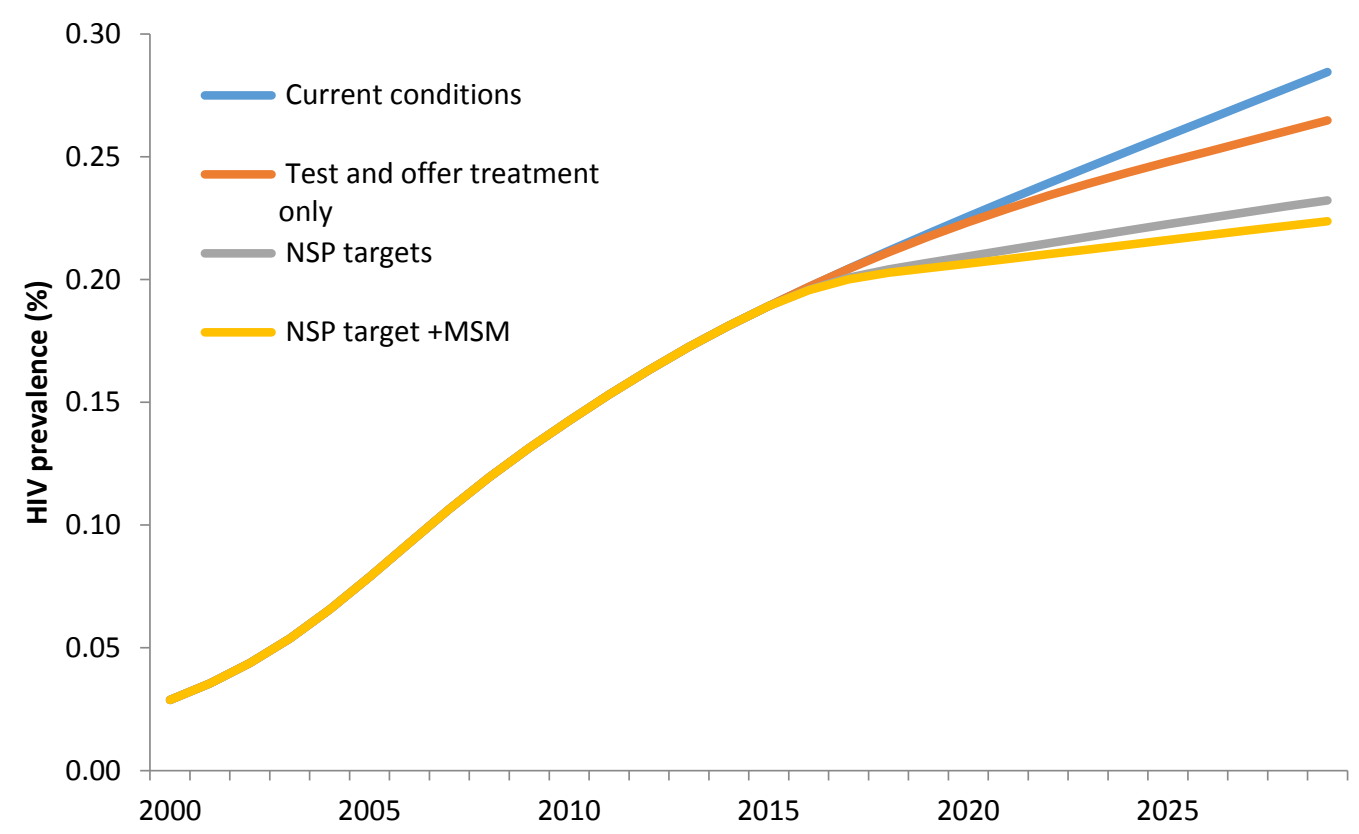

Figure 5.2 Model-predicted evolution of annual HIV incidence under different scenarios, 2000-30

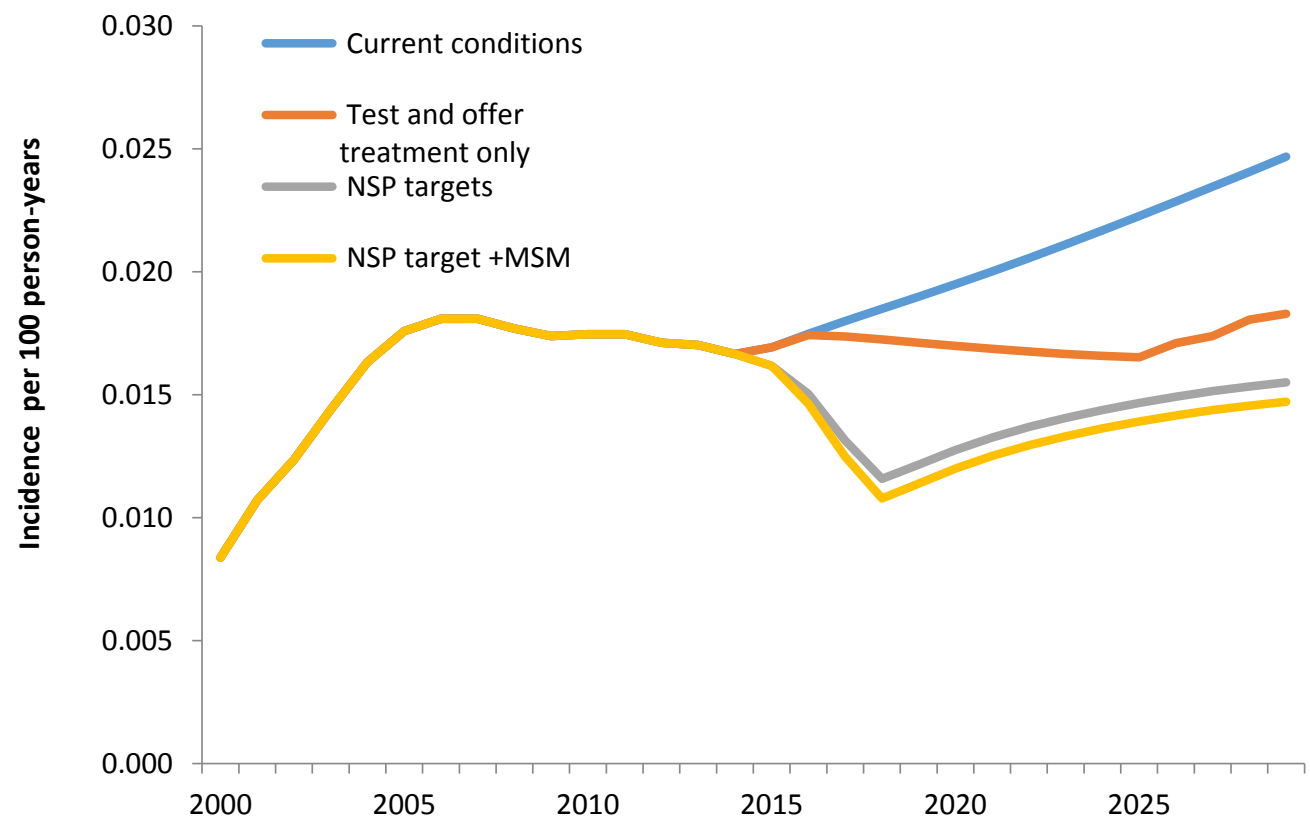

With the 2014 levels and allocations of funding maintained,,25 prevalence, incidence, and the number of deaths are expected to increase. As described earlier, these increases are driven primarily by the rising incidence among MSMW. 
Figure 5.3 Model-predicted evolution of annual HIV-related deaths under different scenarios, 2000-30

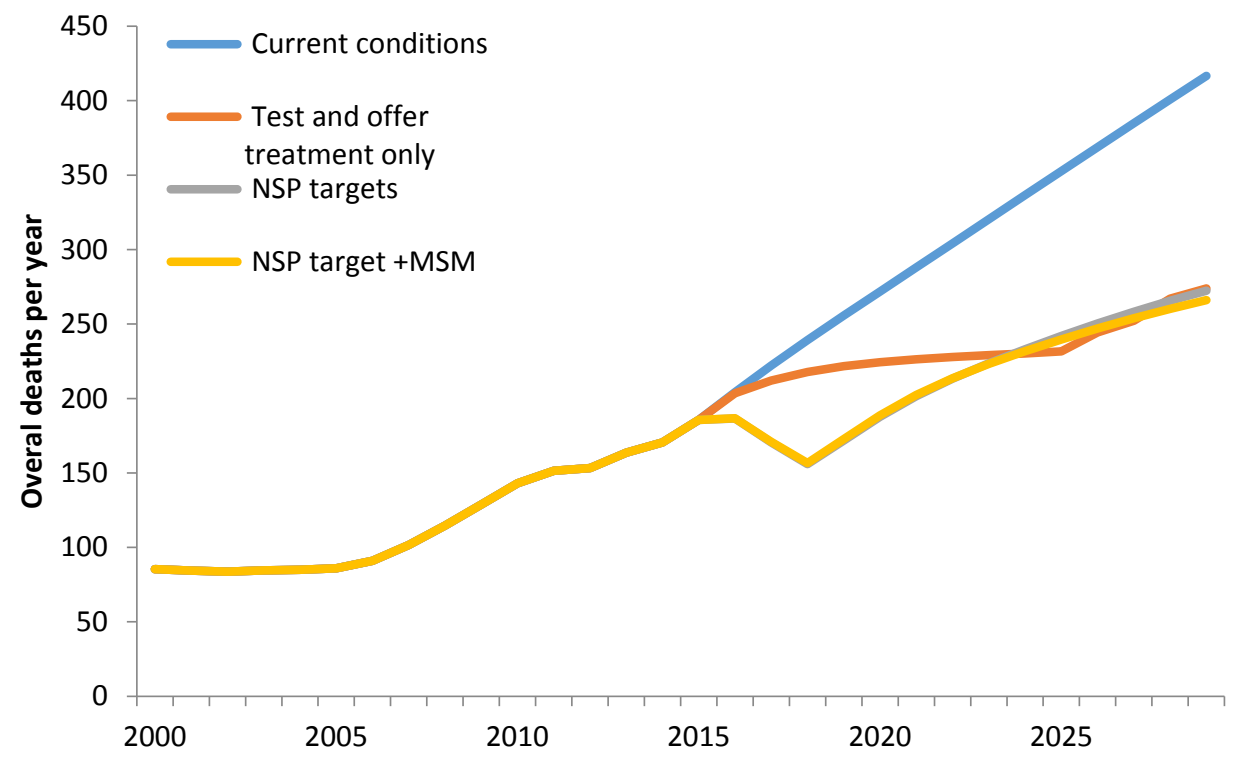

Figure 5.4 Model-predicted prevalence for MSMW under different scenarios, 2000-30

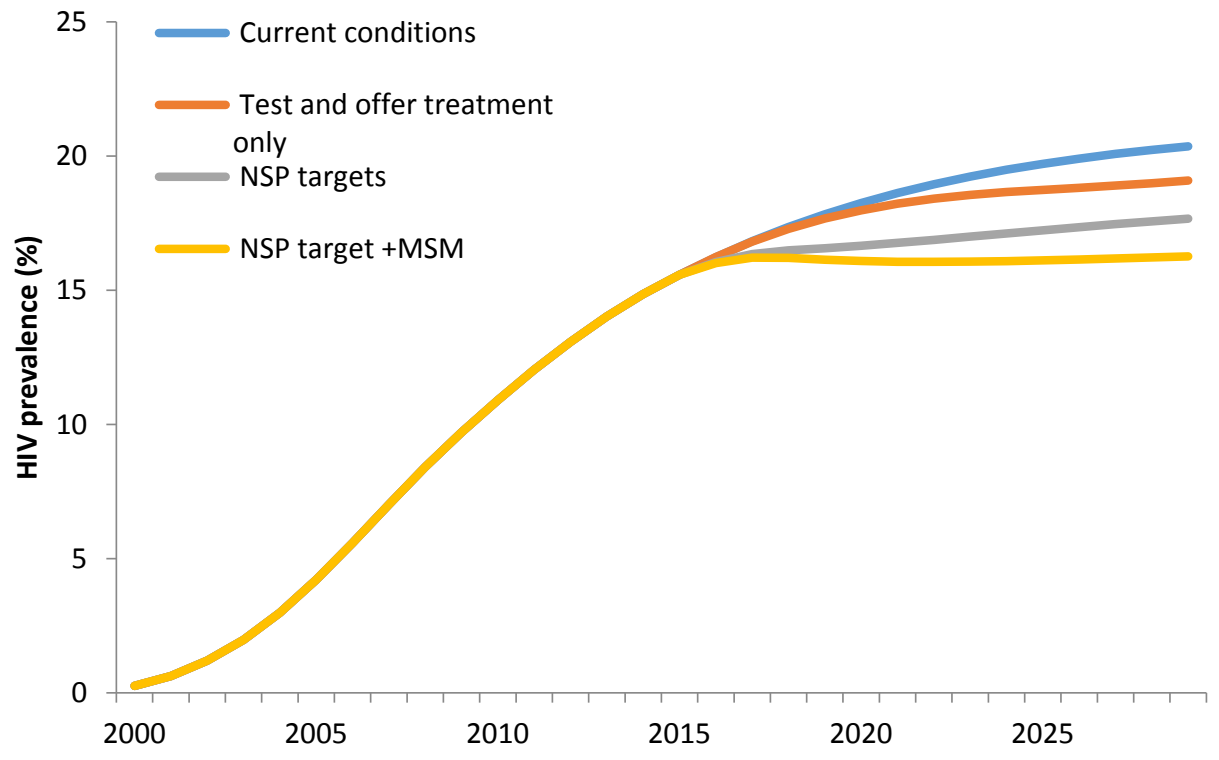

Source: Populated Optima model for Georgia.

The scenario analyses demonstrate that allocating spending to a combination of National HIV Strategic Plan targets and improving condom use among MSMW (Option 3 above) are more effective in reducing overall HIV incidence than the alternative options and are projected to reduce incidence by an estimated 40 percent by 2030. Option 3 is also the most effective in containing prevalence among MSMW (Figure 5.4). Moreover, in reducing the number of deaths over time, each of the three alternative scenarios (Options 1-3) is significantly more effective than the current HIV response spending allocation.

This scenario analysis explores different levels of achievement of program outcomes. In this section, the team analyzes the epidemic impact if specific outcome levels or targets are achieved, regardless of cost and coverage considerations. This approach differs from the optimization analysis in the next section, which is based on the cost-coverage outcome curves (CCOCs). In the optimization analysis presented next, the analysts consider the effects of 
different levels of spending on programs, which then translate into coverage and outcomes according to the CCOCs. Although the CCOCs are informed by projected National HIV Strategic Plan costs and targets, they also consider other information such as past spending, coverage, and outcomes. 
The rest of this page is intentionally left blank. 


\section{WHAT CAN BE IMPROVED BY OPTIMIZING EFFICIENCIES UNDER CURRENT FUNDING?}

An optimization analysis was conducted comparing the allocation of the current budget in 2014 of $\$ 14,757,959$ and an optimized allocation of the same budget for 2015-30.

Overall, prevalence among the low-risk general population in Georgia is still very low. However, the Georgian epidemic clearly is categorized as a concentrated epidemic. Current (2014) HIV spending in Georgia is distributed across a wide range of HIV programs. According to model-based analyses, using 2014 as the baseline year, the current distribution of funding is different from an optimized allocation that minimizes both new infections and deaths (Figure 6.1, Figure 6.2, and Table 6.1). Optimization of the 2014 budget to reduce HIV incidence and deaths averts an estimated 2,969 (15.5 percent) additional HIV infections (mainly among MSMW) and 2,238 (36 percent) additional deaths from 2015 to 2030. To achieve these gains, the following key changes are proposed:

- $\quad$ ART provision should be increased.

- This shift in spending reflects the relatively high effectiveness of ARVs as both treatment and prevention, since PLHIV on treatment have significantly reduced infectiousness. This intervention will reduce incidence and prevalence across all key population groups. Where funding is diverted from programs that target these key groups, some of the optimized budget is "reincorporated" here.

- ART cannot be scaled up unless PLHIV are diagnosed.

- It is therefore necessary to ensure that adequate funding remains allocated to testing, especially among key population groups.

- Spending on low-risk populations (such as HTC) could be more effectively diverted to comprehensive HIV programs.

- In Georgia, low-risk populations are large, and their individual risk of contracting HIV is low. It therefore is more efficient in contexts such as this to target key affected populations who tend to be smaller, more concentrated, and with higher individual risk of infection. Such a focused approach would not, and should not, stop the provision of testing and treatment for low-risk individuals seeking care. Figure suggests that the new allocation to HTC would be less than 0.1 percent of the total budget, while the allocation to treatment would increase overall.

- Investments in MSMW programs should be maintained.

- This population group has the highest prevalence, and individuals from key affected populations may infect partners in the low-risk population. Targeting key populations, therefore, has benefits for both high- and low-risk populations but constitutes a more efficient financial investment, as explained above. Since the epidemic in the low-risk, general population is too small to be self-sustaining without the increased risk from 
"bridging" individuals in key, higher risk populations, the most effective strategy is likely to be the targeting of infections among key populations such as MSMW.

- Investments in and coverage of NSP interventions could be largely maintained, but the proportion of total spending reduced, from current levels.

- Maintaining, but not substantially increasing investment into NSP is in line with current low rates of needle-sharing rates in Georgia, and the stabilizing epidemic among PWID. The favorable status is attributable to the strong historical focus on this key population.

- Recommendations for OST spending should be interpreted with caution.

- OST is defined by UNAIDS and the WHO as one of the essential service components for PWID HIV harm reduction programs. The Optima model considers only benefits to HIV patients. Consequently, service components such as OST that have significant wider benefits to the PWID population and to national public health may be undervalued (chapter 2). Therefore, any recommendations for the reduction of spending on OST programs should be interpreted with caution.

The model thus suggests that, when compared to the current budget allocation, allocating current funding differently could further reduce the spread of the epidemic. However, with a larger budget envelope, it may be possible to avert additional new infections and deaths. The potential gains to increased investment in HIV programming are elaborated in the following section.

Figure 6.1 Comparison of current and optimized budget allocation to minimize both new infections and deaths for 2015-30 (\%)
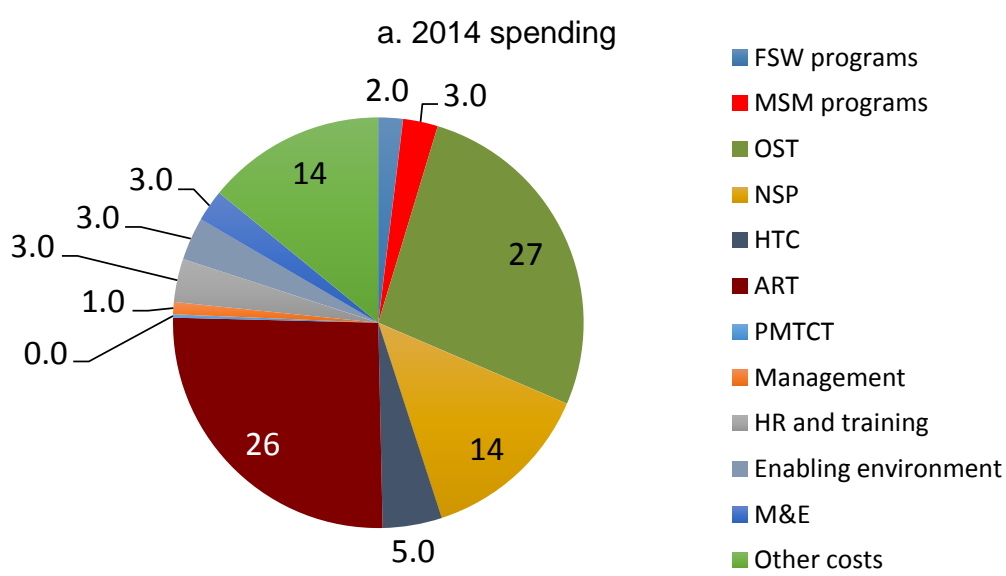

b. 2014 budget, optimized allocation

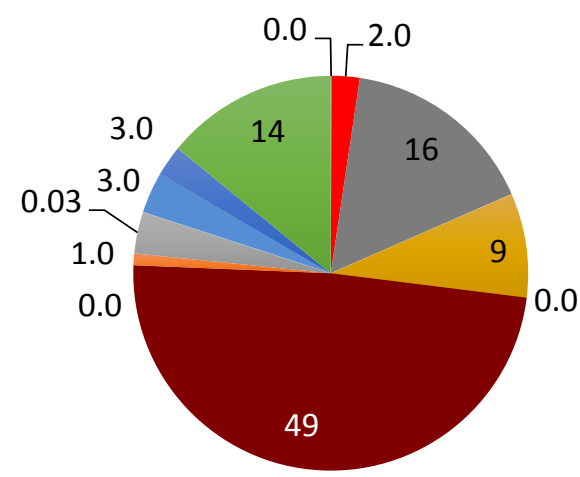

$$
\begin{aligned}
& \text { FSW programs } \\
& \text { MSM programs } \\
& \text {-OST } \\
& \text { NSP } \\
& \text {-HTC } \\
& \text {-ART } \\
& \text {-PMTCT } \\
& \text { Management }
\end{aligned}
$$

Source: Populated Optima model for Georgia. 
Table 6.1 Current and optimized 2014 budget allocations

\begin{tabular}{|c|c|c|c|c|}
\hline & $\begin{array}{r}\text { Current } \\
\text { allocation (US\$) }\end{array}$ & (\%) & $\begin{array}{r}\text { Optimized } \\
\text { allocation } \\
\text { (US\$) }\end{array}$ & (\%) \\
\hline FSW programs & 285,772 & 1.9 & 9,049 & $0.1 \mathrm{a}$ \\
\hline MSM programs & 403,818 & 2.7 & 339,213 & 2.3 \\
\hline OST & $3,948,587$ & 26.8 & $2,369,152$ & 16.1 \\
\hline NSP & $1,996,964$ & 13.5 & $1,260,096$ & 8.5 \\
\hline HTC & 688,716 & 4.7 & 1,021 & $0.0 \mathrm{~b}$ \\
\hline ART & $3,793,600$ & 25.7 & $7,176,744$ & 48.7 \\
\hline РМТСТ & 39,484 & 0.3 & 1,667 & $0.01 \mathrm{c}$ \\
\hline MGMT & 141,034 & 1.0 & 141,034 & 1.0 \\
\hline HR & 502,262 & 3.4 & 502,262 & 3.4 \\
\hline ENV & 499,401 & 3.4 & 499,401 & 3.4 \\
\hline$M \& E$ & 368,748 & 2.5 & 368,748 & 2.5 \\
\hline Other & $2,078,226$ & 14.1 & $2,078,226$ & 14.1 \\
\hline Total & $14,746,612$ & 100.0 & $14,746,612$ & 100.0 \\
\hline
\end{tabular}

Source: Populated Optima model for Georgia.

Note: $\mathrm{a}=$ As explained in the narrative, these programs remain important from an epidemiological point of view and should continue to be provided, by either increasing overall funding for the HIV response or reducing unit costs; $b=$ HIV testing and counselling would continue to be provided as part of programs for key populations. Other persons requesting to be tested for HIV also should continue to receive the service, even if they are not part of key populations. The model suggests that, from a cost-effectiveness perspective when no additional resources are available, expanded testing for the general population is not among the most costeffective programs; c = Pregnant women should continue to be covered with ART as part of the increased ART budget. In practice, covering their ART also would require continued HIV testing and counselling for pregnant women, which also could be financed from maternal health budgets. 
The rest of this page is intentionally left blank. 


\section{WHAT MIGHT BE GAINED OR LOST FROM CHANGES IN HIV SPENDING AND ALLOCATION?}

This analysis considers what could be gained by increasing the HIV budget from 2014 levels. Conversely, the analysis also considers which programs would have the largest impact on the epidemic if less funding were available and the response needed to be further rationalized. Optimized allocations to programs and the corresponding impacts are compared in this analysis for different funding levels.

Given a contraction of funding below the 2014 funding level, optimization suggests that ART, OST, and NSP should be given first priority, followed by programs that target MSMW. This finding is the result of a combination of factors. ART is essential to minimize deaths and contributes to reduce incidence. For prevention, sustaining low rates of needle-sharing and increasing condom use among MSMW are epidemiologically important factors given the key role of these two populations in transmission. The results also are partially due to the fact that the model construct protects funding for OST services. The protection is based on the rationale that nobody on OST should go off OST. OST has substantial benefits outside of HIV as explained in the remarks on the model in section 2. Therefore, 60 percent of OST cost was protected from reductions. Looking exclusively at HIV outcomes, this explicit rationing may not be desirable since easily preventable HIV infections will occur within such a tight funding context. Since OST funding is protected, efforts should be made to ensure that high unit costs are contained and reduced as far as possible without compromising the quality of care.

With budgets 100 percent-200 percent of 2014 program spending, optimization suggests that investment should continue to be focused on ART and programs for key high-risk populations including MSMW and PWID. Spending on key populations with lower incidence (such as FSWs) and programs for the low-risk general population (such as HTC) are recommended only for higher multiples of the current budget, that is, when optimized spending is approximately 200 percent of the 2014 program budget. These two spending options are compared in Figure 7.2

This analysis clearly shows that both increased and optimally allocated spending on HIV programs will continue to yield incremental gains in averting new infections and deaths (Figure 7.1).

Figures 18-20 present increases in spending for the program budgets to 120 percent, 150 percent, and 200 percent, respectively, but not increases in the total HIV response budgets. It was assumed that the indirect cost for management and enablers will be stable so these costs were fixed as US\$ amounts. 
Figure 7.1 Optimized allocations to minimize HIV incidence and deaths by 2030 at different budget levels (2014 budget)*

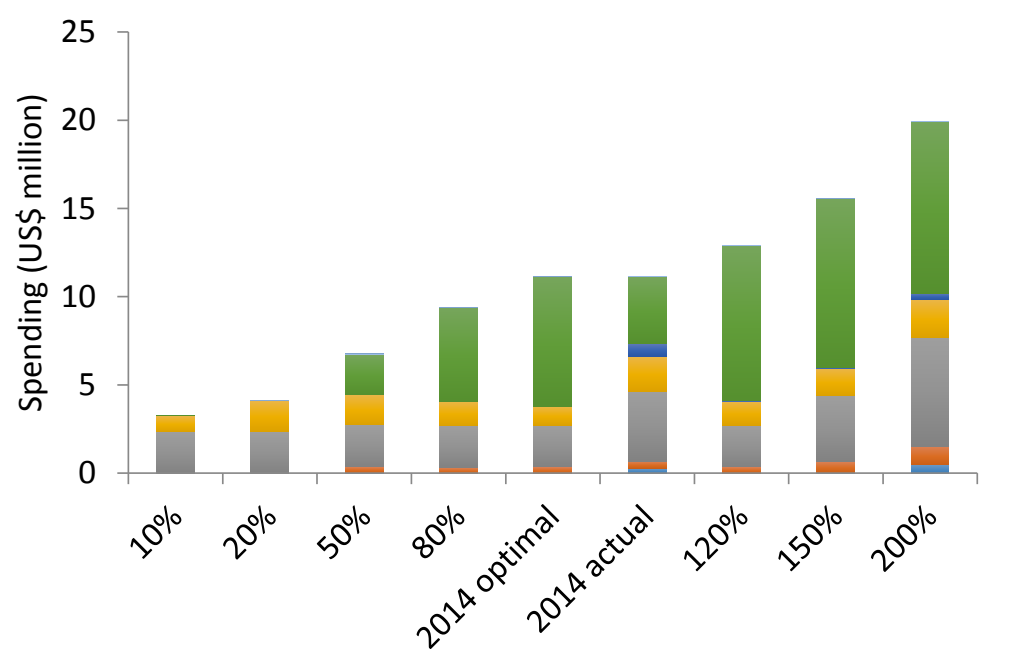

PMTCT

ART

HTC

NSP

OST

MSM programs

FSW programs

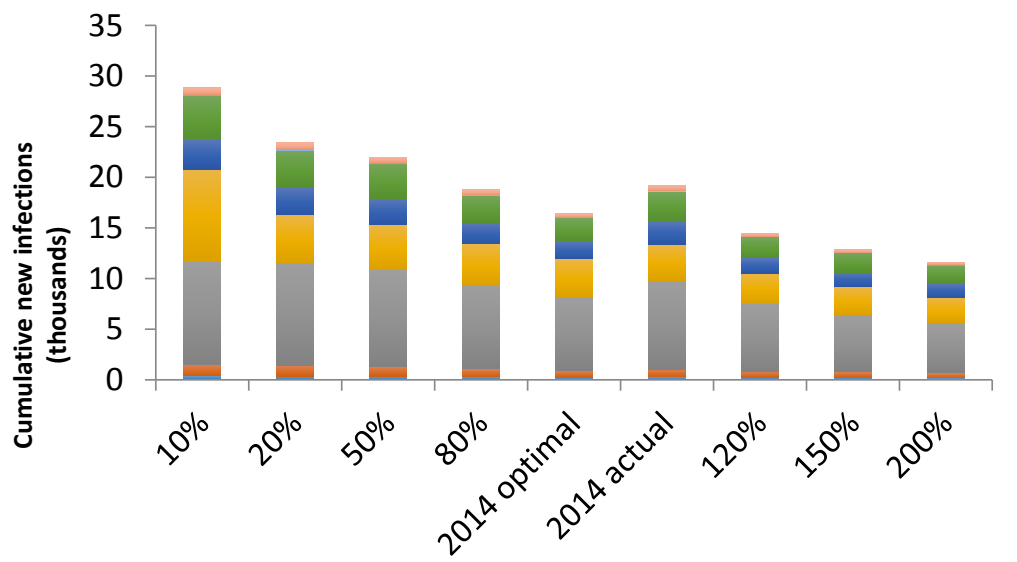

Females [50+]

Males [50+]

- Females 15-49

nales 15-49

PWID

MSMW

Clients

FSW

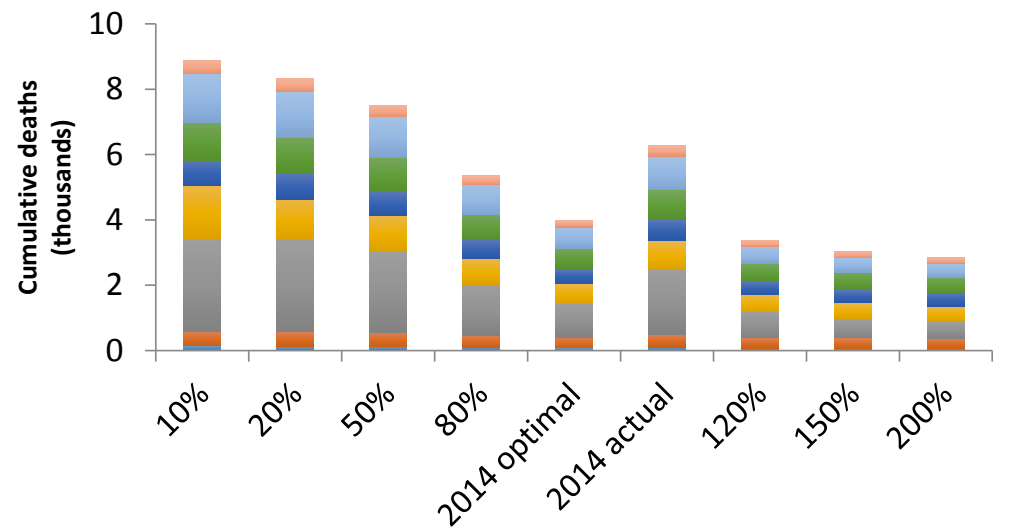

Females [50+]

Males [50+]

Females 15-49

Males 15-49

PWID

MSMW

Clients

FSW

Source: Populated Optima model for Georgia.

Note: ${ }^{*}=$ Only optimized costs are scaled. Nonoptimized spending remains at current levels 
Figure 7.2 Comparing the allocation of 2014 spending against an optimized allocation of 150 percent of current spending

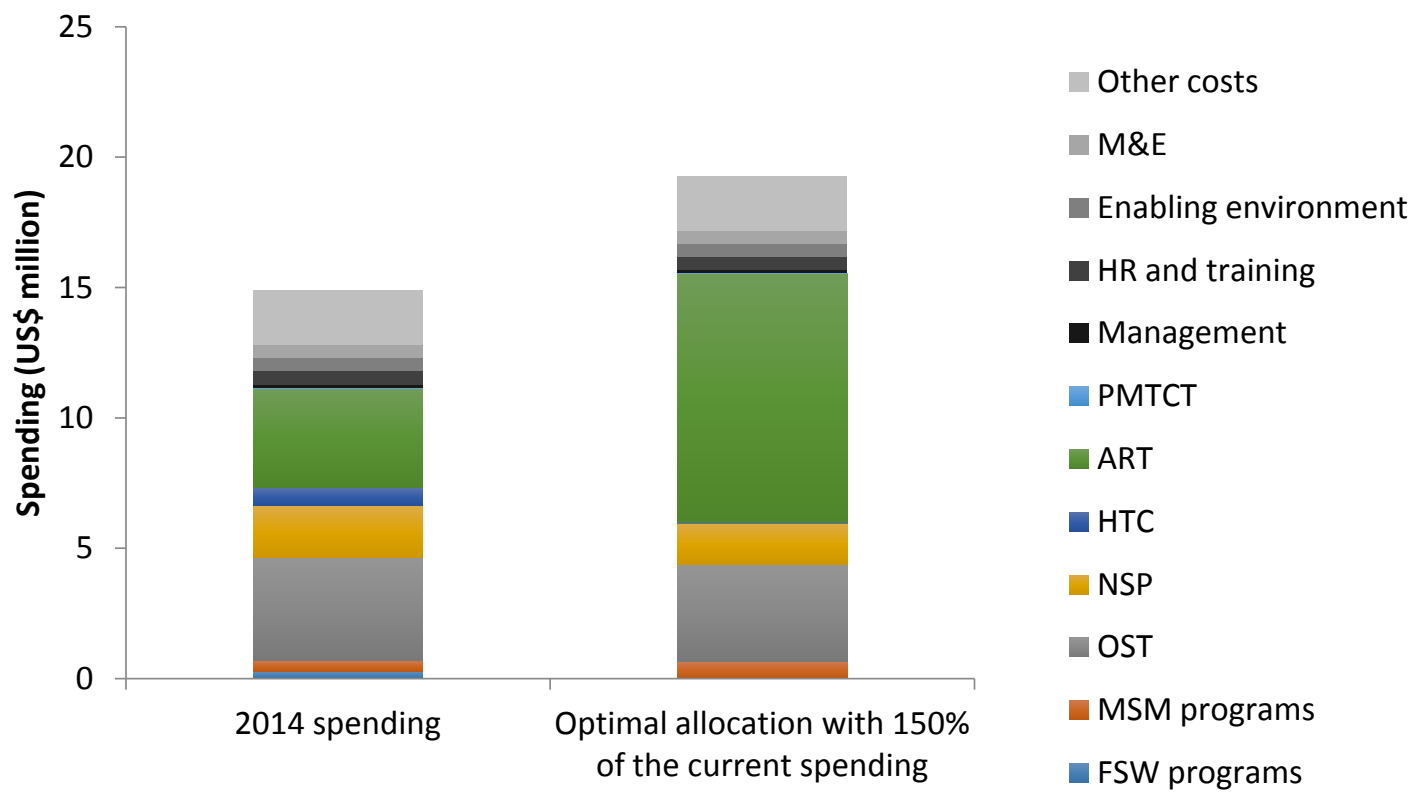

Source: Populated Optima model for Georgia.

Figure 7.2 compares the current 2014 budget allocation against an optimized allocation of 150 percent ( $\$ 19.1$ million) of the 2014 spending on direct programs, and assumes that the indirect program cost for enablers and management cost would remain stable. The larger budget envelope would increase impact by reducing both deaths and new infections (Figure 7.3). This increased coverage would require additional resources and/or technical efficiency gains achieved by reducing the unit costs of programs (without compromising expected outcomes).

Figure 7.3 Comparing the impact on prevalence, deaths, and new infections of 2014 spending against an optimized allocation of 150 percent of the 2014 budget

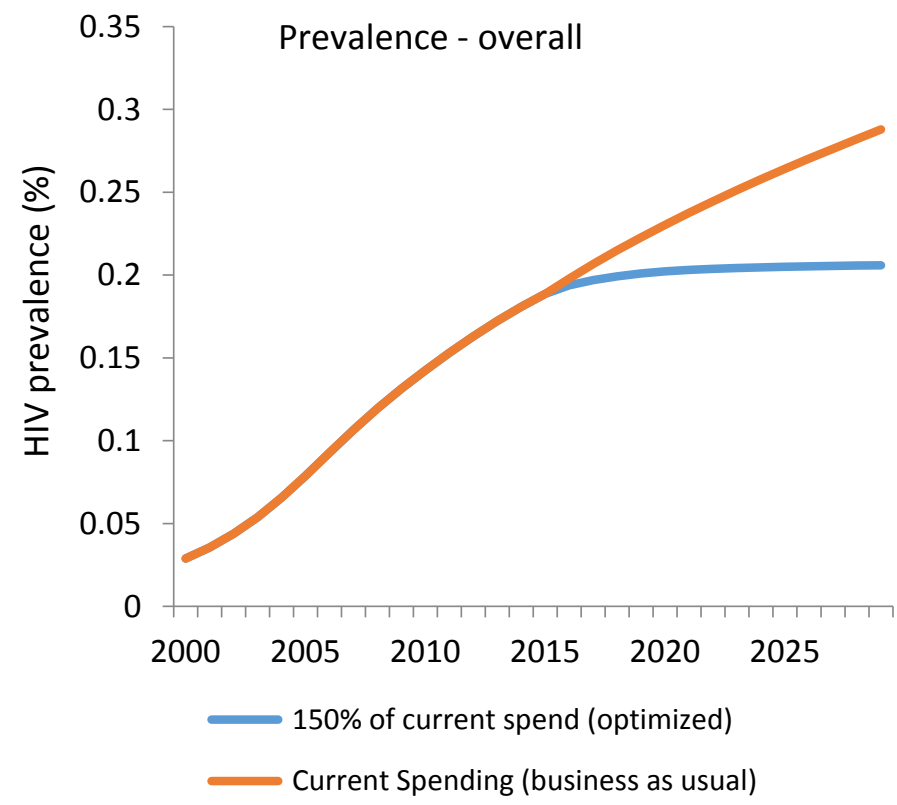



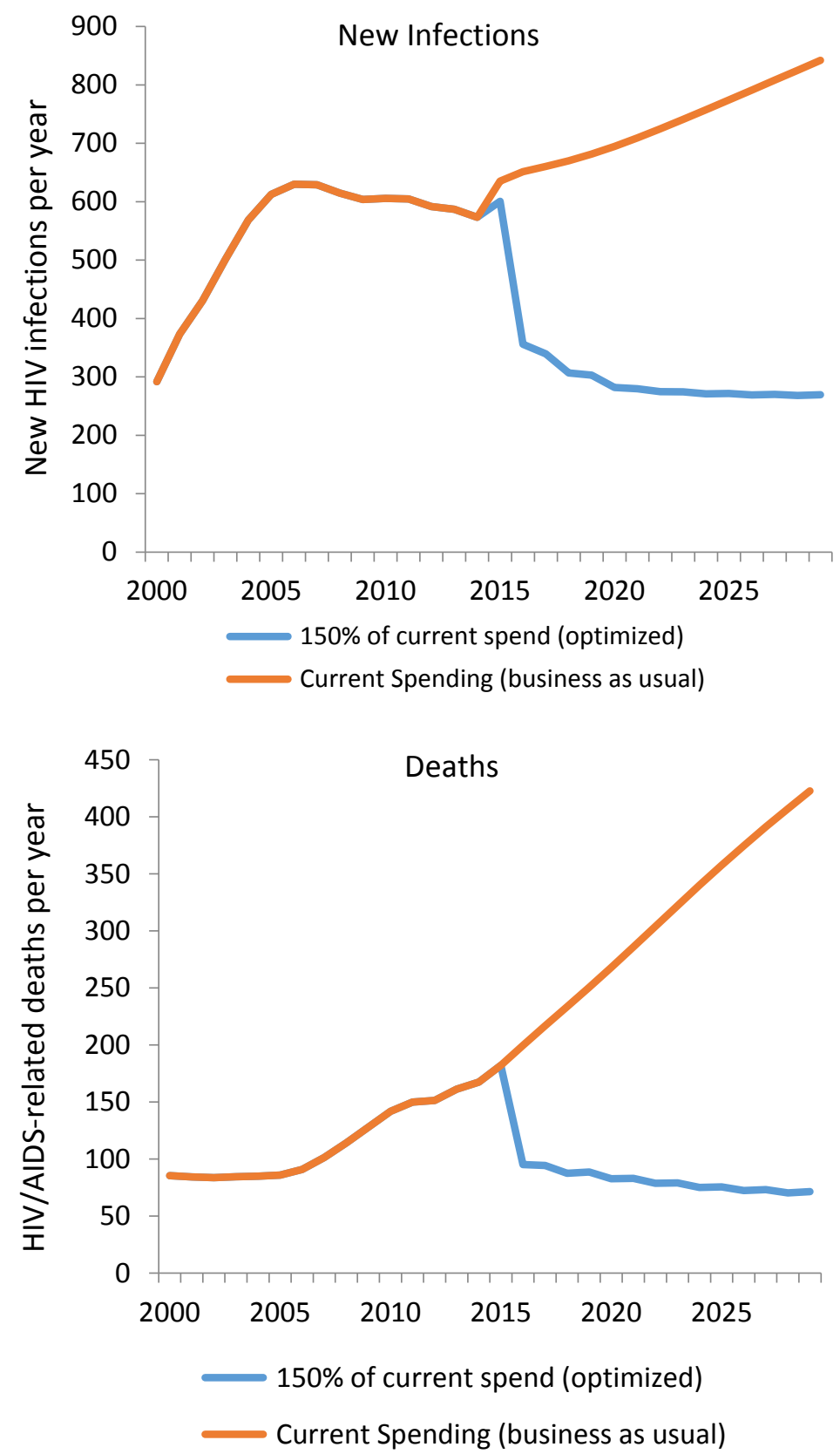

Source: Populated Optima model for Georgia.

The rest of this page is intentionally left blank. 


\section{HOW MUCH WILL IT COST TO ACHIEVE THE TARGETS OF THE NATIONAL HIV STRATEGIC PLAN?}

This analysis identifies the minimum resource requirements to achieve the national HIV strategy targets and long-term program commitments (chapter 2). The analyses in chapter 6 assume fixed amounts of available funding and explored an optimized allocation of those funds to minimize new infections and deaths with the current budget. In chapter 7 , the analyses explore the likely gains from increased investment in the HIV response.

In contrast, the analysis in chapter 8 aims at the full achievement of the 2018 National HIV Strategic Plan targets and determines the minimum budget required to achieve these goals under an optimized allocation. The impact targets used in this analysis are to contain or reduce the current incidence value ( $<600$ per year), to reduce the number of deaths to fewer than 2 per 100,000 by 2020 , and to ensure that at least 75 percent of diagnosed PLHIV are receiving ART by 2020 (outcome target). This analysis assesses the gap in funding required to achieve these targets.

\section{Figure 8.1 Minimum annual spending required to meet National HIV Strategic Plan targets (2014 level)}

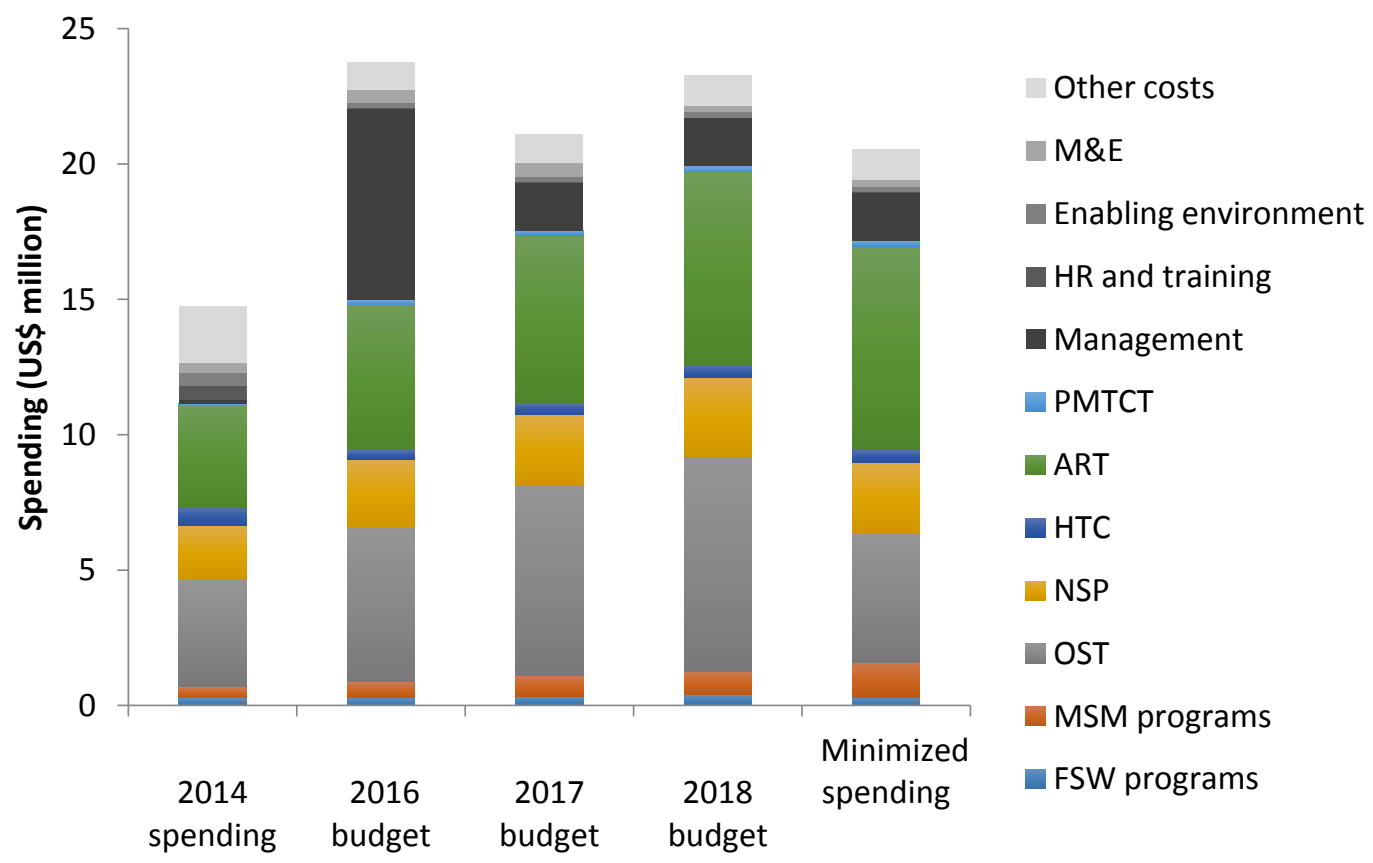

Source: Populated Optima model for Georgia.

Figure 8.1 shows 2014 spending, the 2016-18 National HIV Strategic Plan budget, and the minimum spending required to achieve the National HIV Strategic Plan impact targets. The model results in this section suggest that the National HIV Strategic Plan's impact could be 
achieved with approximately 12 percent less funding than the proposed 2018 National HIV Strategic Plan budget. To achieve the National HIV Strategic Plan targets, the model findings recommend spending an extra 50 percent on MSM programs, 10 percent on HTC and 5 percent on ART, shifting the funding by 25 percent from FSW, 40 percent from OST, and 10 percent from NSP. The cost savings with respect to the 2018 National HIV Strategic Plan are attributed primarily to OST, an area with relatively high unit cost in which higher coverage could be obtained within existing budgets. Additional technical efficiency analysis would be required to determine whether and how such technical efficiency gains could be achieved. 


\section{WHAT IS THE LONG-TERM FINANCIAL COMMITMENT TO HIV SERVICES FOR PLHIV?}

This analysis reviews the impact of current and optimized investment choices 26 on [preexisting?] long-term financial commitments. These commitments are liabilities arising from the need to provide HIV and related health services to PLHIV in the future. In monetary terms, a financial commitment is the discounted cost of providing HIV services to PLHIV in a particular year. The commitment includes HIV treatment cost, HIV-related health care cost, and social mitigation cost.

\section{Figure 9.1 Annual HIV-related spending for all HIV infections, 2010-30}

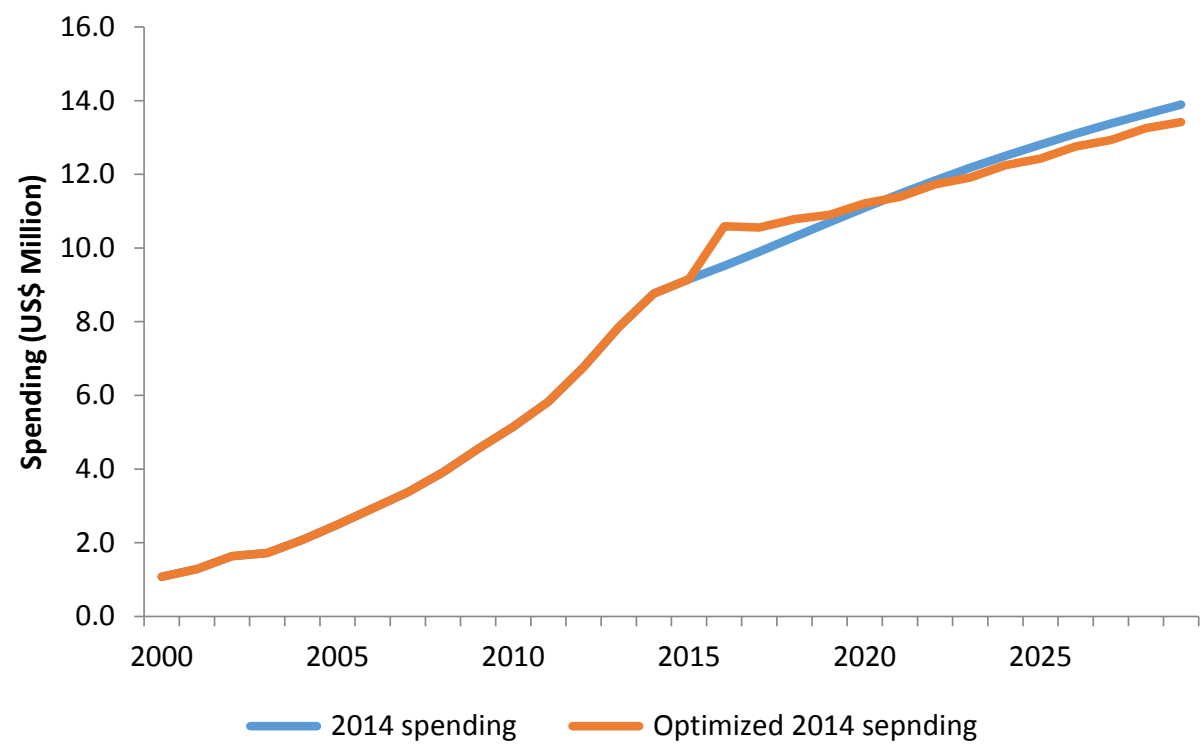

Source: Populated Optima model for Georgia.

Figure 9.1 describes the annual costs for HIV treatment and HIV-related care, which are derived from the number of PLHIV up to 2030.Figure 9.1 compares the current allocation of the 2014 budget to the optimized allocation described in chapter 6 . The model predicts that the costs of the national response will rise under both allocations, driven by the increases in the total number of PLHIV. The analysis estimates that optimizing current allocations could save an average of approximately $\$ 220,000$ annually compared to the current, nonoptimized allocations (Figure 9.1). This savings suggests that, although the optimized allocation will keep more PLHIV alive, the total long-term cost for the response is lower ( $\$ 234.9$ million compared to $\$ 234.7$ million) due to reduced new infections and reduced HIV-related health care through

\footnotetext{
${ }^{26}$ Assuming that the annual budget of $\$ 14.8$ million will be maintained.
} 
reduced opportunistic infections. The results also show that, under the optimized allocation of current spending (approximately $\$ 117$ million), financial commitments caused by new infections will be $\$ 20.7$ million, or 15 percent lower than under the current allocation (approximately $\$ 138$ million) (Figure 9.2).

Figure 9.2 Annual HIV-related spending for all new HIV infections. 2010-30

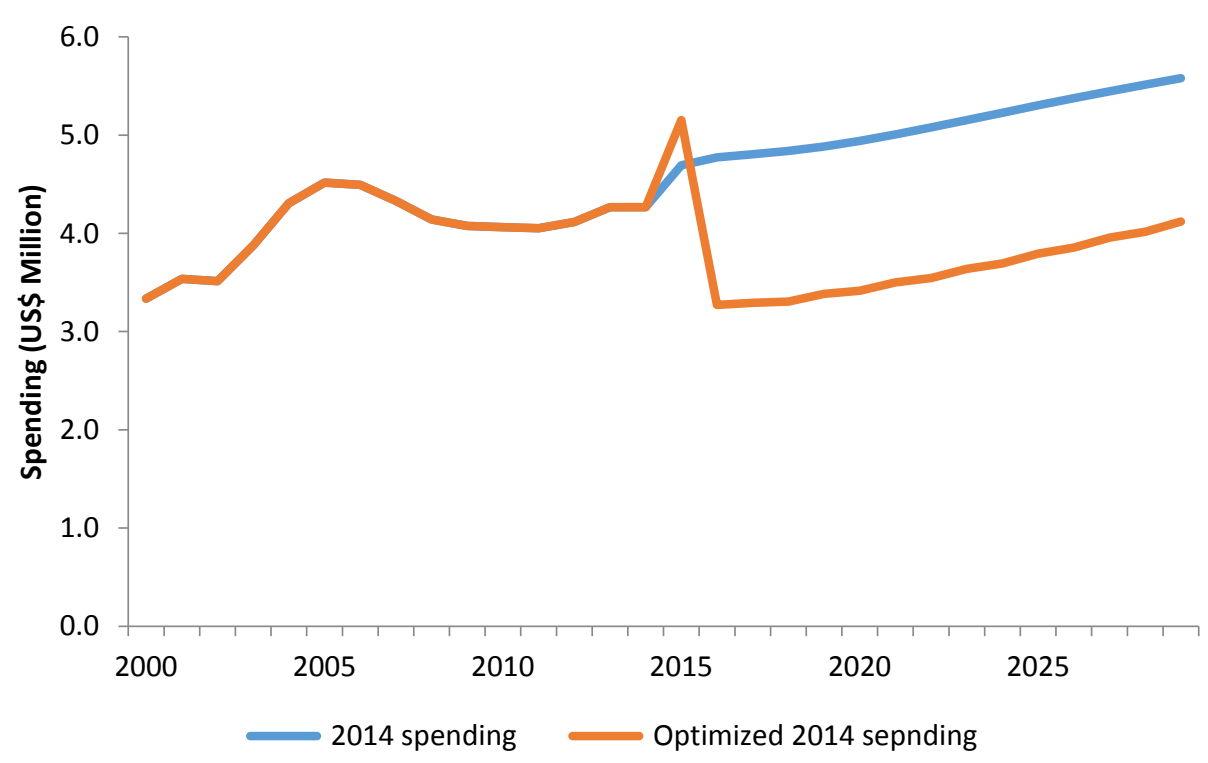

Source: Populated Optima model for Georgia. 


\section{CONCLUSIONS AND RECOMMENDATIONS}

The Georgian government may be able to better allocate current HIV spending to further minimize HIV incidence, prevalence, and HIV-related deaths.

To assess HIV epidemic trends, the analysts used Optima's epidemic module calibrated to HIV prevalence data points available for different subpopulations in Georgia, including key affected populations. The model also was calibrated to data points on the number of people on ART from available data sources and in consultation with Georgian experts. Analyses using this model highlighted a strong risk that, despite efforts to contain the epidemic, prevalence and incidence will continue to increase overall in Georgia.

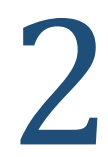

The expected overall increase in the epidemic appears to be driven by increasing incidence and prevalence among MSMW, a key population who currently receive only a small portion of the HIV prevention funding. High-risk behaviors in this group, including low condom use, call for significant strengthening of interventions targeting this key population. Increasing the use of condoms with commercial partners is likely to be an effective preventive measure. Additional programs such as pre-exposure prophylaxis (PrEP) also could be considered.

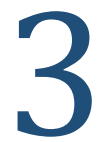

The funding allocations that will be the most effective in containing the epidemic overall are those that prioritize the National HIV Strategic Plan targets, ${ }^{27}$ improve condom use among MSMW, and scale up ART to all populations in need. An optimized allocation of current funding may reduce long-term financial commitments to the HIV response by containing incidence and prevalence.

\footnotetext{
4 Presentation for testing and treatment is delayed, thus increasing costs and reducing positive treatment outcomes. These delays are likely to be caused by multiple factors. The high rate of out-of-pocket (private) spending on healthcare may deter timely and effective care-seeking. Stigma and discrimination may be additional significant deterrents in the Georgian context. These deterrents to effective care-seeking may add the risk of weak adherence to treatment. Risk factors such as these are best addressed with a rights-based approach to care.
}

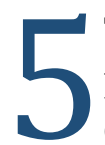

These analyses suggest that diverting funding away from testing in the general population and to prevention among MSMW would improve the efficiency of current spending levels. The team's estimations and contextual data suggest that the HIV epidemic among PWID is relatively well contained in Georgia due to significant and prolonged efforts to target this population. However, even modest reductions in NSP allocations increase new infections among PWID. In analyses with limited total HIV response budgets, the need to scale up and invest more in ART and MSMW programs implied the need to

27 This report references the Final Draft NSP targets available in March 2015. (Government of Georgia, 2015). 
moderately reduce funding for PWID programs. However, due to the risk of rising infections among PWID in such a case, it is essential that coverage levels of NSP and OST are sustained and expanded. Therefore, as much as possible, key MSMW and PWID populations both should be targeted with strong preventive efforts, complemented by comprehensive test-and-offertreatment programs.

Comparing the unit costs of care in Georgia with data from other countries in the Region also suggests that greater efficiency in spending could be achieved through strategies to reduce the average spending per person reached. This is particularly true for OST programs. Care should be taken, however, that these strategies do not compromise the current quality of prevention or treatment. Additional analyses of technical efficiency are necessary before more robust conclusions can be reached.

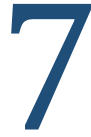

Current annual spending will not be enough to achieve National HIV Strategic Plan and international targets. As a result, additional domestic resources will need to be allocated to HIV spending to fill resource gaps in the overall HIV budget envelope. Although domestic funding for HIV in Georgia has increased since 2006, much of this increase has been financed through out-of-pocket (private) expenditure. Reliance on private, out-ofpocket spending may delay care-seeking, increase the risk of further infections, reduce the cost effectiveness of treatment and ultimately reduce the technical efficiency of HIV spending. Therefore, when establishing short- or medium-term transitional funding mechanisms to supplement and redirect domestic funding sources, emphasis should be placed on increasing state participation in healthcare financing.

8

By describing the likely trajectories of the HIV epidemic under different conditions, highlighting areas of particular risk in the short- to medium-term, and suggesting ways to incrementally improve the efficiency of current spending, these suggestions should assist Georgia in its current HIV response. Modeling the epidemic in the absence of HIV program spending highlighted the significant gains already achieved from current spending in new infections and deaths averted. However, analyses of what is needed to achieve the targets set by the National HIV Strategic Plan have identified a need for continued and even increased investment in an optimized HIV response in Georgia. 


\section{APPENDIXES}

\section{APPENDIX A. TECHNICAL SUMMARY OF OPTIMA}

Appendix A provides a brief technical overview of Optima. A more detailed summary of the model and methods is provided elsewhere (Kerr and others 2015). Optima is based on a dynamic, population-based HIV model. Figure A.1a summarizes the populations and mixing patterns used in Optima. Figure A.1b shows the disease progression implemented in the model. Optima tracks the entire population of people living with HIV (PLHIV) across 5 stages of CD4 count. These CD4 count stages are aligned with the progression of the World Health Organization (WHO) treatment guidelines, namely, acute HIV infection, $>500,350-500,200-$ $350,50-200$, and 50 cells per microliter. Key aspects of the antiretroviral therapy (ART) service delivery cascade are included: from infection to diagnosis, ART initiation on first-line therapy, treatment failure, subsequent lines of therapy, and HIV/AIDS-related or other death.

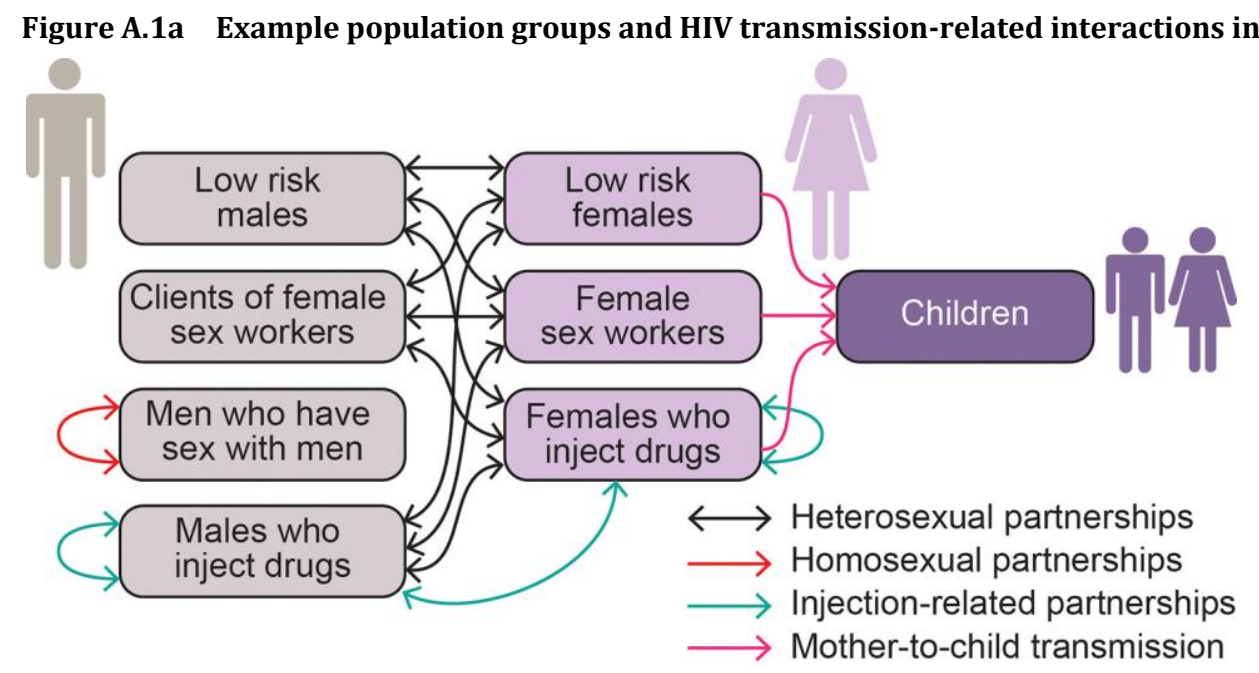

Source: Graphic prepared by UNSW study team.

The model uses a linked system of ordinary differential equations to track the movement of PLHIV among HIV health states. The full set of equations is provided in the supplementary material to a summary paper on the Optima model. The overall population is partitioned in two ways: by population group and by HIV health state. Individuals are assigned to a given population group based on their dominant risk. ${ }^{28}$ HIV infections occur through the interactions among different populations by regular, casual, or commercial (including transactional) sexual partnerships; through sharing of injecting equipment; or through mother-to-child transmission. The force-of-infection is the rate at which uninfected individuals become infected. The rate depends on the number and type of risk events to which individuals are exposed in a given period (either within their population groups or through interaction with other population groups) and the infection probability of each event. Mathematically, the force of- infection has the general form:

$$
\lambda=1-(1-\beta)^{\mathrm{n}},
$$

where $\lambda$ is the force-of-infection, $\beta$ is the transmission probability of each event, and $n$ is the effective number of at-risk events (that is, $\mathrm{n}$ gives the average number of interaction events with HIV-infected people through which HIV transmission may occur). The value of the

28 However, to capture important cross-modal types of transmission, relevant behavioral parameters can be set to non-zero values (for example, males who inject drugs may engage in commercial sex; some MSM may have female sexual partners). 
transmission probability $\beta$ varies across CD4 count compartments (indirectly reflecting the high viral load at early and late stages of infection); differs for different modes of transmission (intravenous drug injection with a contaminated needle-syringe, penile-vaginal or penile-anal intercourse, and mother-to-child); and may be reduced by behavioral interventions (for example, condom use), biological interventions (for example, male circumcision), or ART. There is one force-of-infection term for each type of interaction, for example, casual sexual relationships between male sex workers and female sex workers (FSW). The force-of-infection for a given population will be the sum of all interaction types. ${ }^{29}$ In addition to the force-ofinfection rate, which is the number of individuals who become infected with HIV per year, there are seven other ways by which individuals can change health states. ${ }^{30}$ The change in the number of people in each compartment is determined by the sum over the relevant rates described above multiplied by the population size of the compartments on which they act. ${ }^{31}$

29 For sexual transmission, the force-of-infection is determined by:

- HIV prevalence (weighted by viral load) in partner populations

- Average number of casual, regular, and commercial homosexual and heterosexual acts per person per year

- Proportion of these acts in which condoms are used

- Proportion of men who are circumcised

- Prevalence of sexually transmissible infections (which can increase HIV transmission probability)

- Proportion of acts that are covered by pre-exposure prophylaxis and post-exposure prophylaxis

- Proportion of partners on antiretroviral treatment (art)

- Efficacies of condoms, male circumcision, post-exposure prophylaxis, pre-exposure prophylaxis, and art at preventing HIV transmission.

For injecting-related transmission, the force-of-infection is determined by:

- HIV prevalence (weighted by viral load) in populations of people who use a syringe and then share it

- Number of injections per person per year

- Proportion of injections made with shared equipment

- Fraction of people who inject drugs on opioid substitution therapy and its efficacy in reducing injecting behavior.

For mother-to-child transmission, the number of-infections is determined by:

- Birth rate among women living with HIV

- Proportion of women with HIV who breastfeed

- Probability of perinatal HIV transmission in the absence of intervention

- Proportion of women receiving prevention of mother-to-child transmission (PMTCT), including ART.

30 First, individuals may die, either because of an average background death rate for that population (which is greater for older populations or for people who inject drugs) or because of HIV/AIDS (which depends on CD4 count). Second, in the absence of treatment, individuals progress from higher to lower CD4 counts. Third, individuals can move from undiagnosed to diagnosed states based on their HIV testing rate, which depends on CD4 count (for example, people with AIDS symptoms or primary HIV infection may have a higher testing rate) and population type (for example, FSW may test more frequently than males in the general population). Fourth, diagnosed individuals may commence ART at a rate depending on CD4 count. Fifth, individuals may experience treatment failure due to lack of adherence to therapy or development of drug resistance. Sixth, people may initiate second and subsequent lines of treatment after treatment failure. Finally, while on successful first- or second-line treatment (that is, effective viral suppressive therapy), individuals may progress from lower to higher CD4 counts.

31 For example, the change in the number of undiagnosed HIV-positive FSW with a CD4 count between 200-350 cells per microliter is:

$$
\frac{d U_{\mathrm{FSW}_{200-350}}}{d t}=U_{\mathrm{FSW}_{350-500}} \tau_{350-500}-U_{\mathrm{FSW}_{200-350}}\left(\mu_{200-350}+\tau_{200-350}+\eta_{\mathrm{FSW}_{350-500}}\right),
$$

where UFSW2002350 is the current number of undiagnosed HIV-positive FSW with a CD4 count between 200350 cells per microliter; UFSW3502500 is the same population but with higher CD4 count (350-500 cells/mL); $\mathrm{t}$ is the disease progression rate for the given CD4 count (where $1 / \mathrm{t}$ is the average time to lose $150 \mathrm{CD} 4 \mathrm{cells} / \mathrm{mL}$ ); $\mathrm{m}$ is the death rate; and $\mathrm{h}$ is the HIV testing rate. (Note: This example does not consider movement among populations, such as FSW returning to the general female population and vice versa-something which is included in Optima.) 
Figure A.1b Schematic diagram of the health state structure of the model

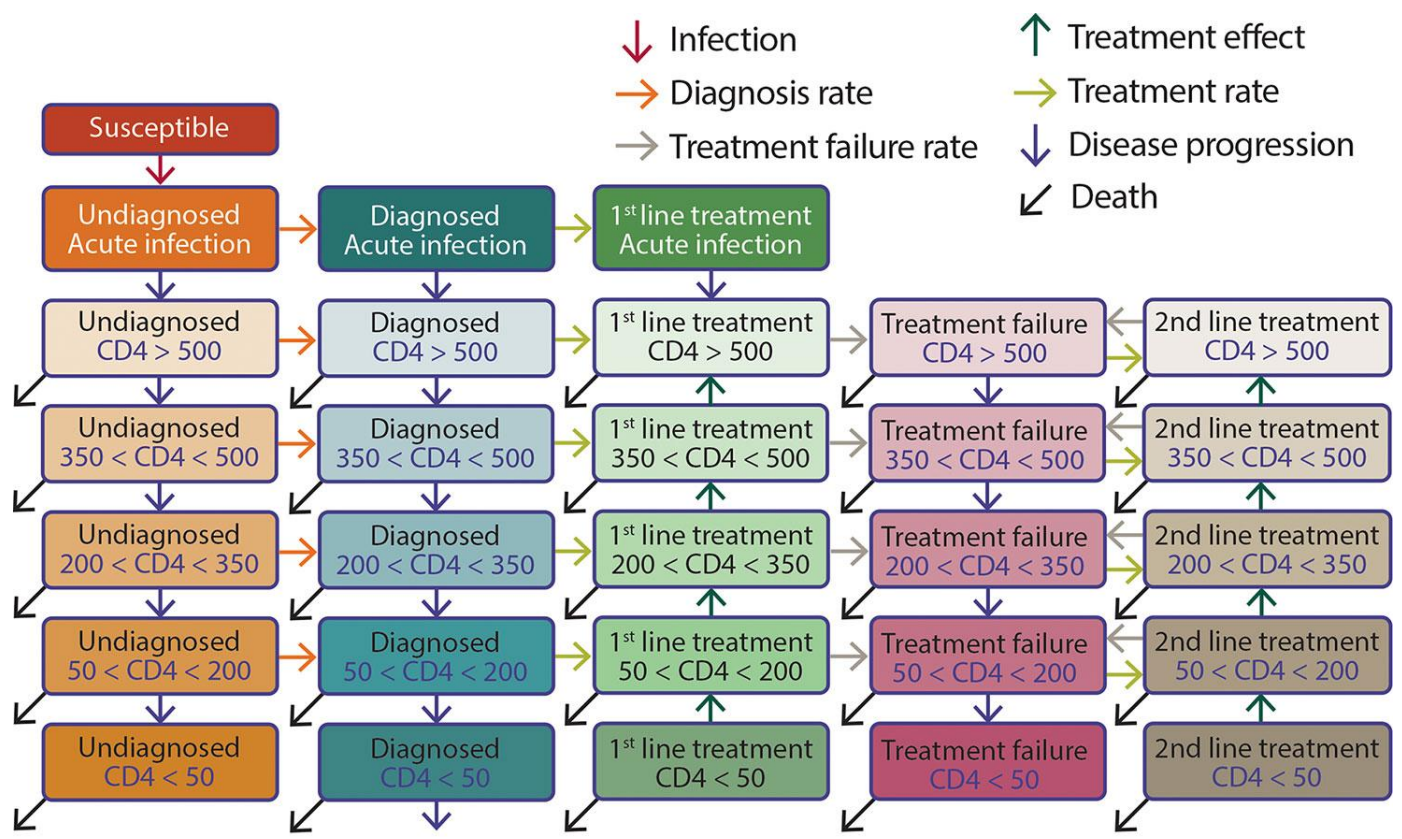

Source: Figure prepared by UNSW study team.

Note: Each compartment represents a single population group with the specified health state. Each arrow represents the movement of numbers of individuals among health states. All compartments except for "susceptible" represent individuals living with HIV. Death includes all causes of death.

Each compartment (Figure A.1b, boxes) corresponds to a single differential equation in the model, and each rate (Figure A.1b, arrows) corresponds to a single term in that equation. Table A.1 lists the parameters used in Optima; most of these are used to calculate the force of infection. The analysts interpret empirical estimates for model parameter values in Bayesian terms as previous distributions. The model then must be calibrated: finding posterior distributions of the model parameter values so+ that the model generates accurate estimates of HIV prevalence, the number of people on treatment, and any other epidemiological data that are available (such as HIV-related deaths). The calibration can be performed automatically, manually, or a combination. Model calibration and validation normally should be performed in consultation with governments in the countries in which the model is being applied.

Table A.1 Input parameters of the model

\begin{tabular}{|c|c|c|c|}
\hline & Biological parameters & Behavioral parameters & $\begin{array}{l}\text { Epidemiological/Other } \\
\text { parameters }\end{array}$ \\
\hline $\begin{array}{l}\text { Population } \\
\text { parameters }\end{array}$ & Background death rate & & Population sizes (T, P) \\
\hline \multirow{6}{*}{$\begin{array}{l}\text { HIV-related } \\
\text { parameters }\end{array}$} & $\begin{array}{l}\text { Sexual HIV transmission } \\
\text { probabilities* }\end{array}$ & \multirow{6}{*}{$\begin{array}{l}\text { Number of sexual partners* }(\mathrm{T}, \mathrm{P}, \mathrm{S}) \\
\text { Number of acts per partner* }(\mathrm{S}) \\
\text { Condom usage probability* }(\mathrm{T}, \mathrm{P}) \\
\text { Circumcision probability* }(\mathrm{T})\end{array}$} & \multirow{6}{*}{$\begin{array}{l}\text { HIV prevalence }(\mathrm{T}, \mathrm{P}) \\
\text { STI prevalence }(\mathrm{T}, \mathrm{P})\end{array}$} \\
\hline & $\begin{array}{l}\text { STI-related transmissibility } \\
\text { increase* }\end{array}$ & & \\
\hline & Condom efficacy* & & \\
\hline & Circumcision efficacy* & & \\
\hline & $\begin{array}{l}\text { HIV health state progression } \\
\text { rates }(\mathrm{H})\end{array}$ & & \\
\hline & HIV-related death rates $(\mathrm{H})$ & & \\
\hline
\end{tabular}


Table A.1 Input parameters of the model (Continued)

\begin{tabular}{|c|c|c|c|}
\hline & Biological parameters & Behavioral parameters & $\begin{array}{l}\text { Epidemiological/Other } \\
\text { parameters }\end{array}$ \\
\hline \multirow[t]{4}{*}{$\begin{array}{l}\text { MTCT } \\
\text { parameters }\end{array}$} & $\begin{array}{l}\text { Mother-to-child transmission } \\
\text { probability* }\end{array}$ & $\begin{array}{l}\text { Birth rate* } \\
\text { PMTCT access rate* }(\mathrm{T})\end{array}$ & \\
\hline & $\begin{array}{l}\text { Injecting HIV } \\
\text { transmissibility* }\end{array}$ & $\begin{array}{l}\text { Number of injections* }(\mathrm{T}) \\
\text { Syringe sharing probability* }(\mathrm{T})\end{array}$ & \\
\hline & Syringe cleaning efficacy* & Syringe cleaning probability* & \\
\hline & Drug-related death rate & Methadone treatment probability $(\mathrm{T})$ & \\
\hline \multirow{2}{*}{$\begin{array}{l}\text { Treatment } \\
\text { parameters }\end{array}$} & $\begin{array}{l}\text { ART efficacy in reducing } \\
\text { infectiousness* }\end{array}$ & \multirow[t]{2}{*}{ HIV testing rates $(\mathrm{T}, \mathrm{P}, \mathrm{H})$} & \multirow{2}{*}{$\begin{array}{l}\text { Number of people on } \\
\text { ART }\end{array}$} \\
\hline & ART failure rates & & \\
\hline \multirow{3}{*}{$\begin{array}{l}\text { Economic } \\
\text { parameters }\end{array}$} & \multirow[t]{3}{*}{ Health utilities } & & $\begin{array}{l}\text { Costs of all prevention, } \\
\text { care and treatment } \\
\text { programs, enablers and } \\
\text { management }(\mathrm{T}, \mathrm{I})\end{array}$ \\
\hline & & & $\begin{array}{l}\text { Discounting and inflation } \\
\text { rates }(\mathrm{T})\end{array}$ \\
\hline & & & Health care costs \\
\hline
\end{tabular}

Source: UNSW study team.

Note: ${ }^{*}=$ Parameter is used to calculate the force of infection; $\mathrm{H}=$ Parameter depends on health state; $\mathrm{I}=$

Parameter depends on intervention type; $\mathrm{P}=$ Parameter depends on population group; $\mathrm{S}=$ Parameter depends on sexual partnership type; $\mathrm{T}=$ Parameter value changes over time.

\section{HIV Resource Optimization and Program Coverage Targets}

A novel component of Optima is its ability to calculate allocations of resources that optimally address one or more HIV-related objectives (for example, impact-level targets in a country's HIV national strategic plan). Because this model also calculates the coverage levels required to achieve these targets, Optima can be used to inform HIV strategic planning and the determination of program coverage levels. The key assumptions of resource optimization are the relationships among (1) the cost of HIV programs for specific target populations, (2) the resulting coverage levels of targeted populations with these HIV programs, and (3) how these coverage levels of HIV programs for targeted populations influence behavioral and clinical outcomes. Such relationships are required to understand how incremental changes in spending (marginal costs) affect HIV epidemics. ${ }^{32}$ Logistic functions can incorporate initial start-up costs and enable changes in behavior to saturate at high spending levels, thus better reflecting program reality. The logistic function has the form:

$$
L(x)=A+\frac{B-A}{1+e^{-(x-C) / D}},
$$

where $\mathrm{L}(\mathrm{x})$ relates spending to coverage; $\mathrm{x}$ is the amount of funding for the program; $\mathrm{A}$ is the lower asymptote value (adjusted to match the value of $\mathrm{L}$ when there is no spending on a program); B is the upper asymptote value (for very high spending); $C$ is the midpoint; and D is the steepness of the transition from A to B. For its fits, the team typically chose saturation values of the coverage to match behavioral data in countries with heavily funded HIV

32 A traditional approach is to apply unit cost values to inform a linear relationship between money spent and coverage attained. This assumption is reasonable for programs such as an established ART program that no longer incurs start-up or initiation costs. However, the assumption is less appropriate for condom promotion and behavior change communication programs. Most HIV programs typically have initial setup costs, followed by a more effective scale-up with increased funding. However, very high coverage levels have saturation effects because these high levels require increased incremental costs due to generating demand and related activities for the most difficult-to-reach groups. Optima uses a logistic function fitted to available input data to model costcoverage curves (Appendix 2). 
responses. ${ }^{33}$ To perform the optimization, Optima uses a global parameter search algorithm called Bayesian adaptive locally linear stochastic descent (BALLSD). BALLSD is similar to simulated annealing in that it makes stochastic downhill steps in parameter space from an initial starting point. However, unlike simulated annealing, BALLSD chooses future step sizes and directions based on the outcome of previous steps. For certain classes of optimization problems, the team has shown that BALLSD can determine optimized solutions with fewer function evaluations than traditional optimization methods, including gradient descent and simulated annealing.

While all HIV interventions have some direct or indirect non-HIV benefits, some programs including opiate substitution therapy (OST) or conditional cash transfers, have multiple substantial proven benefits across different sectors. Such additional benefits were reflected by using the approach of a cross-sectoral financing model to effectively distribute the costs in accordance with the benefits. By adapting standard techniques from welfare economics to attribute the benefits of OST programs across the benefiting sectors, it was estimated that average HIV-related benefits are approximately only 10 percent of the overall health and social benefits of OST. Therefore, only 10 percent of the OST cost was included in the optimization analysis.

\section{Uncertainty Analyses}

Optima uses a Markov chain Monte Carlo (MCMC) algorithm for performing automatic calibration and for computing uncertainties in the model fit to epidemiological data. With this algorithm, the model is run many times (typically, 1,000-10,000) to generate a range of epidemic projections. Their differences represent uncertainty in the expected epidemiological trajectories. The most important assumptions in the optimization analysis are associated with the cost-coverage and coverage-outcome curves. To incorporate uncertainty in these curves, users define upper and lower limits for both coverage and behavior for no spending and for very high spending. ${ }^{34}$

33 Program coverage for zero spending, or behavioral outcomes for zero coverage of formal programs, is inferred using data from early on in the epidemic or just before significant investment in HIV programs. Practically, the team also discussed the zero and high spending cases with local experts, who could advise on private sector HIV service delivery outside the governments' expenditure tracking systems. For each HIV program, the team derived one set of logistic curves that related funding to program coverage levels and another set of curves (generally, linear relationships) that related coverage levels to clinical or behavioral outcomes (the impacts that HIV strategies aim to achieve).

34 All available historical spending data and achieved outcomes of spending, data from comparable settings, experience, and extensive discussion with stakeholders in the country of application can be used to inform these ranges. All logistic curves within these ranges then are allowable and are incorporated in Optima uncertainty analyses. These cost-coverage and coverage-outcome curves thus are reconciled with the epidemiological, behavioral, and biological data in a Bayesian optimal way, thereby enabling the calculation of unified uncertainty estimates. 


\section{APPENDIX B. CALIBRATION FIGURES}

Figure B.1 Calibration of HIV prevalence among key populations, 2000-30a

Prevalence - FSW

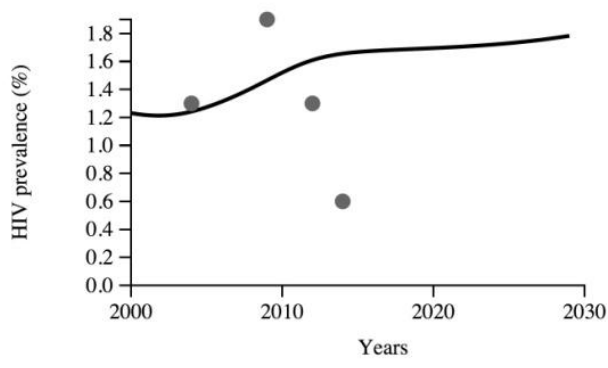

Prevalence - MSMW

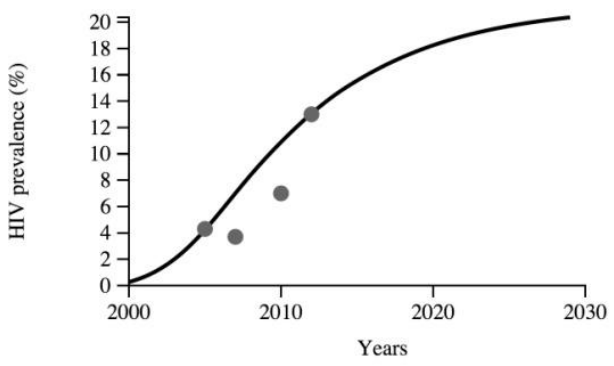

Prevalence - Males 15-49

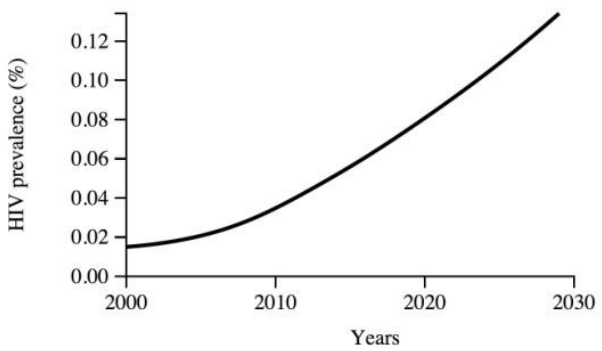

Prevalence - Males [50+]

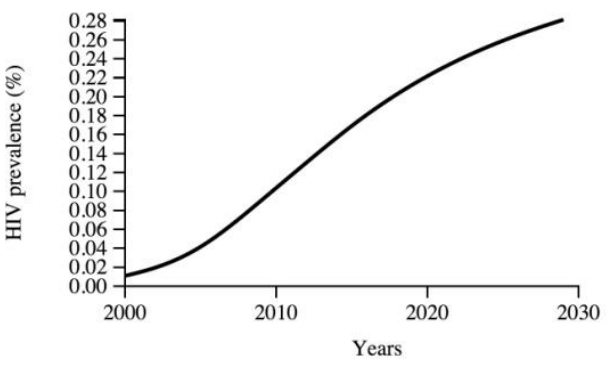

Prevalence - Clients

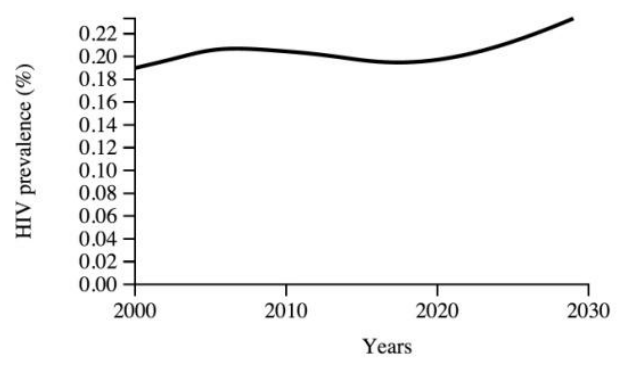

Prevalence - PWID

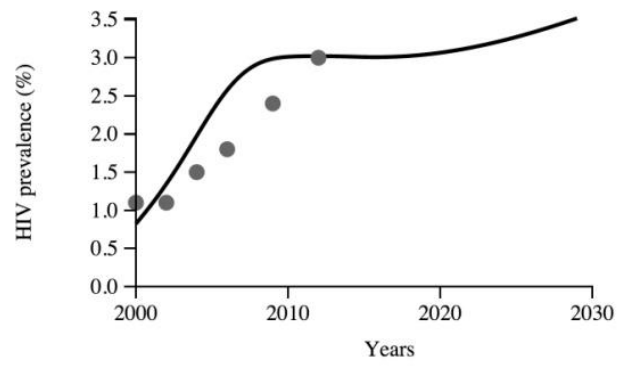

Prevalence - Females 15-49

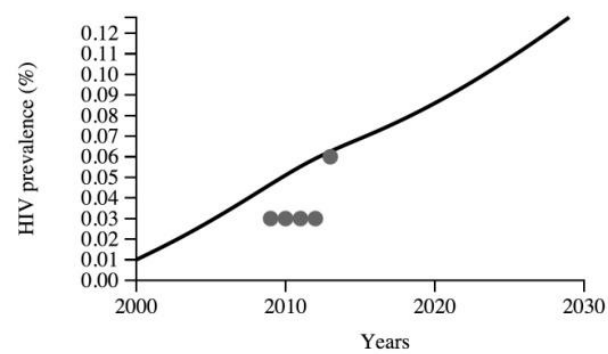

Prevalence - Females [50+]

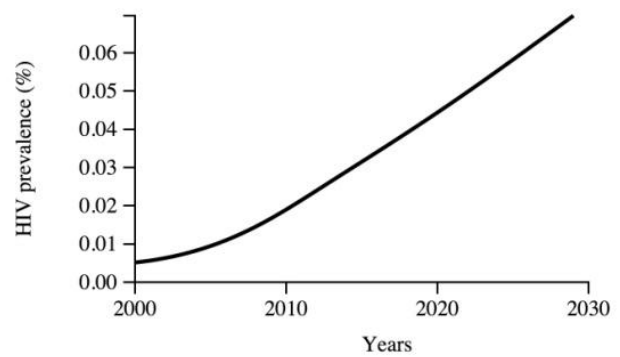

Note: $\mathrm{a}=$ Black dots represent available data for the number of people on ART. Lines attached to these discs represent uncertainty bounds. The solid curve is the best-fitting simulation of total ART patient numbers.

The combination of relatively late diagnosis and high number of PLHIV, together with low testing rate suggests that there is a higher number of PLHIV than currently diagnosed. 
Therefore the upper-bounds of the data points were chose as the best fit for MSMW, PWID, FSW and females 15-49. The stabilization of the curve for PWID is driven by behavioral data and risk reduction such as reduced needle sharing. The data points for FSW are highly variable and an upper data point was chosen to fit with the registered number of females living with HIV.

Figure B.2 Calibration of model to overall HIV prevalence, 2000-30

Prevalence - Overall

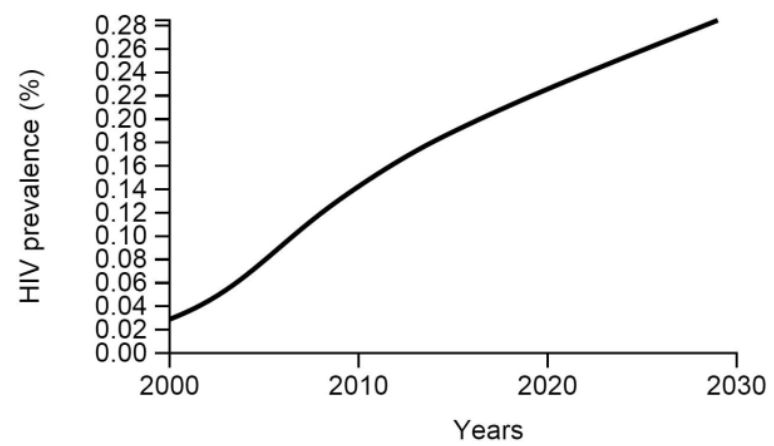

Figure B.3 Calibrated overall Incidence of HIV, 2000-30

Incidence - Overall

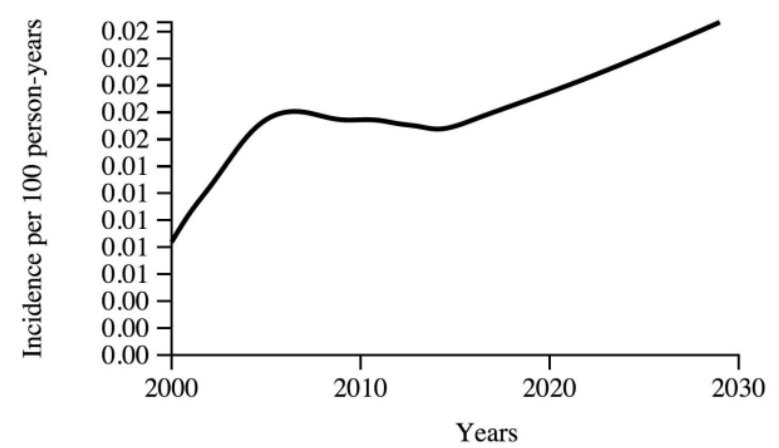


Figure B.4 Calibrated number of DALYs, diagnoses, first and subsequent lines of treatment, 2000-30

DALYs

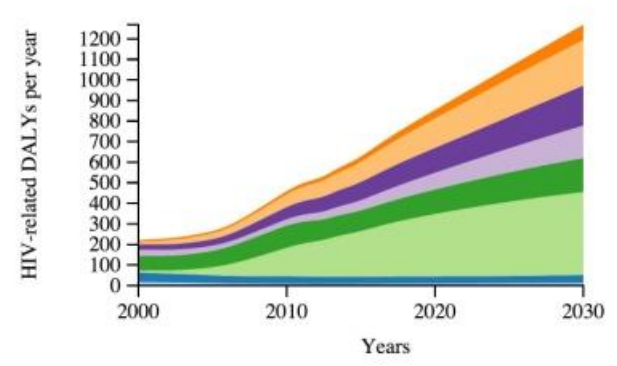

FSW

- Clients

PWID

Males 15-49

Females 15-49

Males $[50+]$

Females [50+]

First-line treatment - Overall

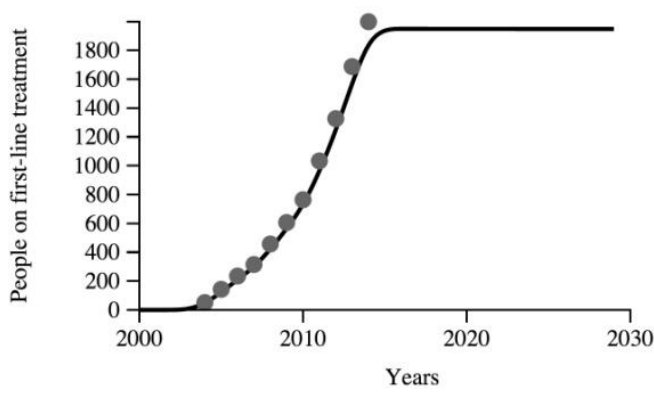

Diagnoses

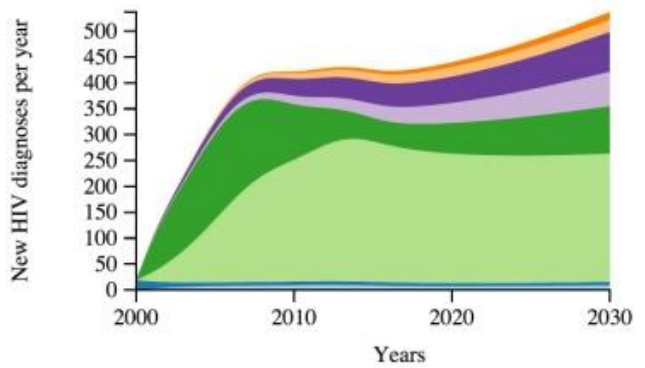

- FSW

- Clients

MSMW

PWID

Males 15-49

Females 15-49

Males $[50+]$

- Females [50+]

Subsequent lines of treatment - Overall

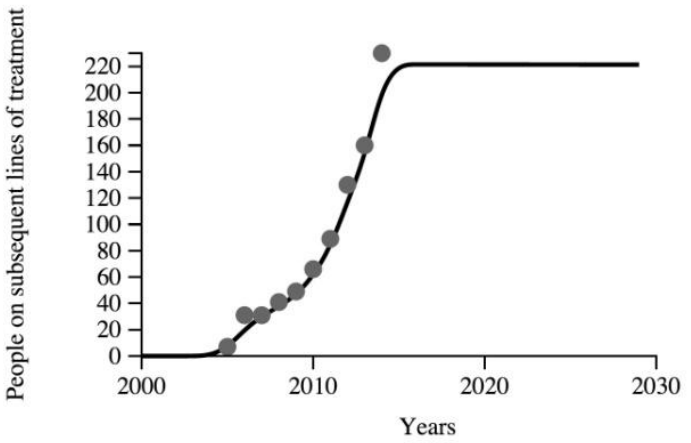




\section{APPENDIX C. COST-COVERAGE-OUTCOME CURVES}

Table C.1 Selected behaviors affected by HIV programs

\begin{tabular}{|c|c|}
\hline HIV Program & Targeted behavior \\
\hline \multirow{2}{*}{$\begin{array}{l}\text { Programs for female sex workers and clients } \\
\text { (package) }\end{array}$} & Proportion of FSW who are tested for HIV each year \\
\hline & $\begin{array}{l}\text { Proportion of sexual acts in which condoms are used with } \\
\text { commercial partners - FSW and clients }\end{array}$ \\
\hline \multirow{3}{*}{$\begin{array}{l}\text { Programs for men who have sex with men } \\
\text { and women (package) }\end{array}$} & $\begin{array}{l}\text { Proportion of sexual acts in which condoms are used with } \\
\text { regular partners by MSMW }\end{array}$ \\
\hline & $\begin{array}{l}\text { Proportion of sexual acts in which condoms are used with casual } \\
\text { partners by MSMW }\end{array}$ \\
\hline & Proportion of MSMW who are tested for HIV each year \\
\hline Opiate substitution therapy & Number of people on OST \\
\hline \multirow{2}{*}{$\begin{array}{l}\text { Needle-syringe program (NSP) and other } \\
\text { prevention for PWID (package) }\end{array}$} & $\begin{array}{l}\text { Proportion of injections using receptively shared needle- } \\
\text { syringes }\end{array}$ \\
\hline & Proportion of PWID who are tested for HIV each year \\
\hline \multirow{4}{*}{ HIV testing and counselling } & Proportion of males 15-49 who are tested for HIV each year \\
\hline & Proportion of females $15-49$ who are tested for HIV each year \\
\hline & Proportion of males 50+ who are tested for HIV each year \\
\hline & Proportion of females 50+ who are tested for HIV each year \\
\hline Antiretroviral therapy & Number of people on ART \\
\hline Prevention of mother-to-child transmission & Proportion of pregnant women covered with PMTCT \\
\hline
\end{tabular}

Figure C.1 FSW: Proportion who are tested for HIV each year

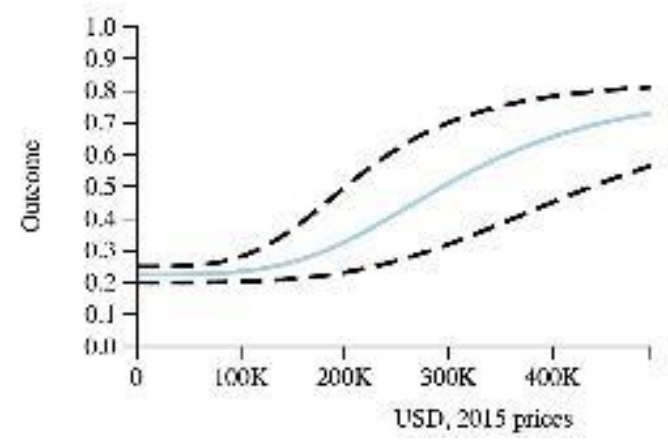

Figure C.2 FSW: Proportion of sexual acts in which condoms are used with commercial partners

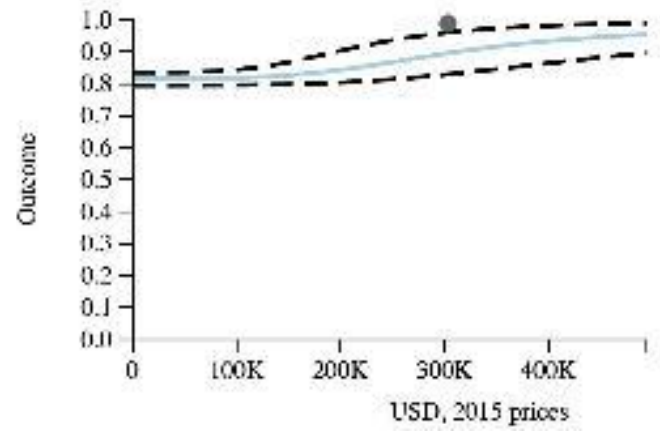


Figure C.3 FSW: Proportion of sexual acts in which condoms are used with commercial partners (clients)

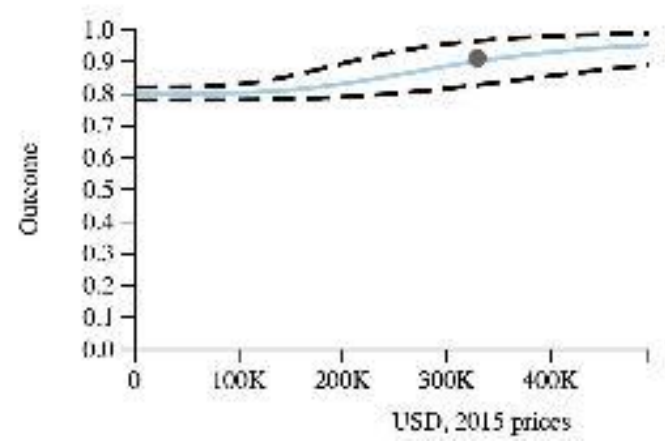

Figure C.4 MSM: Proportion of MSM sexual acts in which condoms are used with regular partners

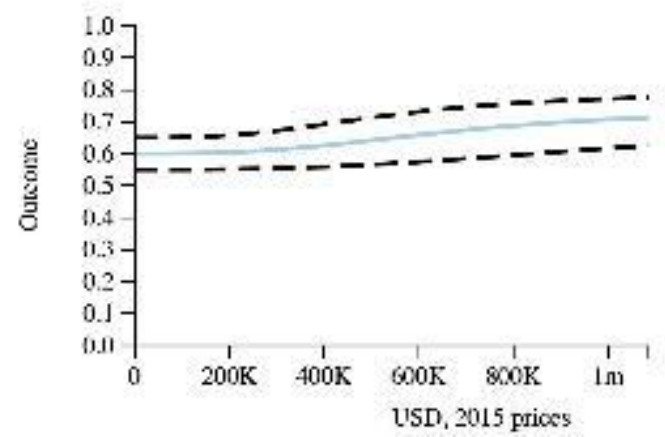

Figure C.5 MSM: Proportion of sexual acts in which condoms are used with casual partners

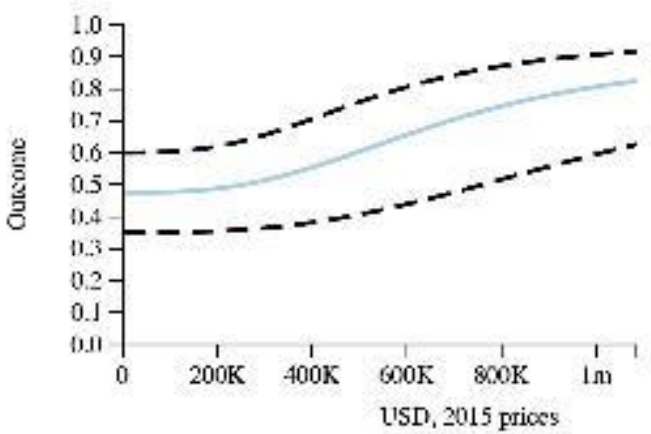


Figure C.6 MSM: Proportion who are tested for HIV each year

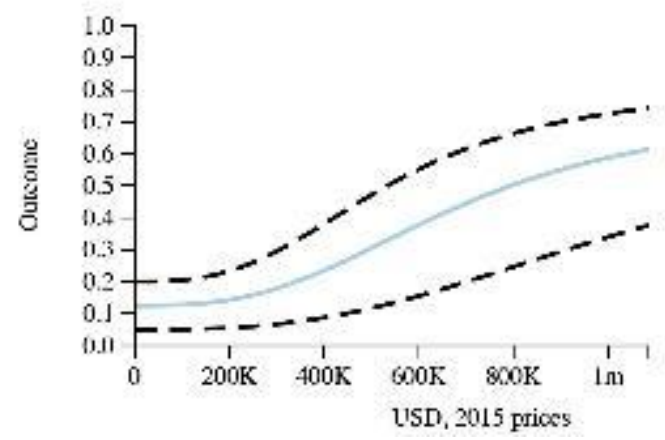

Figure C.7 Opiate substitution therapy: Number of people covered

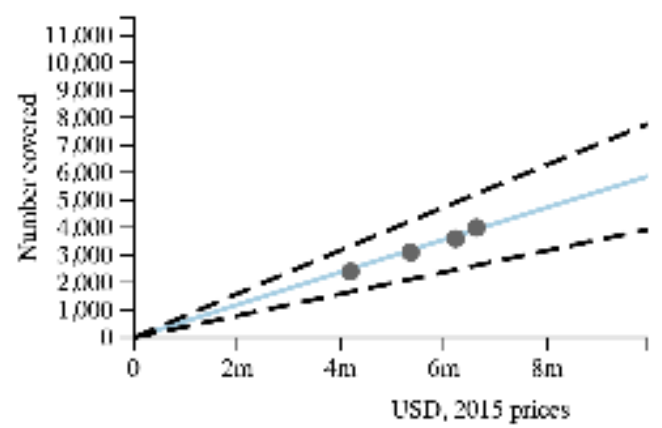

Figure C.8 PWID: Proportion of injections using receptively shared needle-syringes

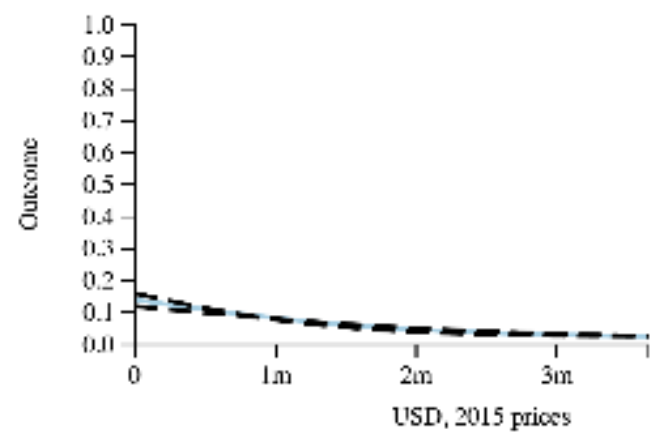

Figure C.9 PWID: Proportion who are tested for HIV each year

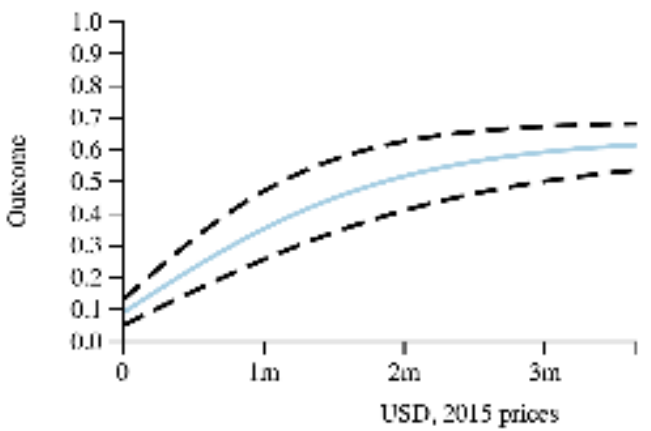


Figure C.10 Males 15-49: Proportion who are tested for HIV each year

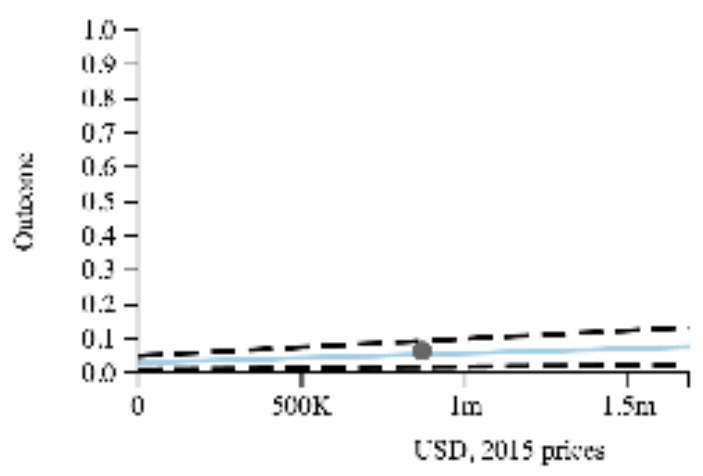

Figure C.11 Females 15-49: Proportion who are tested for HIV each year

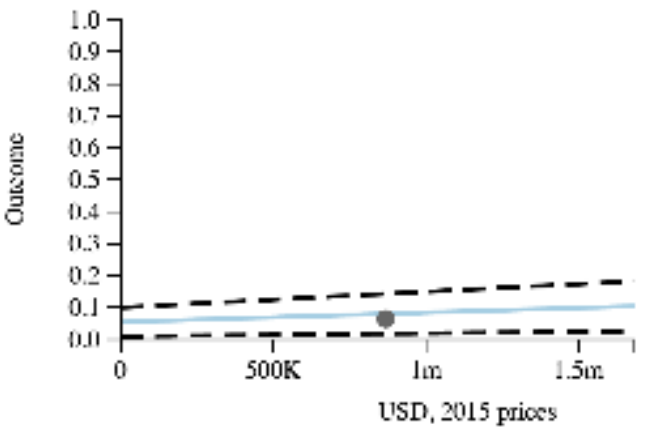

Figure C.12 Males 50+: Proportion who are tested for HIV each year

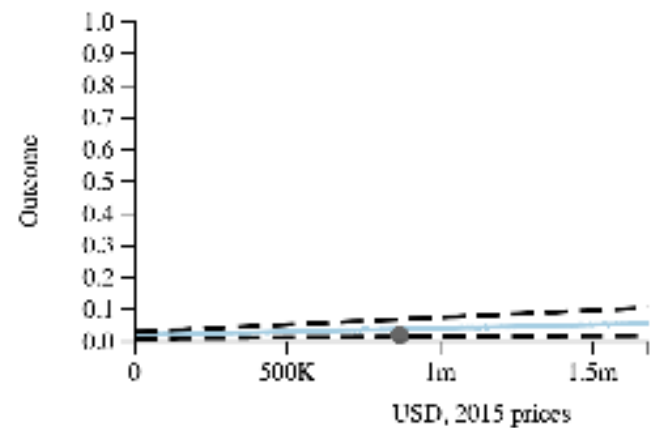

Figure C.13 Females 50+: Proportion who are tested for HIV each year

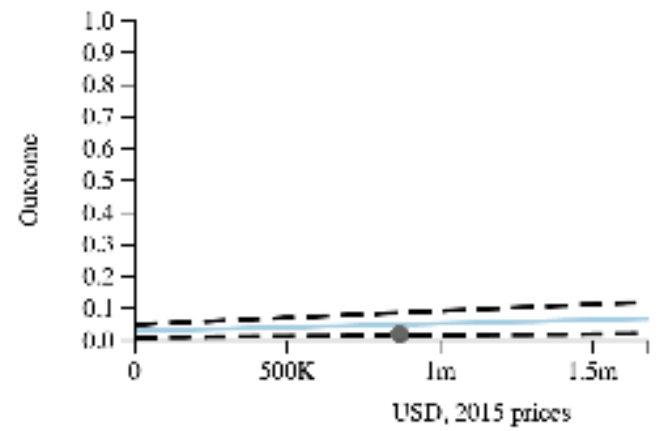


Figure C.14 Antiretroviral therapy: Number of people covered

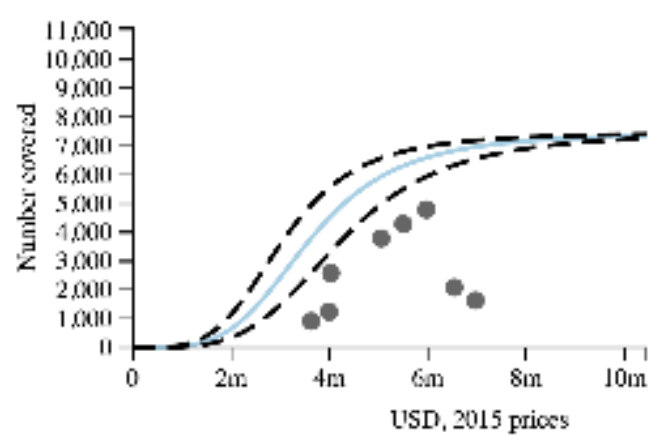

Figure C.15 PMTCT: Proportion of people covered

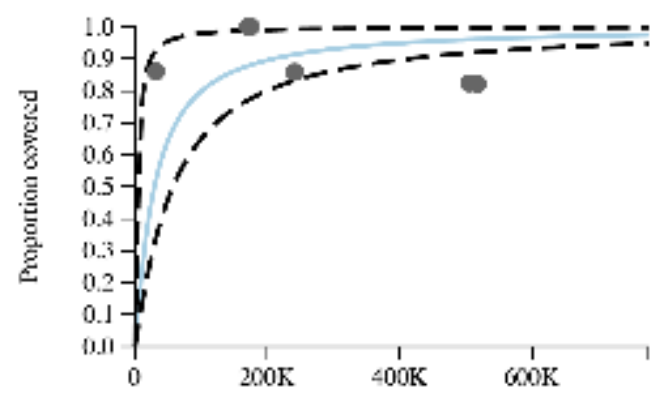

USD, 2015 prioss 


\section{APPENDIX D. DATA TABLES}

Appendix D.1 Data Tables, 2000-14

\begin{tabular}{|c|c|c|c|c|c|c|c|c|c|c|c|c|c|c|c|c|c|}
\hline & & 2000 & 2001 & 2002 & 2003 & 2004 & 2005 & 2006 & 2007 & 2008 & 2009 & 2010 & 2011 & 2012 & 2013 & 2014 & Assumption \\
\hline & High & - & - & - & - & - & - & - & - & - & - & - & - & - & - & 7 & - \\
\hline \multirow[t]{3}{*}{ FSW } & Best & - & - & - & - & - & - & - & - & - & - & - & - & - & - & 7 & - \\
\hline & Low & - & - & - & - & - & - & - & - & - & - & - & - & - & - & 6 & - \\
\hline & High & - & - & - & - & - & - & - & - & - & - & - & - & - & - & - & 167 \\
\hline \multirow[t]{3}{*}{ Clients } & Best & - & - & - & - & - & - & - & - & - & - & - & - & - & - & - & 111 \\
\hline & Low & - & - & - & - & - & - & - & - & - & - & - & - & - & - & - & 56 \\
\hline & High & - & - & - & - & - & - & - & - & - & - & - & - & - & - & 20 & - \\
\hline \multirow[t]{3}{*}{ MSMW } & Best & - & - & - & - & - & - & - & - & - & - & - & - & - & - & 17 & - \\
\hline & Low & - & - & - & - & - & - & - & - & - & - & - & - & - & - & 8 & - \\
\hline & High & - & - & - & - & - & - & - & - & - & 41 & - & - & - & - & & - \\
\hline \multirow[t]{2}{*}{ PWID } & Best & - & - & - & - & - & - & - & - & - & 40 & - & - & - & - & 45 & - \\
\hline & Low & - & - & - & - & - & - & - & - & - & 39 & - & - & - & - & - & - \\
\hline Males 15-49 & Best & 920 & 916 & 909 & 905 & 903 & 910 & 946 & 948 & 949 & 910 & 951 & 952 & 954 & 941 & 880 & - \\
\hline Females 15-49 & Best & 1166 & 1162 & 1153 & 1149 & 1148 & 1153 & 1180 & 1181 & 1172 & 1164 & 1166 & 1161 & 1156 & 1134 & 1120 & - \\
\hline Males 50+ & Best & 513 & 511 & 508 & 514 & 515 & 521 & 537 & 545 & 554 & 563 & 578 & 593 & 606 & 616 & 626 & - \\
\hline Females 50+ & Best & 711 & 708 & 704 & 710 & 714 & 722 & 741 & 754 & 765 & 780 & 797 & 815 & 832 & 843 & 859 & - \\
\hline
\end{tabular}


Table D.2 HIV prevalence, 2000-14 (\%)

\begin{tabular}{|c|c|c|c|c|c|c|c|c|c|c|c|c|c|c|c|c|c|}
\hline & & 2000 & 2001 & 2002 & 2003 & 2004 & 2005 & 2006 & 2007 & 2008 & 2009 & 2010 & 2011 & 2012 & 2013 & 2014 & Assumption \\
\hline FSW & Best & - & - & - & - & 1.30 & - & - & - & - & 1.90 & - & - & 1.30 & - & 0.60 & - \\
\hline \multirow[t]{2}{*}{ Clients } & Best & - & - & - & - & - & - & - & - & - & - & - & - & & - & - & - \\
\hline & High & - & - & - & - & - & - & - & - & - & - & - & - & 18.70 .0 & - & - & - \\
\hline \multirow[t]{3}{*}{ MSMW } & Best & - & - & - & - & - & 4.30 & - & 3.70 & - & - & 7.00 & - & 13.00 .0 & - & - & - \\
\hline & Low & - & - & - & - & - & - & - & - & - & - & - & - & 8.50 & - & - & - \\
\hline & High & 1.10 & - & 1.10 & - & 2.10 & - & 3.60 & - & - & 4.50 & - & - & & - & - & - \\
\hline \multirow[t]{2}{*}{ PWID } & Best & 1.10 & - & 1.10 & - & 1.50 & - & 1.80 & - & - & 2.40 & - & - & 3.00 & - & - & - \\
\hline & Low & 1.10 & - & 1.1 & - & 0.40 & - & 0.00 & - & - & 2.10 & - & - & - & - & - & - \\
\hline Males 15-49 & Best & - & - & - & - & - & - & - & - & - & - & - & - & - & - & - & 0.07 \\
\hline Females 15-49 & Best & - & - & - & - & - & - & - & - & - & 0.03 & 0.03 & 0.03 & 0.03 & 0.06 & - & - \\
\hline Males 50+ & Best & - & - & - & - & - & - & - & - & - & - & - & - & - & - & - & 0.02 \\
\hline Females 50+ & Best & - & - & - & - & - & - & - & - & - & - & - & - & - & - & - & 0.02 \\
\hline
\end{tabular}


Table D.3 Testing and treatment

\begin{tabular}{|c|c|c|c|c|c|c|c|c|c|c|c|c|c|c|c|c|c|}
\hline & & 2000 & 2001 & 2002 & 2003 & 2004 & 2005 & 2006 & 2007 & 2008 & 2009 & 2010 & 2011 & 2012 & 2013 & 2014 & Assumption \\
\hline \multirow{8}{*}{$\begin{array}{l}\text { Testing rate per } \\
\text { year }(\%)\end{array}$} & FSW (\%) & - & - & - & - & - & - & 33 & - & - & - & - & 28 & 42 & 42 & - & - \\
\hline & Clients & - & - & - & - & - & - & - & - & - & - & - & - & - & - & - & - \\
\hline & MSMW (\%) & - & - & - & - & - & 27 & - & 30 & - & - & 26 & 26 & 34 & 34 & - & - \\
\hline & PWID (\%) & - & - & - & - & - & - & - & - & - & - & - & 57 & 15 & 15 & - & - \\
\hline & Males 15-49 (\%) & - & - & - & - & - & - & - & - & - & - & 6 & - & - & - & - & - \\
\hline & $\begin{array}{l}\text { Females 15-49 } \\
(\%)\end{array}$ & - & - & - & - & - & - & - & - & - & - & 6 & - & - & - & - & - \\
\hline & Males 50+ (\%) & - & - & - & - & - & - & - & - & - & - & 2 & - & - & - & - & - \\
\hline & Females 50+ (\%) & - & - & - & - & - & - & - & - & - & - & 2 & - & - & - & - & - \\
\hline \multirow{3}{*}{$\begin{array}{l}\text { Probability being tested } \\
\text { with CD4 <200 per year }\end{array}$} & High (\%) & - & - & - & - & - & - & - & - & - & - & - & - & - & - & - & 30 \\
\hline & Average (\%) & - & - & - & - & - & - & - & - & - & - & - & - & - & - & - & 65 \\
\hline & Low (\%) & - & - & - & - & - & - & - & - & - & - & - & - & - & - & - & 80 \\
\hline \multicolumn{2}{|c|}{ Number on first-line treatment } & 0 & 0 & 0 & 0 & 51 & 143 & 235 & 315 & 457 & 606 & 764 & 1033 & 1326 & 1687 & 1998 & - \\
\hline \multicolumn{2}{|c|}{ Number on subsequent lines of treatment } & 0 & 0 & 0 & 0 & 0 & 7 & 31 & 31 & 41 & 49 & 66 & 89 & 130 & 160 & 230 & - \\
\hline \multicolumn{2}{|c|}{ Treatment eligibility criterion } & 200 & 200 & 200 & 200 & 200 & 200 & 200 & 200 & 200 & 200 & 200 & 250 & 350 & 500 & 500 & - \\
\hline \multirow{8}{*}{$\begin{array}{l}\% \text { covered by } \\
\text { pre-exposure } \\
\text { prophylaxis }\end{array}$} & FSW & 0 & 0 & 0 & 0 & 0 & 0 & 0 & 0 & 0 & 0 & 0 & 0 & 0 & 0 & - & - \\
\hline & Clients & 0 & 0 & 0 & 0 & 0 & 0 & 0 & 0 & 0 & 0 & 0 & 0 & 0 & 0 & - & - \\
\hline & MSMW & 0 & 0 & 0 & 0 & 0 & 0 & 0 & 0 & 0 & 0 & 0 & 0 & 0 & 0 & - & - \\
\hline & PWID & 0 & 0 & 0 & 0 & 0 & 0 & 0 & 0 & 0 & 0 & 0 & 0 & 0 & 0 & - & - \\
\hline & Males 15-49 & 0 & 0 & 0 & 0 & 0 & 0 & 0 & 0 & 0 & 0 & 0 & 0 & 0 & 0 & - & - \\
\hline & Females 15-49 & 0 & 0 & 0 & 0 & 0 & 0 & 0 & 0 & 0 & 0 & 0 & 0 & 0 & 0 & - & - \\
\hline & Males 50+ & 0 & 0 & 0 & 0 & 0 & 0 & 0 & 0 & 0 & 0 & 0 & 0 & 0 & 0 & - & - \\
\hline & Females 50+ & 0 & 0 & 0 & 0 & 0 & 0 & 0 & 0 & 0 & 0 & 0 & 0 & 0 & 0 & - & - \\
\hline
\end{tabular}


Table D.3 Testing and treatment (Continued)

\begin{tabular}{|c|c|c|c|c|c|c|c|c|c|c|c|c|c|c|c|c|c|}
\hline & & 2000 & 2001 & 2002 & 2003 & 2004 & 2005 & 2006 & 2007 & 2008 & 2009 & 2010 & 2011 & 2012 & 2013 & 2014 & Assumption \\
\hline $\begin{array}{l}\text { \% of women on PMTCT } \\
\text { (Option B/B+) }\end{array}$ & & - & - & - & - & - & - & - & - & - & 80.80 & 82.10 & 82.30 & 85.80 & 86.00 & - & - \\
\hline & FSW & 0.046 & 0.045 & 0.045 & 0.046 & 0.046 & 0.047 & 0.049 & 0.050 & 0.051 & 0.052 & 0.053 & 0.052 & 0.052 & - & - & - \\
\hline \multirow[t]{2}{*}{ Birth rate } & Females 15-49 & 0.046 & 0.045 & 0.045 & 0.046 & 0.046 & 0.047 & 0.049 & 0.050 & 0.051 & 0.052 & 0.053 & 0.052 & 0.052 & - & - & - \\
\hline & Females 50+ & - & - & - & - & - & - & - & - & - & - & - & - & - & - & - & 0.00 \\
\hline $\begin{array}{l}\text { \% HIV-positive women } \\
\text { who breastfeed }\end{array}$ & & - & - & - & - & - & - & - & - & - & - & - & - & - & - & - & 12 \\
\hline
\end{tabular}

\section{Table D.4 Optional indicators}

\begin{tabular}{|c|c|c|c|c|c|c|c|c|c|c|c|c|c|c|c|}
\hline & 2000 & 2001 & 2002 & 2003 & 2004 & 2005 & 2006 & 2007 & 2008 & 2009 & 2010 & 2011 & 2012 & 2013 & 2014 \\
\hline Number of HIV tests per year & - & - & - & - & 24.31 & 26.03 & 16.99 & 16.99 & 18.79 & 17.56 & 25.37 & 21.80 & 15.56 & 18.09 & - \\
\hline Number of HIV diagnoses per year & 79 & 93 & 95 & 100 & 163 & 242 & 276 & 344 & 351 & 385 & 455 & 424 & 526 & 490 & 564 \\
\hline $\begin{array}{l}\text { Modeled estimate of new HIV } \\
\text { infections per year }\end{array}$ & 255 & 301 & 356 & 405 & 461 & 503 & 542 & 575 & 627 & 649 & 691 & 718 & 679 & 639 & - \\
\hline Modeled estimate of HIV prevalence & 0.04 & 0.05 & 0.06 & 0.07 & 0.09 & 0.10 & 0.12 & 0.14 & 0.16 & 0.18 & 0.20 & 0.23 & 0.25 & 0.27 & - \\
\hline Number of HIV-related deaths & 34 & 44 & 56 & 71 & 86 & 84 & 78 & 79 & 99 & 109 & 129 & 157 & 147 & 110 & - \\
\hline $\begin{array}{l}\text { Number of people initiating ART } \\
\text { each year }\end{array}$ & - & - & - & - & 52 & 130 & 136 & 135 & 195 & 229 & 238 & 389 & 431 & 523 & 520 \\
\hline
\end{tabular}


Table D.5 Sexual acts per person per year

\begin{tabular}{|c|c|c|c|c|c|c|c|c|c|c|c|c|c|c|c|c|c|}
\hline & & 2000 & 2001 & 2002 & 2003 & 2004 & 2005 & 2006 & 2007 & 2008 & 2009 & 2010 & 2011 & 2012 & 2013 & 2014 & Assumption \\
\hline \multirow{8}{*}{$\begin{array}{l}\text { Average } \\
\text { number of } \\
\text { regular } \\
\text { sexual acts }\end{array}$} & FSW & - & - & - & - & - & - & - & - & - & - & - & - & 66.24 & - & 38.40 & - \\
\hline & Clients & - & - & - & - & - & - & - & - & - & - & - & - & - & - & - & 54 \\
\hline & MSMW & - & - & - & - & - & - & - & - & - & - & 19.5 & - & 15.42 & - & - & - \\
\hline & PWID & - & - & - & - & - & - & - & - & - & - & - & - & - & - & - & 54 \\
\hline & Males 15-49 & - & - & - & - & - & - & - & - & - & - & - & - & - & - & - & 54 \\
\hline & Females 15-49 & - & - & - & - & - & - & - & - & - & - & - & - & - & - & - & 54 \\
\hline & Males 50+ & - & - & - & - & - & - & - & - & - & - & - & - & - & - & - & 27 \\
\hline & Females 50+ & - & - & - & - & - & - & - & - & - & - & - & - & - & - & - & 27 \\
\hline \multirow{8}{*}{$\begin{array}{l}\text { Average } \\
\text { number of } \\
\text { casual sexual } \\
\text { acts }\end{array}$} & FSW & - & - & - & - & - & - & - & - & - & - & - & - & - & - & - & 15 \\
\hline & Clients & - & - & - & - & - & - & - & - & - & - & - & - & - & - & - & 6 \\
\hline & MSMW & - & - & - & - & - & - & - & - & - & - & 60.0 & - & 60.0 & - & - & - \\
\hline & PWID & - & - & - & - & - & - & - & - & - & - & - & - & - & - & - & 12 \\
\hline & Males 15-49 & - & - & - & - & - & - & - & - & - & - & - & - & - & - & - & 6 \\
\hline & Females 15-49 & - & - & - & - & - & - & - & - & - & - & - & - & - & - & - & 6 \\
\hline & Males 50+ & - & - & - & - & - & - & - & - & - & - & - & - & - & - & - & 3 \\
\hline & Females 50+ & - & - & - & - & - & - & - & - & - & - & - & - & - & - & - & 1 \\
\hline \multirow{8}{*}{$\begin{array}{l}\text { Average } \\
\text { number of } \\
\text { commercial } \\
\text { sexual } \\
\text { acts }\end{array}$} & FSW & - & - & 494 & & 572 & & 546 & - & - & - & - & - & 426.4 & - & 554.8 & - \\
\hline & Clients & - & - & - & - & - & - & - & - & - & - & - & - & - & - & - & 33 \\
\hline & MSMW & - & - & - & - & - & - & - & - & - & - & - & - & - & - & - & - \\
\hline & PWID & - & - & - & - & - & - & - & - & - & - & - & - & - & - & - & 33 \\
\hline & Males 15-49 & - & - & - & - & - & - & - & - & - & - & - & - & - & - & - & 0 \\
\hline & Females 15-49 & - & - & - & - & - & - & - & - & - & - & - & - & - & - & - & 0 \\
\hline & Males 50+ & - & - & - & - & - & - & - & - & - & - & - & - & - & - & - & 0 \\
\hline & Females 50+ & - & - & - & - & - & - & - & - & - & - & - & - & - & - & - & 0 \\
\hline
\end{tabular}


Table D.6 Condom use and circumcision probability

\begin{tabular}{|c|c|c|c|c|c|c|c|c|c|c|c|c|c|c|c|c|c|}
\hline & & 2000 & 2001 & 2002 & 2003 & 2004 & 2005 & 2006 & 2007 & 2008 & 2009 & 2010 & 2011 & 2012 & 2013 & 2014 & Assumption \\
\hline \multirow{8}{*}{$\begin{array}{l}\text { Condom use } \\
\% \text { for } \\
\text { regular } \\
\text { acts }\end{array}$} & FSW & - & - & - & - & - & - & - & - & - & - & - & - & 66.24 & - & 38.40 & - \\
\hline & Clients & - & - & - & - & - & - & - & - & - & - & - & - & - & - & - & 54 \\
\hline & MSMW & - & - & - & - & - & - & - & - & - & - & 19.5 & - & 15.42 & - & - & - \\
\hline & PWID & - & - & - & - & - & - & - & - & - & - & - & - & - & - & - & 54 \\
\hline & Males 15-49 & - & - & - & - & - & - & - & - & - & - & - & - & - & - & - & 54 \\
\hline & Females 15-49 & - & - & - & - & - & - & - & - & - & - & - & - & - & - & - & 54 \\
\hline & Males 50+ & - & - & - & - & - & - & - & - & - & - & - & - & - & - & - & 27 \\
\hline & Females 50+ & - & - & - & - & - & - & - & - & - & - & - & - & - & - & - & 27 \\
\hline \multirow{8}{*}{$\begin{array}{l}\text { Condom use } \\
\% \text { for casual } \\
\text { acts }\end{array}$} & FSW & - & - & - & - & - & - & - & - & - & - & - & - & - & - & - & 15 \\
\hline & Clients & - & - & - & - & - & - & - & - & - & - & - & - & - & - & - & 6 \\
\hline & MSMW & - & - & - & - & - & - & - & - & - & - & 60.0 & - & 60.0 & - & - & \\
\hline & PWID & - & - & - & - & - & - & - & - & - & - & - & - & - & - & - & 12 \\
\hline & Males 15-49 & - & - & - & - & - & - & - & - & - & - & - & - & - & - & - & 6 \\
\hline & Females 15-49 & - & - & - & - & - & - & - & - & - & - & - & - & - & - & - & 6 \\
\hline & Males 50+ & - & - & - & - & - & - & - & - & - & - & - & - & - & - & - & 3 \\
\hline & Females $50+$ & - & - & - & - & - & - & - & - & - & - & - & - & - & - & - & 1 \\
\hline \multirow{8}{*}{$\begin{array}{l}\text { Condom use } \\
\% \text { for } \\
\text { commercial } \\
\text { acts }\end{array}$} & FSW & - & - & 494 & - & 572 & - & 546 & - & - & - & - & - & 426.4 & & 554.8 & - \\
\hline & Clients & - & - & - & - & - & - & - & - & - & - & - & - & - & - & - & 33 \\
\hline & MSMW & - & - & - & - & - & - & - & - & - & - & - & - & - & - & - & - \\
\hline & PWID & - & - & - & - & - & - & - & - & - & - & - & - & - & - & - & 33 \\
\hline & Males 15-49 & - & - & - & - & - & - & - & - & - & - & - & - & - & - & - & 0 \\
\hline & Females 15-49 & - & - & - & - & - & - & - & - & - & - & - & - & - & - & - & 0 \\
\hline & Males 50+ & - & - & - & - & - & - & - & - & - & - & - & - & - & - & - & 0 \\
\hline & Females $50+$ & - & - & - & - & - & - & - & - & - & - & - & - & - & - & - & 0 \\
\hline
\end{tabular}


Table D.6 Condom use and circumcision probability (Continued)

\begin{tabular}{|c|c|c|c|c|c|c|c|c|c|c|c|c|c|c|c|c|c|}
\hline & & 2000 & 2001 & 2002 & 2003 & 2004 & 2005 & 2006 & 2007 & 2008 & 2009 & 2010 & 2011 & 2012 & 2013 & 2014 & Assumption \\
\hline \multirow{5}{*}{$\begin{array}{l}\text { Circumcision } \\
\text { probability }\end{array}$} & Clients & - & - & - & - & - & - & - & - & - & - & - & - & - & - & - & 0 \\
\hline & MSMW & - & - & - & - & - & - & - & - & - & - & - & - & - & - & - & 0 \\
\hline & PWID & - & - & - & - & - & - & - & - & - & - & - & - & - & - & - & 0 \\
\hline & Males 15-49 & - & - & - & - & - & - & - & - & - & - & - & - & - & - & - & 0 \\
\hline & Males 50+ & - & - & - & - & - & - & - & - & - & - & - & - & - & - & - & 0 \\
\hline
\end{tabular}

Table D.7 Non-HIV deaths, sexually transmitted infections, and tuberculosis prevalence

\begin{tabular}{|c|c|c|c|c|c|c|c|c|c|c|c|c|c|c|c|c|c|}
\hline & & 2000 & 2001 & 2002 & 2003 & 2004 & 2005 & 2006 & 2007 & 2008 & 2009 & 2010 & 2011 & 2012 & 2013 & 2014 & Assumption \\
\hline \multirow{8}{*}{$\begin{array}{l}\% \text { People die } \\
\text { from non-HIV- } \\
\text { related causes } \\
\text { per year }\end{array}$} & FSW (\%) & 0.2 & 0.2 & 0.2 & 0.2 & 0.2 & 0.2 & 0.2 & 0.2 & 0.2 & 0.2 & 0. & 0.2 & 0.2 & 0.2 & 0.2 & - \\
\hline & Clients (\%) & 0.3 & 0.3 & 0.3 & 0.3 & 0.3 & 0.2 & 0.2 & 0.2 & 0.2 & 0.2 & 0.2 & 0.2 & 0.2 & 0.2 & 0.2 & - \\
\hline & MSMW (\%) & 0.3 & 0.3 & 0.3 & 0.3 & 0.3 & 0.2 & 0.2 & 0.2 & 0.2 & 0.2 & 0.2 & 0.2 & 0.2 & 0.2 & 0.2 & - \\
\hline & PWID (\%) & 1.8 & 1.8 & 1.8 & 1.8 & 1.8 & 1.7 & 1.7 & 1.7 & 1.7 & 1.7 & 1.6 & 1.6 & 1.6 & 1.6 & 1.7 & - \\
\hline & Males 15-49 (\%) & 0.3 & 0.3 & 0.3 & 0.3 & 0.3 & 0.2 & 0.2 & 0.2 & 0.2 & 0.2 & 0.2 & 0.2 & 0.2 & 0.2 & 0.2 & - \\
\hline & $\begin{array}{l}\text { Females 15-49 } \\
(\%)\end{array}$ & 0.1 & 0.1 & 0.1 & 0.1 & 0.1 & 0.1 & 0.1 & 0.1 & 0.1 & 0.1 & 0.1 & 0.1 & 0.1 & 0.1 & 0.1 & - \\
\hline & Males 50+ (\%) & 3.5 & 3.5 & 3.5 & 3.5 & 3.5 & 3.7 & 3.7 & 3.6 & 3.6 & 3.5 & 3.6 & 3.8 & 3.7 & 3.7 & 3.6 & - \\
\hline & Females $50+(\%)$ & 2.8 & 2.8 & 2.9 & 2.9 & 2.8 & 2.9 & 2.9 & 2.9 & 2.8 & 2.8 & 2.9 & 3.1 & 3.0 & 2.9 & 2.9 & - \\
\hline
\end{tabular}


Table D.7 Non-HIV deaths, sexually transmitted infections, and tuberculosis prevalence (Continued)

\begin{tabular}{|c|c|c|c|c|c|c|c|c|c|c|c|c|c|c|c|c|c|}
\hline & & 2000 & 2001 & 2002 & 2003 & 2004 & 2005 & 2006 & 2007 & 2008 & 2009 & 2010 & 2011 & 2012 & 2013 & 2014 & Assumption \\
\hline \multirow{8}{*}{$\begin{array}{l}\text { Prevalence of } \\
\text { ulcerative STIs }\end{array}$} & FSW (\%) & - & - & 28.8 & - & 48.7 & - & 23.8 & - & - & 45.5 & - & - & 34.6 & - & - & - \\
\hline & Clients (\%) & - & - & - & - & - & - & & - & - & - & - & - & - & - & - & 10 \\
\hline & MSMW (\%) & - & - & - & - & - & - & 27.1 & - & - & - & 10.9 & - & 32.9 & - & - & - \\
\hline & PWID (\%) & - & - & - & - & - & - & - & - & - & - & - & - & - & - & - & 5 \\
\hline & Males 15-49 (\%) & - & - & - & - & - & - & - & - & - & - & - & - & - & - & - & 3 \\
\hline & Females 15-49 (\%) & - & - & - & - & - & - & - & - & - & - & 2.6 & - & - & - & - & - \\
\hline & Males 50+ (\%) & - & - & - & - & - & - & - & - & - & - & - & - & - & - & - & 1 \\
\hline & Females 50+ (\%) & - & - & - & - & - & - & - & - & - & - & - & - & - & - & - & 1 \\
\hline \multirow{8}{*}{$\begin{array}{l}\text { Prevalence of } \\
\text { discharging } \\
\text { STIs }\end{array}$} & FSW (\%) & - & - & 25.3 & - & 22.3 & - & 21.4 & - & - & 5.7 & - & - & 14.4 & - & - & - \\
\hline & Clients (\%) & - & - & - & - & - & - & - & - & - & - & - & - & - & - & - & 10 \\
\hline & MSMW (\%) & - & - & - & - & - & - & - & - & - & - & - & - & - & - & - & 2 \\
\hline & PWID (\%) & - & - & - & - & - & - & - & - & - & - & - & - & - & - & - & 5 \\
\hline & Males 15-49 (\%) & - & - & - & - & - & - & - & - & - & - & - & - & - & - & - & 2 \\
\hline & Females 15-49 (\%) & - & - & - & - & - & - & - & - & - & - & - & - & - & - & - & 4 \\
\hline & Males 50+ $(\%)$ & - & - & - & - & - & - & - & - & - & - & - & - & - & - & - & 1 \\
\hline & Females 50+ (\%) & - & - & - & - & - & - & - & - & - & - & - & - & - & - & - & 1 \\
\hline \multirow{8}{*}{$\begin{array}{l}\text { Tuberculosis } \\
\text { prevalence }\end{array}$} & FSW (\%) & - & - & - & - & - & - & - & - & - & - & - & - & - & - & - & 0.08 \\
\hline & Clients (\%) & - & - & - & - & - & - & - & - & - & - & - & - & - & - & - & 0.18 \\
\hline & MSMW (\%) & - & - & - & - & - & - & - & - & - & - & - & - & - & - & - & 0.18 \\
\hline & PWID (\%) & - & - & - & - & - & - & - & - & - & - & - & - & - & & 0.8 & - \\
\hline & Males 15-49 (\%) & - & - & - & - & - & - & - & - & - & - & - & - & - & 0.18 & - & - \\
\hline & Females 15-49 (\%) & - & - & - & - & - & - & - & - & - & - & - & - & - & 0.08 & - & - \\
\hline & Males 50+ (\%) & - & - & - & - & - & - & - & - & - & - & - & - & - & - & - & 0.18 \\
\hline & Females $50+(\%)$ & - & - & - & - & - & - & - & - & - & - & - & - & - & - & - & 0.08 \\
\hline
\end{tabular}


Table D.8 Injecting drug use parameters

\begin{tabular}{|c|c|c|c|c|c|c|c|c|c|c|c|c|c|c|c|c|}
\hline & & 2000 & 2001 & 2002 & 2003 & 2004 & 2005 & 2006 & 2007 & 2008 & 2009 & 2010 & 2011 & 2012 & 2013 & Assumption \\
\hline \multirow{8}{*}{$\begin{array}{l}\text { Average no. } \\
\text { injections/ } \\
\text { person/year }\end{array}$} & FSW & - & - & - & - & - & - & - & - & - & - & - & - & - & - & 0 \\
\hline & Clients & - & - & - & - & - & - & - & - & - & - & - & - & - & - & 0 \\
\hline & MSMW & - & - & - & - & - & - & - & - & - & - & - & - & - & - & 0 \\
\hline & PWID & - & - & - & - & - & - & - & - & - & - & - & - & - & - & 180 \\
\hline & Males 15-49 & - & - & - & - & - & - & - & - & - & - & - & - & - & - & 0 \\
\hline & Females 15-49 & - & - & - & - & - & - & - & - & - & - & - & - & - & - & 0 \\
\hline & Males 50+ & - & - & - & - & - & - & - & - & - & - & - & - & - & - & 0 \\
\hline & Females 50+ & - & - & - & - & - & - & - & - & - & - & - & - & - & - & 0 \\
\hline \multirow{2}{*}{$\begin{array}{l}\text { Drug use } \\
\text { parameters }\end{array}$} & $\%$ shared injections & - & - & 10 & - & 14 & - & - & 6 & - & 3 & - & - & 5 & - & - \\
\hline & PWID on OST & - & - & & - & - & - & - & - & - & 1,599 & 1,920 & 1,760 & 2,080 & 4,635 & - \\
\hline
\end{tabular}


Table D.9 Transitions

\begin{tabular}{|c|c|c|c|c|c|c|c|c|c|}
\hline & & FSW & Clients & MSMW & PWID & $\begin{array}{l}\text { Males } \\
15-49\end{array}$ & $\begin{array}{r}\text { Females } \\
15-49\end{array}$ & $\begin{array}{c}\text { Males } \\
50+\end{array}$ & $\begin{array}{r}\text { Females } \\
50+\end{array}$ \\
\hline \multirow{8}{*}{$\begin{array}{l}\text { Age-related } \\
\text { transitions }\end{array}$} & FSW & - & - & - & - & - & - & - & 25 \\
\hline & Clients & - & - & - & - & - & - & 25 & - \\
\hline & MSMW & - & - & - & - & - & - & 25 & - \\
\hline & PWID & - & - & - & - & - & - & 25 & - \\
\hline & Males 15-49 & - & - & - & - & - & - & 35 & - \\
\hline & Females 15-49 & - & - & - & - & - & - & - & 35 \\
\hline & Males 50+ & - & - & - & - & - & - & - & - \\
\hline & Females $50+$ & - & - & - & - & - & - & - & - \\
\hline \multirow{8}{*}{$\begin{array}{l}\text { Risk-related } \\
\text { transitions }\end{array}$} & FSW & - & - & - & - & - & 20 & - & - \\
\hline & Clients & - & - & - & - & 25 & - & - & - \\
\hline & MSMW & - & - & - & - & - & - & - & - \\
\hline & PWID & - & - & - & - & 25 & - & - & - \\
\hline & Males 15-49 & - & - & - & - & - & - & - & - \\
\hline & Females 15-49 & - & - & - & - & - & - & - & - \\
\hline & Males 50+ & - & - & - & - & - & - & - & - \\
\hline & Females 50+ & - & - & - & - & - & - & - & - \\
\hline
\end{tabular}


Table D.10 Partnerships

\begin{tabular}{|c|c|c|c|c|c|c|c|c|c|}
\hline & & FSW & Clients & MSMW & PWID & $\begin{array}{r}\text { Males } \\
15-49\end{array}$ & $\begin{array}{r}\text { Females } \\
15-49\end{array}$ & $\begin{array}{r}\text { Males } \\
\mathbf{5 0 +}\end{array}$ & $\begin{array}{r}\text { Females } \\
50+\end{array}$ \\
\hline \multirow{8}{*}{$\begin{array}{l}\text { Regular } \\
\text { sexual } \\
\text { interactions }\end{array}$} & FSW & - & - & - & - & - & - & - & - \\
\hline & Clients & 10 & - & - & - & - & 1 & - & 0 \\
\hline & MSMW & - & - & 0 & - & - & 1 & - & - \\
\hline & PWID & 10 & - & - & - & - & 1 & - & - \\
\hline & Males 15-49 & 0.1 & - & - & - & - & 1 & - & - \\
\hline & Females 15-49 & - & - & - & - & - & - & - & - \\
\hline & Males 50+ & 0.1 & - & - & - & - & - & - & 1 \\
\hline & Females 50+ & - & - & - & - & - & - & - & - \\
\hline \multirow{8}{*}{$\begin{array}{l}\text { Casual sexual } \\
\text { interactions }\end{array}$} & FSW & - & - & - & - & - & - & - & - \\
\hline & Clients & 10 & - & - & - & - & 1 & - & - \\
\hline & MSMW & - & - & 1 & - & - & 0 & - & - \\
\hline & PWID & 10 & - & - & - & - & 1 & - & - \\
\hline & Males 15-49 & 0.1 & - & - & - & - & 10 & - & 1 \\
\hline & Females 15-49 & - & - & - & - & - & - & - & - \\
\hline & Males 50+ & 0.1 & - & - & - & - & 1 & - & 2 \\
\hline & Females 50+ & - & - & - & - & - & - & - & - \\
\hline \multirow{8}{*}{$\begin{array}{l}\text { Commercial } \\
\text { sexual } \\
\text { interactions }\end{array}$} & FSW & - & - & - & - & - & - & - & - \\
\hline & Clients & 1 & - & - & - & - & - & - & - \\
\hline & MSMW & 0 & - & 1 & - & - & - & - & - \\
\hline & PWID & 0 & - & - & - & - & - & - & - \\
\hline & Males 15-49 & 0 & - & - & - & - & - & - & - \\
\hline & Females 15-49 & - & - & - & - & - & - & - & - \\
\hline & Males 50+ & 0 & - & - & - & - & - & - & - \\
\hline & Females 50+ & - & - & - & - & - & - & - & - \\
\hline \multirow{9}{*}{$\begin{array}{l}\text { Injecting } \\
\text { interactions }\end{array}$} & FSW & - & - & - & - & - & - & - & - \\
\hline & Clients & - & - & - & - & - & - & - & - \\
\hline & MSMW & - & - & - & - & - & - & - & - \\
\hline & PWID & - & - & - & 1 & - & - & - & - \\
\hline & Males 15-49 & - & - & - & - & - & - & - & - \\
\hline & Females 15-49 & - & - & - & - & - & - & - & - \\
\hline & Males 50+ & - & - & - & - & - & - & - & - \\
\hline & Females 50+ & - & - & - & - & - & - & - & - \\
\hline & FSW & - & - & - & - & - & - & - & - \\
\hline
\end{tabular}




\section{APPENDIX E. GLOSSARY}

Allocative efficiency

(AE)

\section{Behavioral \\ intervention \\ Biomedical \\ intervention}

Bottom-up costing

Cost-effectiveness

analysis (CEA)

Effectiveness

Efficiency

Financial

sustainability

HIV incidence

HIV prevalence

Implementation

efficiency

Incremental cost-

effectiveness ratio

(ICER)

Model

Opioid substitution therapy (OST)
Within a defined resource envelope, AE of health or HIV-specific interventions provides the right intervention to the right people at the right place in the correct way to maximize targeted health outcomes.

Discourages risky behaviors and reinforces protective ones, typically by addressing knowledge, attitudes, norms, and skills.

Biomedical HIV intervention strategies use medical and public health approaches to block infection, decrease infectiousness, and reduce susceptibility.

Costing method that identifies all of the resources that are used to provide a service and assigns a value to each of them. These values then are summed and linked to a unit of activity to derive a total unit cost.

Form of economic analysis that compares the relative costs and outcomes (effects) of two or more courses of action.

Degree of achievement of a (health) outcome in a real-world implementation setting.

Achievement of an output with the lowest possible input without compromising quality.

Ability of government and its partners to continue spending on a health or HIV outcome for the required duration and to meet any cost of borrowing without compromising the government's, household's, or other funding partner's financial position.

Estimated total number (or rate) of new (total number of diagnosed and undiagnosed) HIV infections in a given period.

Percentage of people who are infected with HIV at a given point in time.

Set of measures to ensure that programs are implemented in a way that achieves outputs with the lowest input of resources. In practical terms, improving implementation efficiency means identifying better delivery solutions. Doing so requires improving planning, designing service delivery models, and assessing and addressing service delivery "roadblocks." Implementation efficiency will improve the scale, coverage, and quality of programs.

Equation commonly used in health economics to provide a practical approach to decision making regarding health interventions. ICER is the ratio of the change in costs to incremental benefits of a therapeutic intervention or treatment.

Computer system designed to demonstrate the probable effect of two or more variables that might be brought to bear on an outcome. Such models can reduce the effort required to manipulate these factors and present the results in an accessible format.

Medical procedure of replacing an illegal opioid, such as heroin, with a longer acting but less euphoric opioid. Methadone or buprenorphine typically are used, and the drug is taken under medical supervision. 
Opportunistic infection under medical

(OI prophylaxis)

Pre-exposure prophylaxis (PrEP)

Program effectiveness

Program sustainability

Return on investments (ROI)

Saturation

Technical efficiency

Top-down costing

Universal health coverage (UC)
Treatment given to PLHIV to prevent either a first episode of an OI (primary prophylaxis) or the recurrence of infection (secondary prophylaxis).

Method for people who do not have HIV but are at substantial risk of acquiring it to prevent HIV infection by taking an antiretroviral drug.

Program effectiveness incorporates evaluations to establish what works and impacts disease and/or transmission intensity, disseminating proven practice, and improving the public health results of programs.

Ability to maintain the institutions, management, human resources, service delivery, and demand generation components of a national response until impact goals have been achieved and maintained over time as intended by the strategy.

Performance measure used to evaluate the efficiency of an investment or to compare the efficiency of a number of different investments. To calculate ROI, the benefit (return) of an investment is divided by the cost of the investment; the result is expressed as a percentage or a ratio.

Maximum level of coverage that a program can achieve.

Delivery of a (health) service in a way that produces maximum output at the lowest possible unit cost while according with operational quality standards.

Costing method that divides total expenditure (quantum of funding available) for a given area or policy by total units of activity (such as patients served) to derive a unit cost.

Universal health coverage (UC), is defined as ensuring that all people have access to the promotive, preventive, curative, rehabilitative, and palliative health services that they need, of sufficient quality to be effective, while ensuring that the use of these services does not expose the user to financial hardship. 


\section{APPENDIX F. REFERENCES}

Anderson, S.-J., P. Cherutich, N. Kilonzo, I. Cremin, D. Fecht, D. Kimanga, M. Harper, R.L. Masha, P.B. Ngongo, W. Maina, M. Dybul, and T.B. Hallett. 2014. "Maximising the Effect of Combination HIV Prevention thro-ugh Prioritisation of the People and Places in Greatest Need: A Modelling Study." The Lancet 384 (July): 249-56.

Chanturidze, T., T. Ugulava, A. Durán, T. Ensor, and E. Richardson. 2009. “Georgia: Health System Review." Health Systems in Transition 11 (8):1-116.

Craig, A.P., H.-H. Thein, L. Zhang, R.T. Gray, K. Henderson, D. Wilson, M. Gorgens, and D.P. Wilson. 2014. "Spending of HIV Resources in Asia and Eastern Europe: Systematic Review Reveals the Need to Shift Funding Allocations toward Priority Populations." Journal of the International AIDS Society 17: 18822.

Curatio International Foundation. 2011. HIV Risk and Prevention Behavior among MSM in Tbilisi, Bio-Behavioral Survey 2010. Tbilisi.

. 2012. Bio-Behavioral Surveillance Survey with biomarker component among HIV/AIDS risk groups, identifying the number of injective drug users (IDU), Operations survey, 2012. Tbilisi.

. 2013a. HIV risk and prevention behavior among Men who have Sex with Men in Tbilisi, Georgia. Bio-behavioral surveillance survey in 2012. Tbilisi.

. 2013b. HIV risk and prevention behaviours among People Who Inject Drugs in six cities of Georgia; Bio-behavioral surveillance survey in Tbilisi, Batumi, Zugdidi, Telavi, Gori, Kutaisi in 2012. Tbilisi.

. 2013c. 12.HIV risk and prevention behaviour among Female Sex Workers in two cities of Georgia. Bio-behavioral surveillance survey in Tbilisi and Batumi in 2012. Tbilisi.

. 2014a. Population Size Estimation of Female Sex Workers in Tblisi and Batumi, Georgia, August 2014. Curatio International Foundation. Tbilisi.

. 2014b. Population Size Estimation of Men Who Have Sex with Men in Georgia, August 2014. http://www.curatiofoundation.org/uploads/other/0/255.pdf.

Dublin Declaration on Partnership to Fight HIV/AIDS in Europe and Central Asia. 2004. Breaking the Barriers: Partnership to Fight HIV/AIDS in Europe and Central Asia Conference, February 23-24. Dublin, Ireland.

Eaton, J.W., N.A. Menzies, J. Stover, V. Cambiano, L. Chindelevitch, A. Cori, J.A. Hontelez, S. Humair, C.C. Kerr, D.J. Klein, S. Mishra, K.M. Mitchell, B.E. Nichols, P. Vickerman, R. Bakker, T. Bärnighausen, A. Bershteyn, D.E. Bloom, M.C. Boily, S.T. Chang, T. Cohen, P.J. Dodd, C. Fraser, C. Gopalappa, J. Lundgren, N.K. Martin, E. Mikkelsen, E. Mountain, Q.D. Pham, M. Pickles, A. Phillips, L. Platt, C. Pretorius, H.J. Prudden, J.A. Salomon, D.A. Van de Vijver, S.J. de Vlas, B.G. Wagner, R.G. White, D.P. Wilson, L. Zhang, J. Blandford, G. Meyer-Rath, M. Remme, P. Revill, N. Sangrujee, F. Terris-Prestholt, M. Doherty, N. Shaffer, P.J. Easterbrook, G. Hirnschall, and T.B. Hallett. 2014. "Health Benefits, Costs, and Cost-Effectiveness of Earlier Eligibility for Adult Antiretroviral Therapy and Expanded Treatment Coverage: A Combined Analysis of 12 Mathematical Models." The Lancet Global Health 2: e23-e34. 
Fraser, N., C. Benedikt, M. Obst, E. Masaki, M. Görgens, R. Stuart, A. Shattock, R. Gray, and D.P. Wilson. 2014. "Sudan's HIV Response: Value for Money in a Low-Level HIV Epidemic. Findings from the HIV Allocative Efficiency Study." World Bank, Washington, DC. http://documents.worldbank.org/curated/en/2014/09/20457933/sudans-hivresponse-value-money-low-level-hiv-epidemic-findings-hiv-allocative-efficiencystudy.

Georgia, Government of. 2014. Georgia Country Progress Report, January 2012 to December 2013. Global AIDS Response Report. National Center for Disease Control and Public Health. Tbilisi.

Georgia, Government of. 2015. Georgia Final Draft National Strategic Plan. Tbilisi. March.

IMF (International Monetary Fund). 2014. "World Economic Outlook Database" (WEOdata). Washington, DC. https://www.imf.org/external/pubs/ft/weo/2014/02/weodata/index.aspx.

Kerr, C.C., R.M. Stuart, R.T. Gray, A.J. Shattock, N. Fraser, C. Benedikt, M. Haacker, M. Berdnikov, A.M. Mahmood, S.A. Jaber, M. Gorgens, and D.P. Wilson. 2015. Optima: A Model for HIV Epidemic Analysis, Program Prioritization, and Resource Optimization." JAIDS (Journal of Acquired Immune Deficiency Syndromes) (March).

http://mobile.journals.Iww.com/jaids/ layouts/oaks.journals.mobile/articleviewer.asp $\underline{x}$ ? year $=2015$ \&issue $=07010$ \&article $=00017$.

Kerr, C.C., T. Smolinski, S. Dura-Bernal, and D.P. Wilson. Under review. "Optimization by Bayesian Adaptive Locally Linear Stochastic Descent." "Nature Scientific Reports." http://scholar.google.com/citations?view_op=view_citation\&hl=en\&user=TFy7ncUAA AAJ\&citation_for_view=TFy7ncUAAAAJ:Ug5p-4gJ2f0C.

National Center for Disease Control and Public Health. 2014. Global AIDS Response Progress Report. Georgia. Country Report. January 2012 to December 2013. Tbilisi.

OECD (Organisation for Economic Co-operation and Development). 2014. Creditor Reporting System. Paris. https://stats.oecd.org/Index.aspx?DataSetCode=CRS1.

Tajikistan, Republic of. 2014. "Modelling an Optimized Investment Approach for Tajikistan: Sustainable Financing of National HIV Responses." By C. Hamelmann, P. Duric, C. Kerr, and D.P. Wilson, Ministry of Health. Dushanbe. http://www.eurasia.undp.org/content/dam/rbec/docs/UNDP20Modelling20Tajikista n English.pdf.

UNAIDS (Joint United Nations Program on HIV/AIDS). 2014a. AIDSinfo database. Geneva. http://www.unaids.org/en/dataanalysis/datatools/aidsinfo.

2014b. “Fast-Track: Ending the AIDS Epidemic by 2030." Geneva. 2014c. "The Gap Report." Geneva.

2014d. Global AIDS Response Progress Report of Georgia (GARPR) 2014. Geneva.

2014e. "90-90-90: An Ambitious Treatment Target to Help End the AIDS Epidemic." Geneva.

2015. "How AIDS Changed Everything: HIV Estimates with Uncertainty Bounds 1990-2014." Geneva

UNGASS (United Nations General Assembly). 2011. Resolution adopted by the General Assembly 65/277. Political Declaration on HIV and AIDS: Intensifying Our Efforts to Eliminate HIV and AIDS. New York. 
University of Washington. 2014. 2010 Global Burden of Disease Study. Data Visualizations.

IHME (Institute for Health Metrics and Evaluation), Seattle.

http://vizhub.healthdata.org/gbd-cause-patterns/i

http://www.healthdata.org/results/data-visualizations.

USAID (United States Agency for International Development). 2014. Georgia HIV

Prevention Project. "Sustainable HIV Prevention in Georgia: Challenges,

Opportunities, and Recommended Actions." Policy Paper. Washington, DC.

WHO (World Health Organization). 2014. National Health Accounts.

http://www.who.int/health-accounts/en/.

WHO Europe. 2014. HIV-AIDS Treatment and Care in Georgia. Evaluation Report. WHO Europe, Copenhagen. September.

Wilson, D.P., B. Donald, A.J. Shattock, D. Wilson, N. Fraser-Hurt. 2015. "The Cost-Effectiveness of Harm Reduction." International Journal of Drug Policy 26 (Suppl 1): S5-S11.

World Bank. 2014. World Development Indicators. Washington, DC. http://data.worldbank.org/data-catalog/world-development-indicators. 